\title{
Restorative Agriculture: Reclamation of Marginal Agricultural Land for a Volunteer-Run Community Farm
}

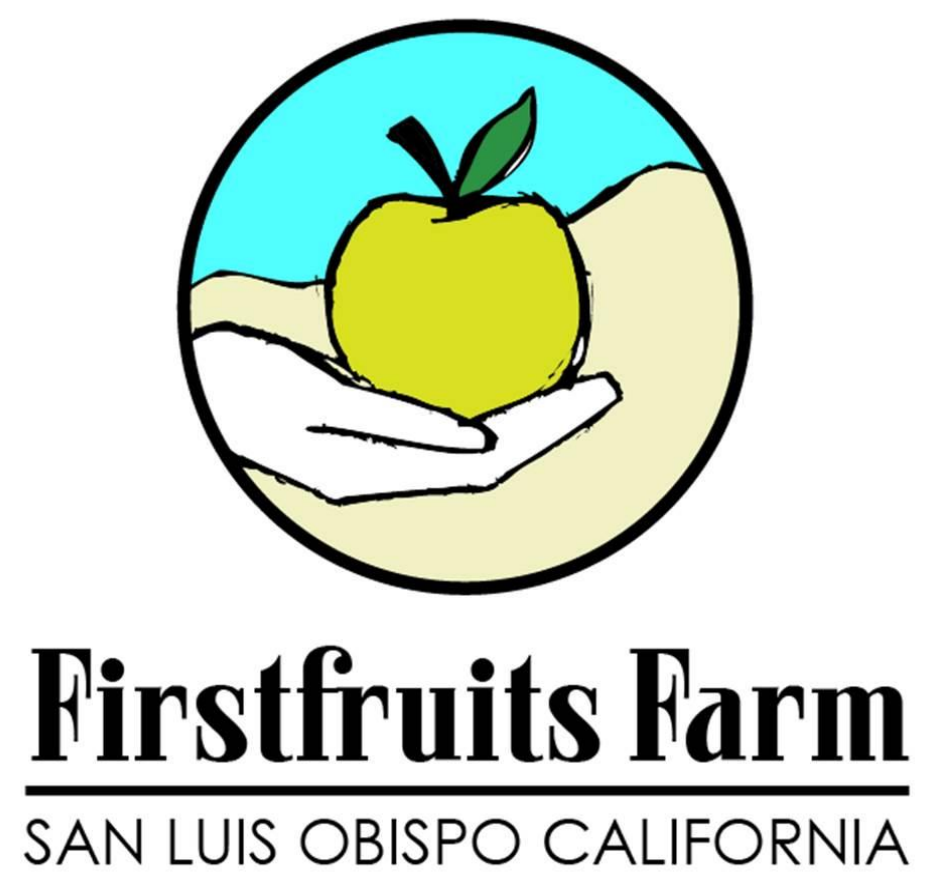

Darin Laity

California Polytechnic State University

Fall 2013 


\section{Table of Contents}

Part 1: Concept

Part 2: Background

Part 3: Project Development

Part 4: Sustaining Operations

Part 5: Results

Part 6: Future Goals

Part 7: Conclusions 
"I know of no pursuit in which more real and important services can be rendered to any country than by improving its agriculture..." - George Washington

\section{Part 1: Concept}

Agriculture, as a human endeavor, has a unique and profound capacity to bring restoration to our communities, our economies, and our environment. In many ways, agriculture is the very bedrock of human civilization, and when well-managed and strategically employed, is replete with provisions for human health, social well-being, community development, environmental stewardship, and economic prosperity. The project detailed here was conceived in this spirit: that a multitude of benefits could be achieved by applying a restorative approach to an agricultural enterprise. To put it another way, the overarching vision for this project sought to answer a fundamental question: How might agricultural knowledge provide a restorative social, environmental, spiritual and economic benefit to this community? The understanding that there are social, environmental, spiritual, and economic issues in our community that need to be restored/revived/redeemed is presumed. A full discourse on those subjects is beyond the scope of this report, but it is important to acknowledge the existence and interconnectedness of these issues.

Sadly, in many areas of the world, the term sustainable agriculture does not provide the appropriate description, or guiding vision for the agricultural methods necessary to produce healthy, high quality food. In these areas where agricultural land has been degraded or lost (both in the industrialized and unindustrialized world), the land and its productivity must be restored, not sustained. This was another aspiration of this project: to explore agriculture beyond sustainability - to consider curative, redemptive, restorative agriculture. After the first year of production, we witnessed restoration happening in many ways, both expected and unexpected. To be clear, this project continues to evolve and the greatest impacts are still coming to fruition. But in a relatively short period of time, very real and quantifiable results have been realized. What follows is a summary of the background, development, sustainment, and first-year results of Firstfruits Farm.

\section{Project Proposal}

The original proposal for this project was submitted and approved in March 2013, but the formulation of the vision and the preparation for the project began in late 2010 . The original proposal and objectives were drafted as follows:

Proposal - Create a volunteer-run community farm to: provide fresh, high quality, organic produce to economically disadvantaged families and individuals within San Luis Obispo; build relationships between volunteers and recipients; provide agricultural education and vocational skills to farm volunteers; create and encourage ecumenical cooperation 
Objectives - Develop an organizational plan for the project, form a leadership team to oversee the development and operations of the project, prepare farmland for production, seek volunteers and build a core team for farm work, acquire material and financial resources for farm operations, create marketing materials and provide $P R$ information to media, establish and maintain volunteer communication and social media, maintain farm operations, manage weekly volunteer farm work, ensure delivery of produce to those in the community who need it most

"Here are two facts that should not both be true:

- There is sufficient food produced in the world every year to feed every human being on the planet.

- Nearly 800 million people literally go hungry every day, with more than a third of the earth's population -- 2 billion men and women -- malnourished one way or another, according to the United Nations Food and Agriculture Organization." - Michael Dorris

\section{Part 2: Background}

With a poverty rate of $15.7 \%$ (2012), San Luis Obispo County has an economic hardship rate which is higher than the $14.7 \%$ national average. Amongst other California counties, it is roughly average, with Merced (30.0\%) and San Mateo (7.2\%) having the highest and lowest poverty rates respectively. ${ }^{1}$ With a population of nearly 275,000 (2012), San Luis Obispo is home to more than 43,000 people living below the federal poverty line. ${ }^{2}$ Furthermore, according to a recent study by the UCLA Center for Health Policy Research, more than 23\%, or approximately 11,000 people in San Luis Obispo County are unable to afford enough food on a regular basis. (See Figure 1 )

To counter this food insecurity, the Food Bank Coalition of San Luis Obispo County collects and distributes more than 5 million pounds of food annually to economically disadvantaged individuals and families in the county. ${ }^{3}$ Much of this food is donated by local grocery stores, supermarkets, farmers, and individuals. These efforts provide a key safety net to thousands of families in the county. Unfortunately, most of the donated packaged food has exceeded its expiration date and is usually comes from unsold seconds. Much of the donated produce comes from the leftovers from local farmer's markets and/or gleaned harvests. After volunteering at a food distribution subsidiary of the Food Bank, it became clear that much of the donated food is of low quality, packaged and processed, and low in nutrition. The produce that passed through the doors was often wilted, damaged and unappealing. The need for high quality, nutritionally dense, fresh fruits and vegetables was (and is) clear.

\footnotetext{
${ }^{1}$ Public Policy Institute of California (http://www.ppic.org/content/pubs/jtf/jtf_povertyjtf.pdf)

${ }^{2}$ U.S. Census Bureau (2012)

${ }^{3}$ Food Bank Coalition website: http://www.slofoodbank.org/about_us.php
} 


\section{San Luis Obispo County Food Security ${ }^{4}$}

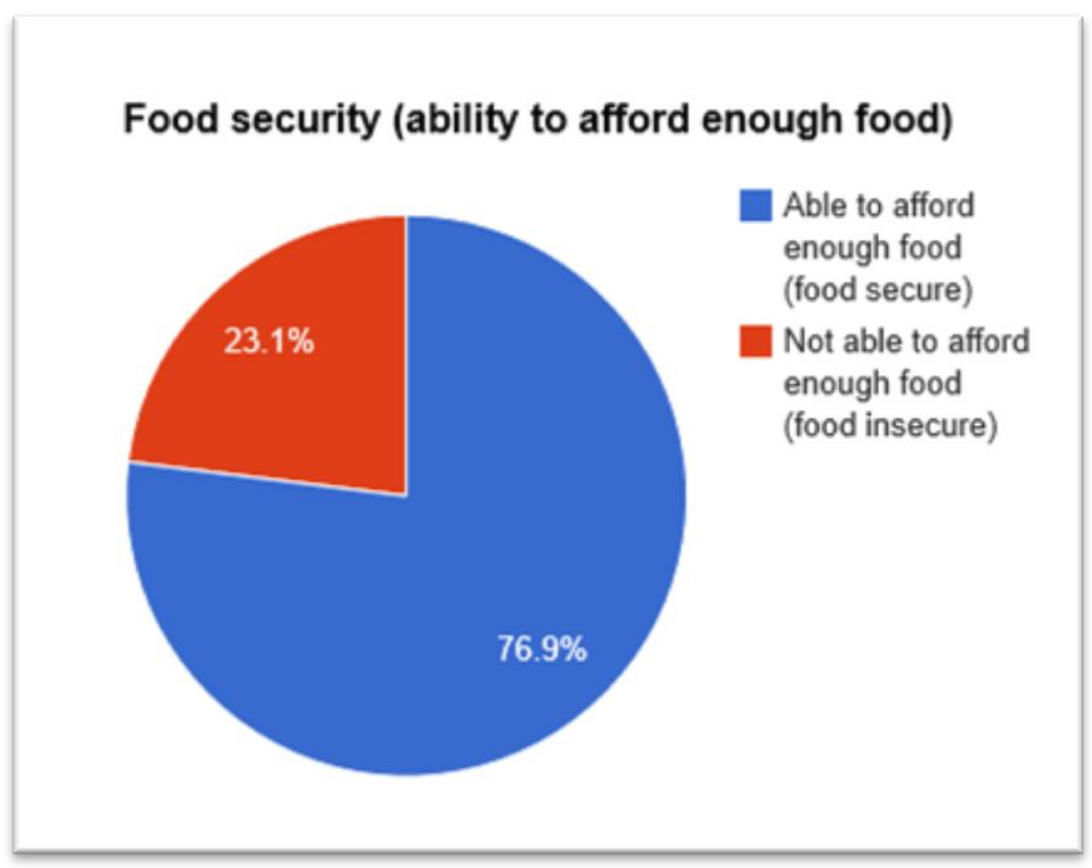

Figure 1

In early 2012, after meeting with pastors from two local churches (Trinity Presbyterian Church, SLO and Grace Church, SLO) and discussing logistics with a local landowner, we began to examine the feasibility of starting a farm that could provide high quality, fresh produce to at least one of the Food Bank subsidiaries. This subsidiary, named God's Storehouse - which is hosted and managed by Grace Church, SLO - opens their doors each and every Saturday morning to distribute food to local families and individuals. On a typical Saturday, there are between 150 and 200 families and individuals that show up to collect their food. It has become an essential food resource for these people, some of which are homeless, and many of which are in imminent danger of becoming homeless.

The intent of the meetings with the pastors was to determine if the congregations of the two churches could be mobilized to provide the necessary volunteer and financial support to maintain the farm operations. After these meetings, we concluded that this project was worthwhile and we believed that the congregations would be motivated to support it. Further discussions led us to decide that Grace Church should focus their primary efforts on maintaining God's Storehouse, and the oversight of the farm project should be maintained as a ministry of

\footnotetext{
${ }^{4}$ UCLA Center for Health Policy Research
} 
Trinity Presbyterian Church. However, members of Grace Church were highly encouraged to get involved with the farm project and become volunteers.

The 10-acre parcel of land that would be used for the farm operation was generously offered by a local family who live on the property. The land had been recently cultivated and used in an organic operation by myself, and a two acre section was planned for the community farm. The parcel is located on the south side of San Luis Obispo, off of Buckley Road and Davenport Creek Road. Irrigation water would be provided by a shared well that provides water to three different nearby properties. 
"It is, in every way, in the best interest of urban consumers to be surrounded by productive land, well farmed and well maintained by thriving farm families in thriving farm communities... It is possible, I think, to say that... a Christian agriculture [is] formed upon the understanding that it is sinful for people to misuse or destroy what they did not make. The Creation is a unique, irreplaceable gift, therefore to be used with humility, respect, and skill." - Wendell Berry

\section{Part 3: Project Development}

The foundation of this farm project unfolded over a five year period, beginning in early 2008 . This next section provides a summary of the restorative development of the farmland to return it to agricultural production. It is included to help put into context the realities and challenges of starting a farm operation from scratch, as well as explore the concept of restorative agriculture. Later sections will detail the organizational development of the volunteer-run farm, as well as ongoing restorative efforts on the farmland. But it is important to understand the entirety of the scope of work necessary to create a productive and successful operation when working on land that has been fallow for many years.

\section{Farm History}

Much of the practical agricultural experience and understanding of soils that helped make this land productive again, came from the education gleaned by working as an intern with Jim Terrick, farmer and owner of Los Osos Valley Organic Farm. This wise and experienced farmer provided an approximately year-long internship that equipped me with enough knowledge and confidence to try a small farm enterprise on my own. In 2008, after discussing my interest in restorative agricultural with the landowners (who were/are longtime family friends) of the project land, they offered their land to be used by me as a "proving grounds" to develop a small market farm. I operated this little farm for two years and it gave me the opportunity to experiment with different production techniques and work on soil rehabilitation.

The entire south San Luis Obispo area had been used in agriculture for many years before it was parceled up and sold as rural residential properties. Those many years of agricultural production left the soil on the farm owners' property in a degraded state: weeds grew only a few inches, if at all, despite abundant rainfall, soil water retention was poor, pest problems were abundant, and soil microbial life was extremely diminished. It was a perfect laboratory to try some restoration work. 


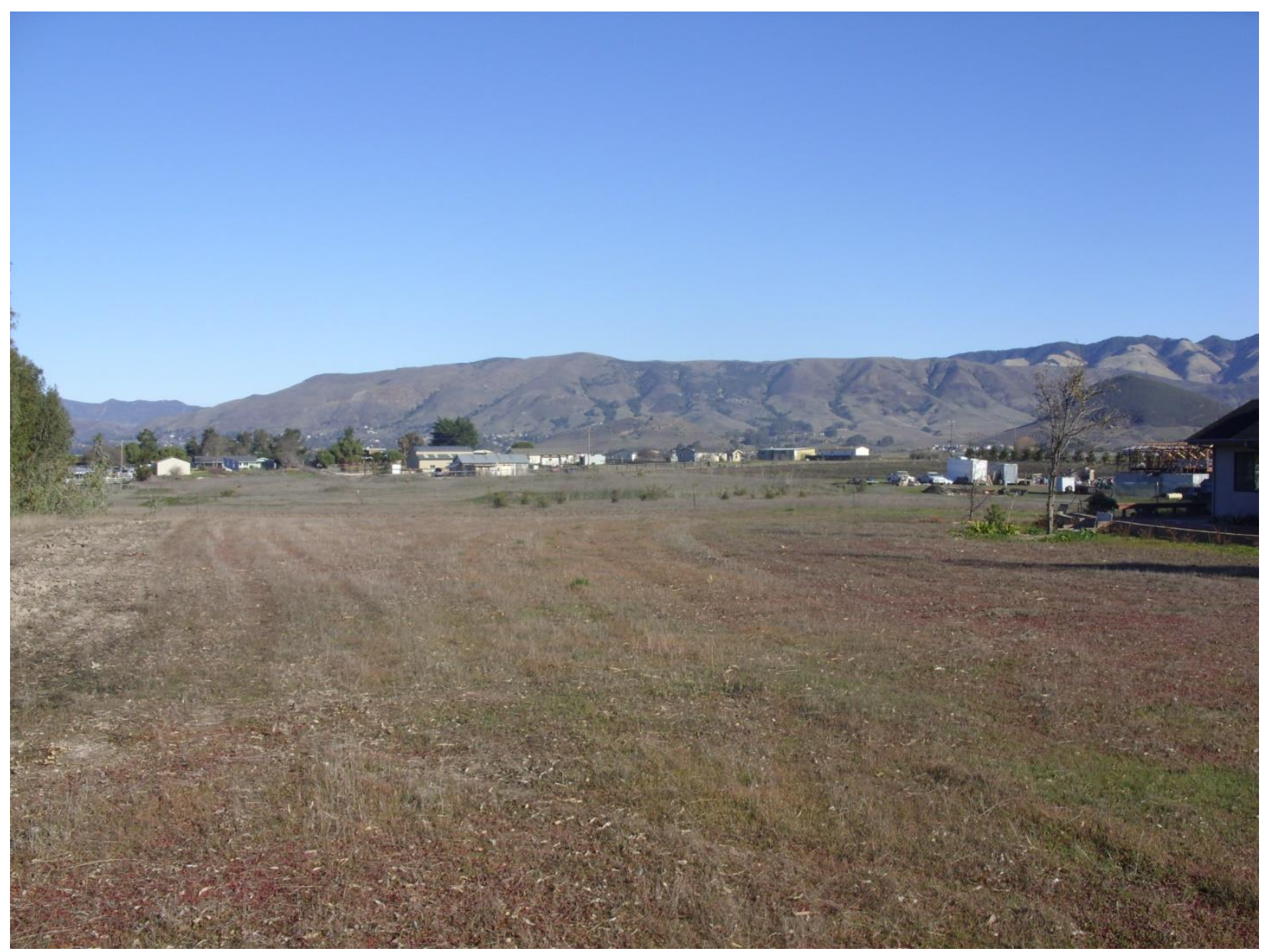

Before beginning any crop production, it is essential to figure out what conditions your crops will be growing in. A comprehensive soil test provides much of this vital information. Before beginning production in 2008 , a soil test was conducted. The results showed a severe shortage of calcium as a percentage of base saturation, a severe shortage of humus and soil organic matter, a shortage of sulfur, nitrogen, phosphorous, and potassium, and very low quantities of key trace minerals including: boron, zinc, and copper. (See Figure 2) 


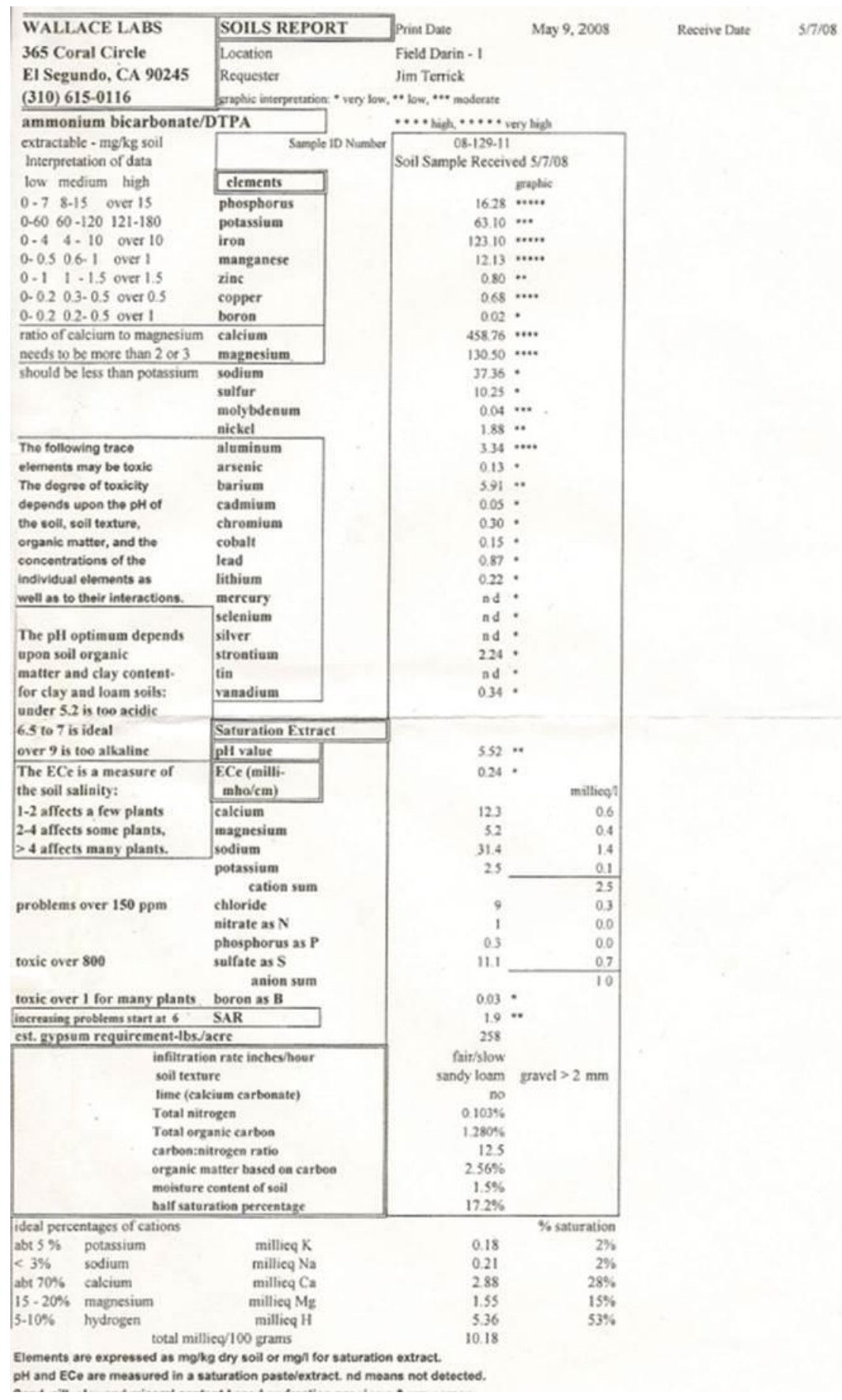

Figure 2

To correct these deficiencies, the following steps were taken in this order:

1. The field was disked and tilled to open up the soil, turn weeds under, and prepare the ground for amendments.

2. Thirteen tons/acre of composted horse manure was applied to the field to greatly increase soil organic matter, improve water retention, increase mineral levels (primarily potassium), and stimulate microbial life. 
3. Two tons/acre of limestone (calcium carbonate), 500 pounds/acre of soft rock phosphate, 100 pounds/acre of sulfur, 50 pounds of a trace mineral blend (containing zinc, manganese, and copper), and 50 pounds/acre of boron were applied to improve the mineral balance of the soil. More of each of these were needed, but the applications must be made in stages (during subsequent years) to allow the minerals to become bioavailable and integrated into the soil.

4. A soil-building cover crop comprised of a legume/oat blend (bell beans, winter peas, purple vetch, and cayuse oats) was sown at a rate of 150 pounds/acre in the field before the rainy season began. The legumes were inoculated with beneficial rhizobia to improve the nitrogen fixing factor. The cover crop was planted at a higher than normal application rate to accomplish: increased nitrogen availability in the soil, hasten the bioavailability of the applied amendments (especially phosphorous) to future crops, to increase soil organic matter by creating a green manure, to stabilize the soil and protect against erosion, to choke out noxious and invasive weeds, and to stimulate beneficial soil microbial life.

5. The following spring, the mature cover crop was mowed and disked into the soil and the ground was prepared for production.

The results of the soil improvement efforts were immediate and remarkable. The quality of most crops was exceptional and the farm progressed from unproductive to productive in a matter of months. There was, however, still work to be done to continue improving the soil for all types of crops. There were still mineral deficiencies and certain crops (like tomatoes) were vulnerable to problems. The soil improvement efforts needed to continue, and another soil test was conducted in 2009. The new test results showed an improvement across the board from the previous year's efforts, including: an increase in soil organic matter from $2.56 \%$ to $3.5 \%$, significant improvements in levels of phosphorous, sulfur, nitrogen, potassium, and boron, and some improvement in the levels of calcium. 
Soil Test - 2009

\section{PROFESSIONAL SOIL REPORT}

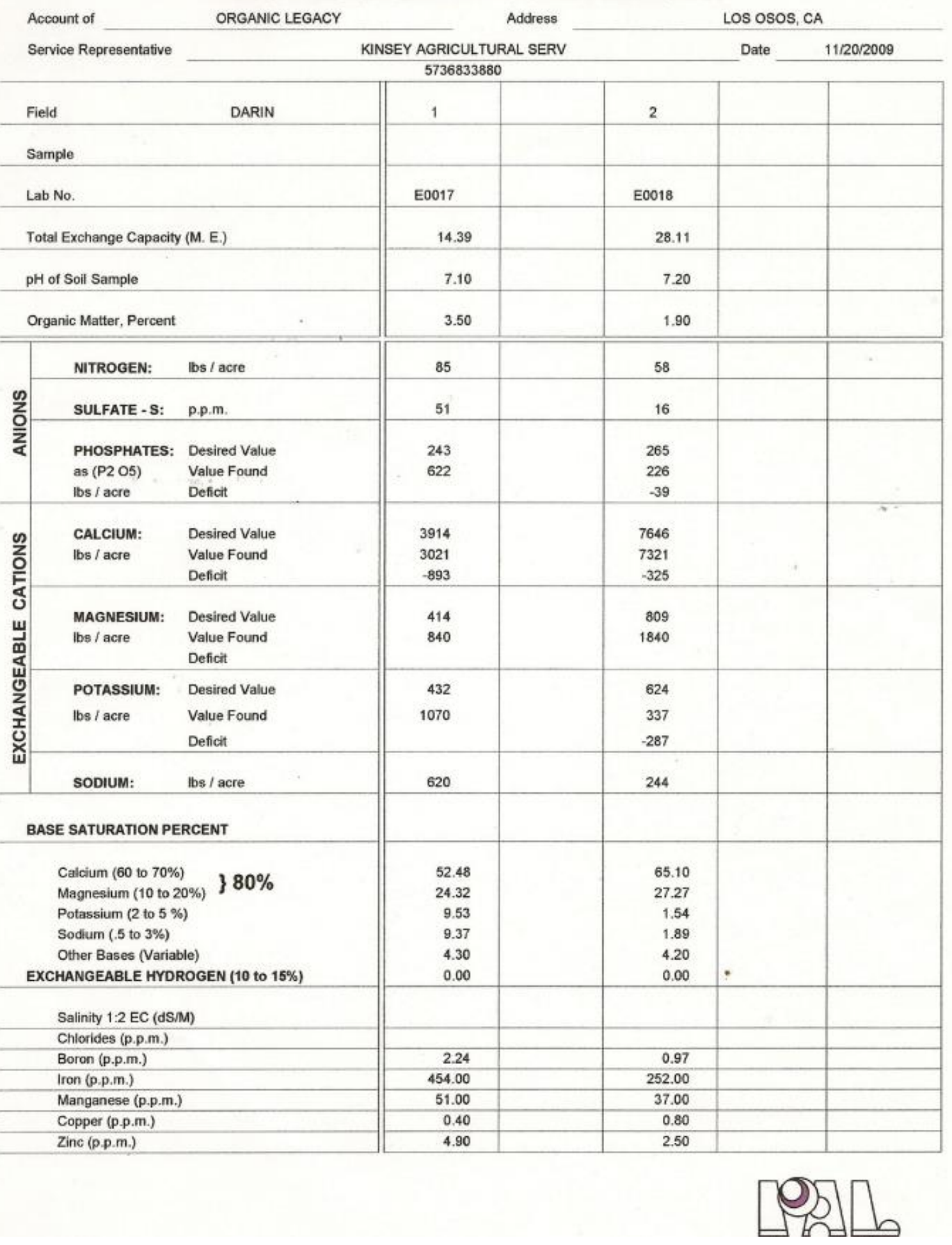




\section{Cover Crop Progression (2009)}
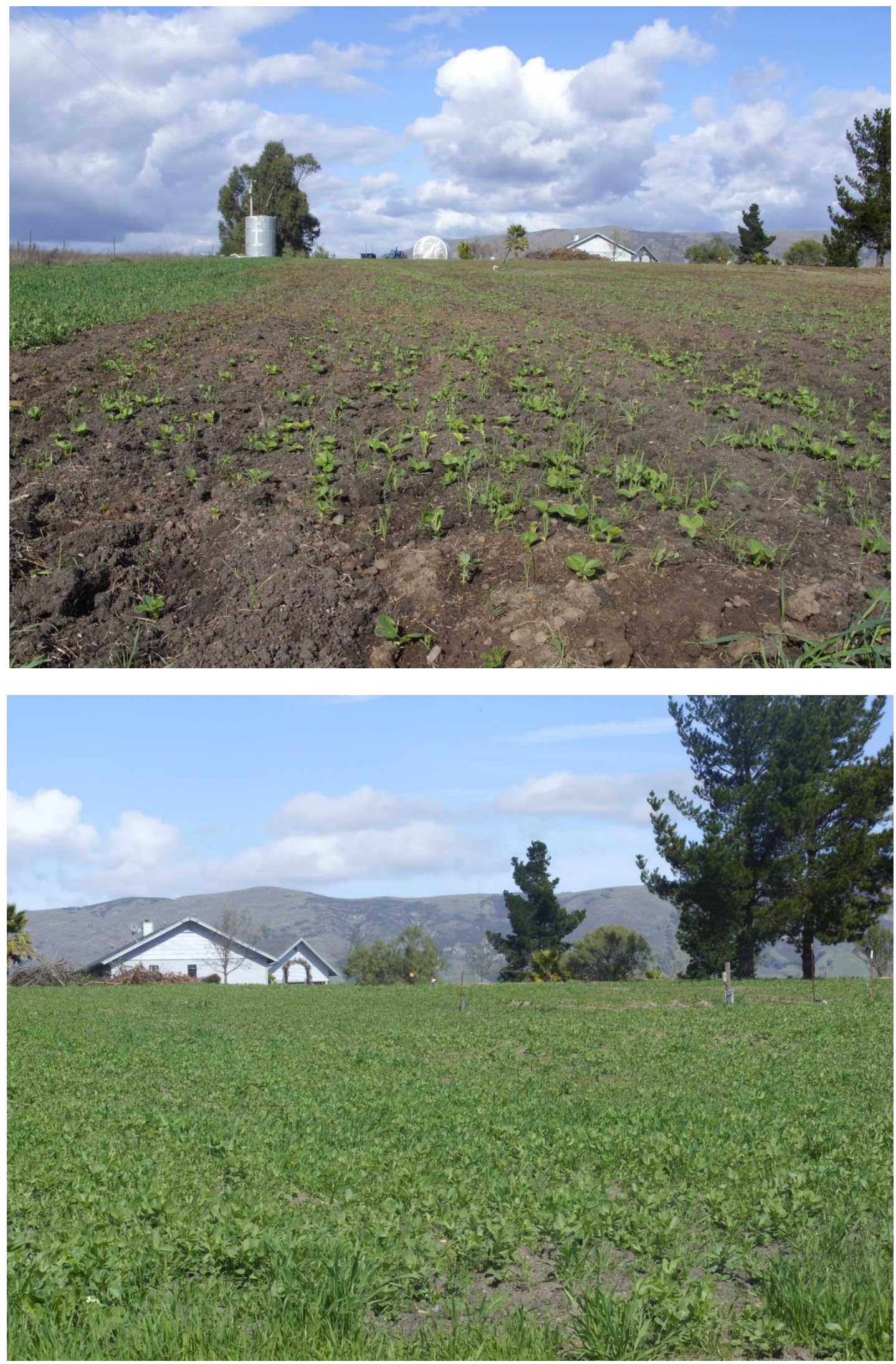

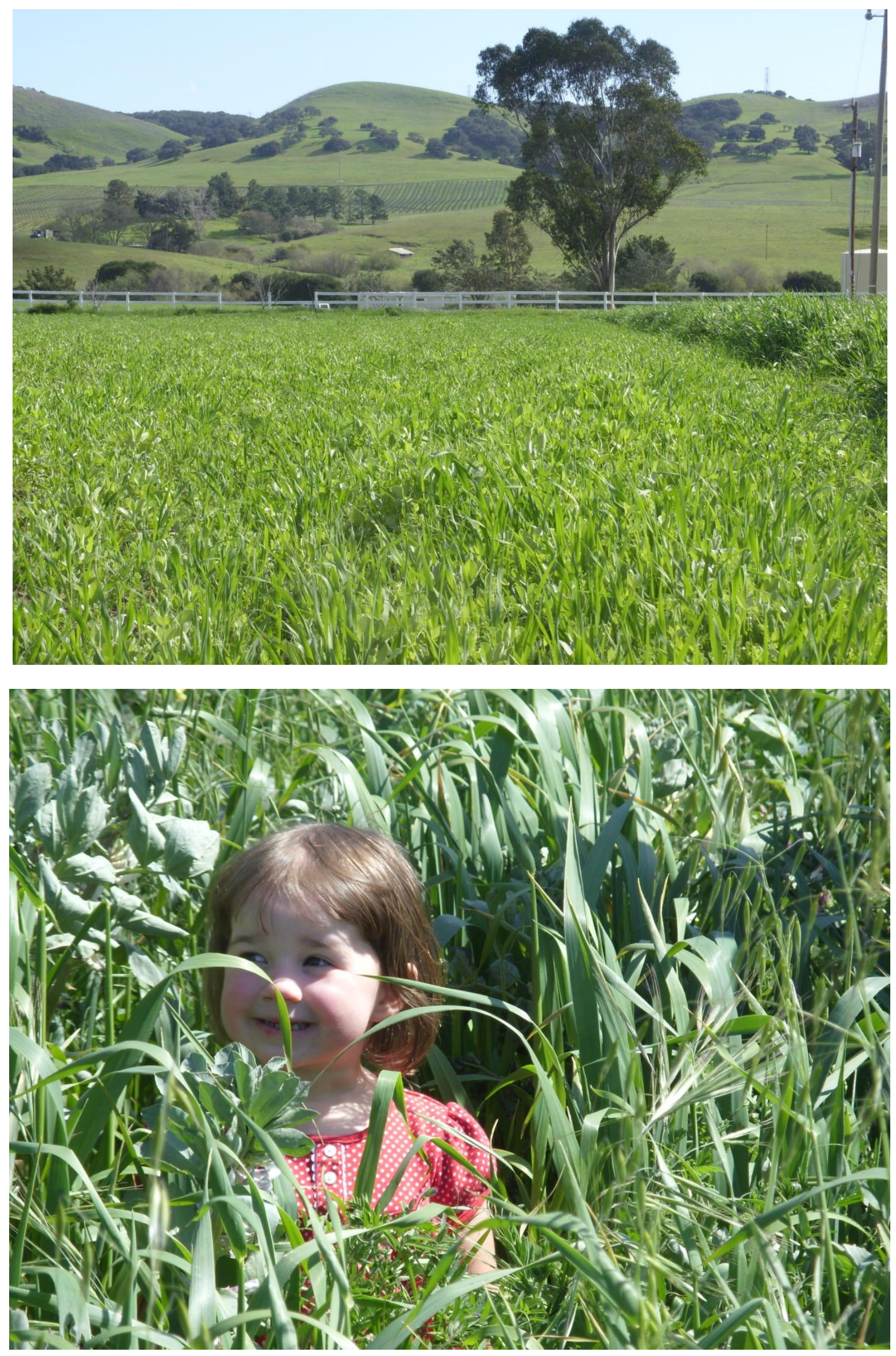


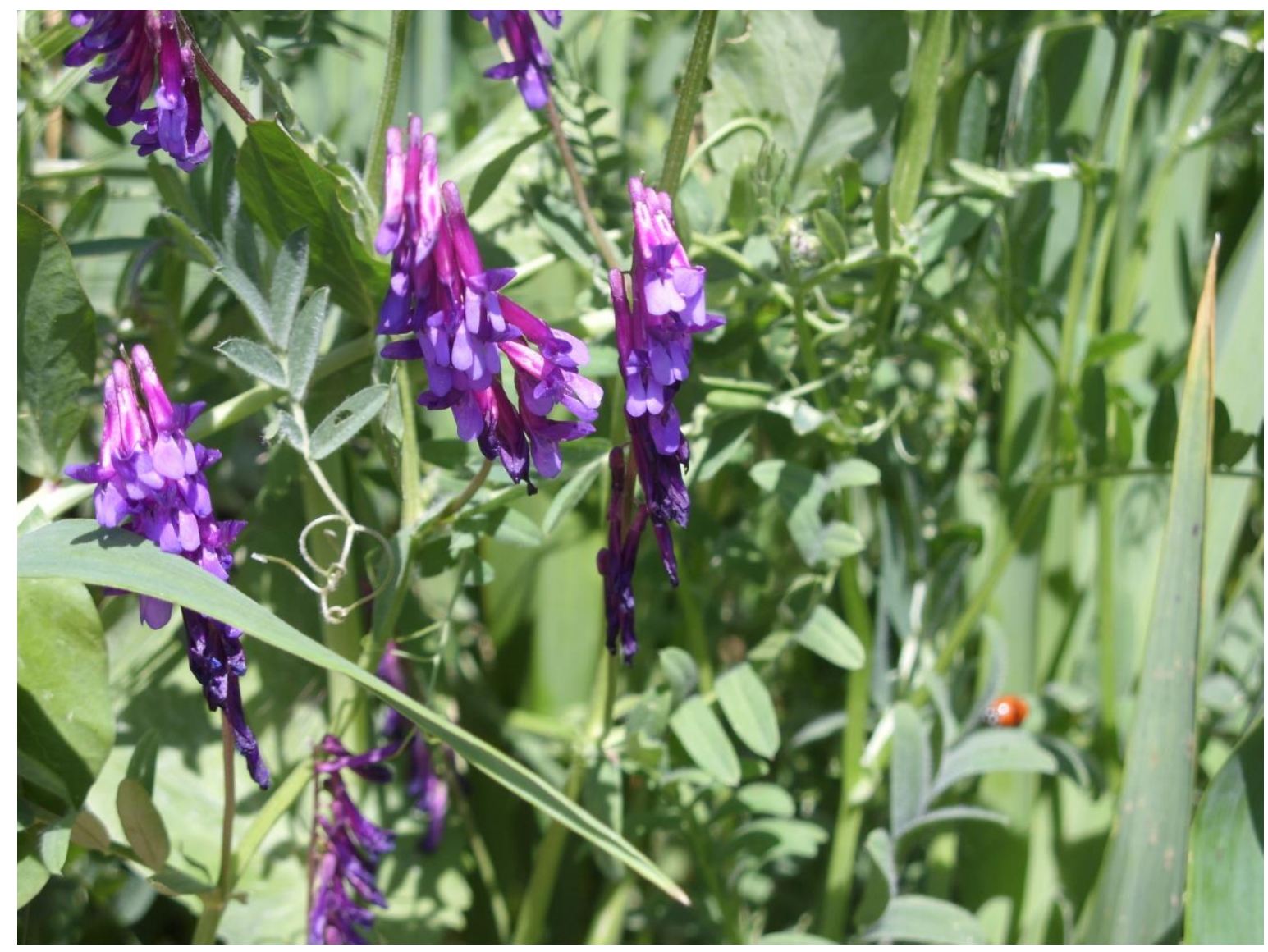

The next year (Fall 2009), the following steps were taken to continue with the soil improvement program:

1. The field was again tilled and prepared for amendment application.

2. One ton/acre of gypsum (calcium sulfate), 100 pounds/acre of soft rock phosphate, 50 pounds/acre of Azomite (trace minerals), and 25 pounds/acre of boron were applied to the field.

3. The same soil-building cover crop was applied at 120 pounds/acre.

The following crop production year (2010) showed additional improvements in crop quality, pest and disease resistance, and yields.

The farm was cover cropped once again in the fall of 2010 before production activity ceased in 2011 and 2012. Another cover crop was planted in the fall of 2012 (using the same seed blend) in preparation for the new community farm operation, and another soil test was conducted in early 2013. 


\section{Soil Test - 2013}

\section{Kinsey Agricultural Services, Inc.}

PLOT ID: G5T6D

Phone 573-683-3880 Fax 573-683-6227 e-mail nealOkinseyegecm

Client: ORGANIC LEGACY I JIM TERRICK

City : LOS OSOS, CA

Date : 21-Jun-13

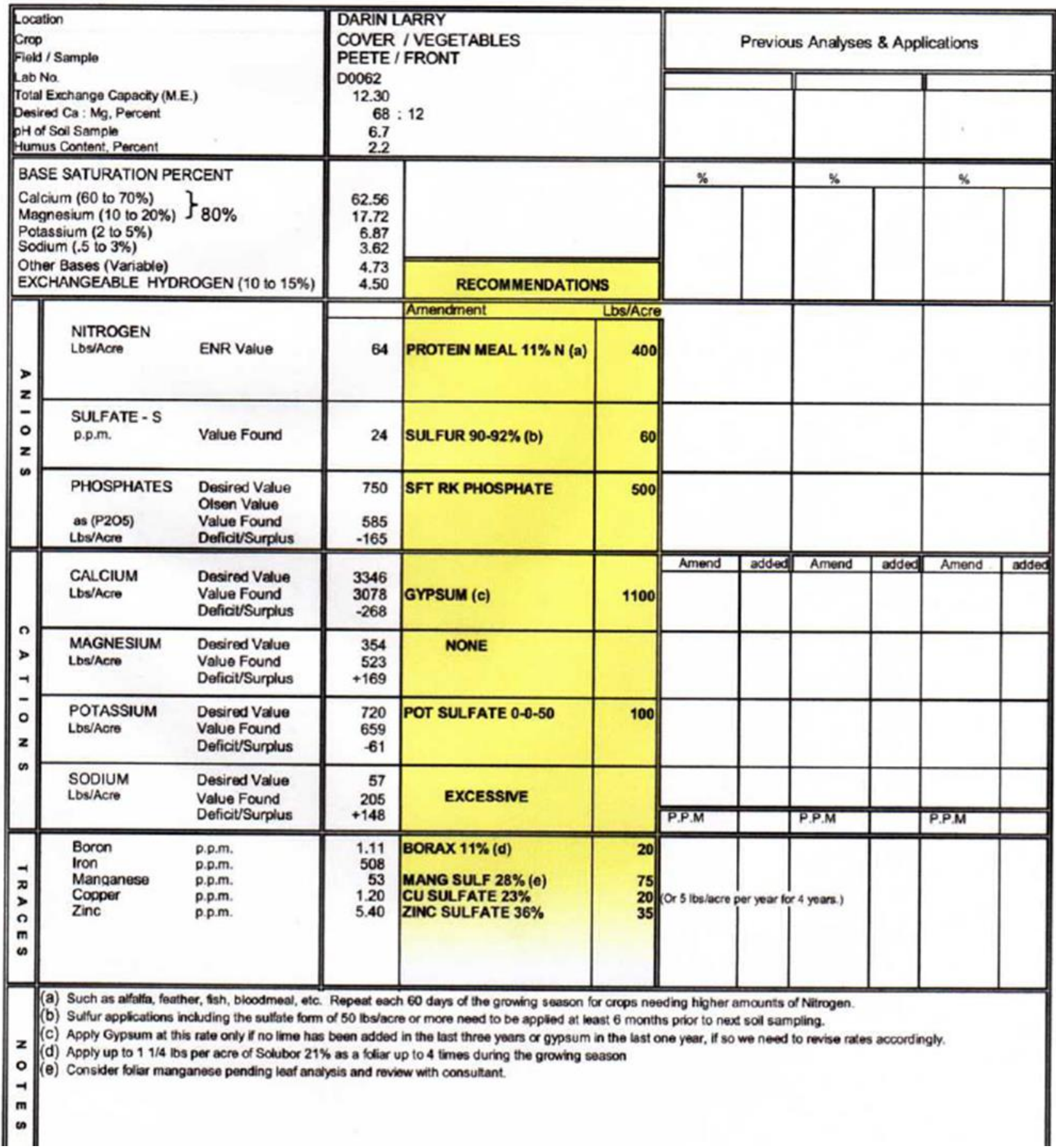




\section{Early Planning for the Community Farm}

The first discussions involving the idea of creating a community-benefit farm that would be maintained by volunteers began in November 2011. Over the next year, I met with the landowner and another of the principal founders of the farm concept on several occasions to plan the farm project. Since I was the only one with agricultural experience, I provided the strategic guidance on farm production. The other principal founder spent a great deal of time building relationships with local businesses and organizations to seek material support for the farm. The landowner (also a pastor at Grace Church) discussed the project with Grace Church leadership and the God's Storehouse crew to shore up volunteer support for the farm.

As the vision of the farm began to take shape, we realized that a larger pool of volunteers would be necessary to ensure success. We approached the pastor of Trinity Presbyterian Church, to discuss the prospects of Trinity lending the support of its congregation to the farm, and he immediately liked the idea. There were additional discussions to examine the idea of the farm becoming a joint ministry of the two churches, but it was ultimately determined that this idea would introduce undesired complexity into the organizational development. The farm would become a ministry of Trinity Presbyterian Church, with members of Grace Church participating alongside those of Trinity.

\section{Vision}

During the early discussions with the leadership at Trinity, a vision for the farm began to take shape. Some of the key goals that we wanted the farm to achieve were:

1. To significantly improve the quality of food offered at God's Storehouse by providing fresher, organic fruits and vegetables.

2. To include the food recipients in the development and operation of the farm.

3. To foster ecumenical cooperation by working together with another church in the community.

4. To provide an opportunity for church members to build stronger relationships by working alongside one another toward a worthwhile cause.

In the summer of 2012, as I was preparing to present the farm vision to both church congregations, I had a serendipitous meeting with a gentleman, who had a great deal of experience working with, and organizing volunteers. As he shared his experiences with running volunteer organizations, it became clear to me that we were not yet prepared to present the farm idea to the congregations. There was considerable organizational development and refinement of vision still to be done. Some of the key considerations that he pointed out to ensure success were: 
1. What is our vision? Is it to have a project as a means to build relationships, or to provide high quality produce? These have the potential to be mutually exclusive if not carefully considered. For instance, including the food recipients in the development and operation of the farm could be a great opportunity to build relationships with them, but it could also entangle the development process, create inefficiencies in the operation, and introduce competing ideas and conflicts that would ultimately degrade the effectiveness of the agricultural production. Both goals could be accomplished, but additional strategies would likely be necessary. Regardless, the vision must be clear.

2. What clearly defined roles will be established for the volunteers? Volunteers need to know what their roles are in the project. It provides them with clearer expectations, defines responsibilities, reduces conflicts, and ensures that tasks are accomplished.

3. How will you ensure "self-promoters" don't hijack the process? By means of the openinvitation for help, volunteer organizations can present opportunities for certain personalities to attempt to seize control and advance their own agendas. This can derail the original vision and introduce ongoing conflict into the organization.

4. How will you encourage "ownership" of the project by the volunteers? Volunteers are more likely to remain committed when: their ideas are considered, they are appreciated, they are given some freedom, and they feel like their contributions are meaningful.

5. How will you avoid volunteer "burn-out"? Volunteers can easily be overworked (by their own accord or by the demands of leadership) and flame out.

6. How will you keep the volunteer pool "well-stocked"? Through natural attrition or volunteer burn-out, the number of volunteers involved in a project will erode over time.

Taking these points into consideration, I spent some time re-drafting our vision, sketching out a rough organizational plan and preparing some materials that could guide our future leadership team through the process of creating an organizational structure. My intent was not to answer all of these questions on my own, but to present them to our future leadership for us all to work through. I did, however, feel it was important to define some basic leadership roles at the outset to provide some foundational guidance during the formation of the leadership team.

After reconsidering the question about our vision, my new draft of the vision took the following form:

1. To significantly improve the quality of food offered at many food distribution centers by providing fresh, nutritionally dense, local, organically grown, top quality fruits and vegetables.

2. To educate and reconnect people to the knowledge of how food is produced.

3. To work together, building relationships with each other and with the food recipients.

4. To take a step toward building social justice by improving health and food security.

5. To foster ecumenical cooperation and build community within our county. 
To address the question about clearly defined roles, I conceived the following leadership roles for the team:

1. Volunteer Coordinator(s) - team member(s) dedicated to ensuring the farm volunteers are provided regular updates about farm work opportunities and other needs and encourage maximum participation

2. Finance Coordinator - team member responsible for maintaining accounting of farm expenses and donations and ensuring funds are available for ongoing operations

3. Donations Coordinator - team member who actively seeks material and/or financial donations from businesses and organizations in the community

4. Special Projects Coordinator - team member responsible for coordinating special projects (such as greenhouse construction, sink installation, etc)

5. Marketing/Public Relations Coordinator - team member who serves as a liaison and/or spokesperson to the media and the public

6. Special Events Coordinator - team member responsible for coordinating special events (like the end-of-year Harvest Dinner)

7. Farm Manager(s) - team member(s) dedicated to planning, management, and instruction of farm operations

\section{Presenting the Idea}

To help instill ownership of the project and reduce the likelihood of "self-promoters" taking over the operation, I decided to plan a couple of farm workdays, followed by a brainstorming session to solicit ideas from interested volunteers. I intended for the workdays to begin before the first leadership team meeting because I wanted to be able to identify and personally approach potential leaders based on observed leadership qualities rather than rely on individuals to step forward and assume leadership positions without my foreknowledge of their qualities or personalities. The brainstorming session was meant to instill early ownership in the project. In the end, due to scheduling conflicts, we were unable to hold any farm workdays and I was forced to trust that the right people would step forward for the right jobs. But before we could accomplish any of this, we needed to get the word out about the farm idea!

By December 2012, with the spring growing season fast approaching, the need to present the farm idea to the church congregations was becoming more urgent. Once we presented the idea, we could begin the process of "recruiting to task" and further develop the brainstorming by including more people in the process. After coordinating with leadership at both churches, we decided to hold the informational meeting in mid-January after the holiday season had wrapped up. On January 13, 2013, I used the following PowerPoint presentation and notes to outline the farm concept to about 50 people who showed up for the meeting: 
Presentation Used for First Congregational Meeting about the Farm (11 Slides)

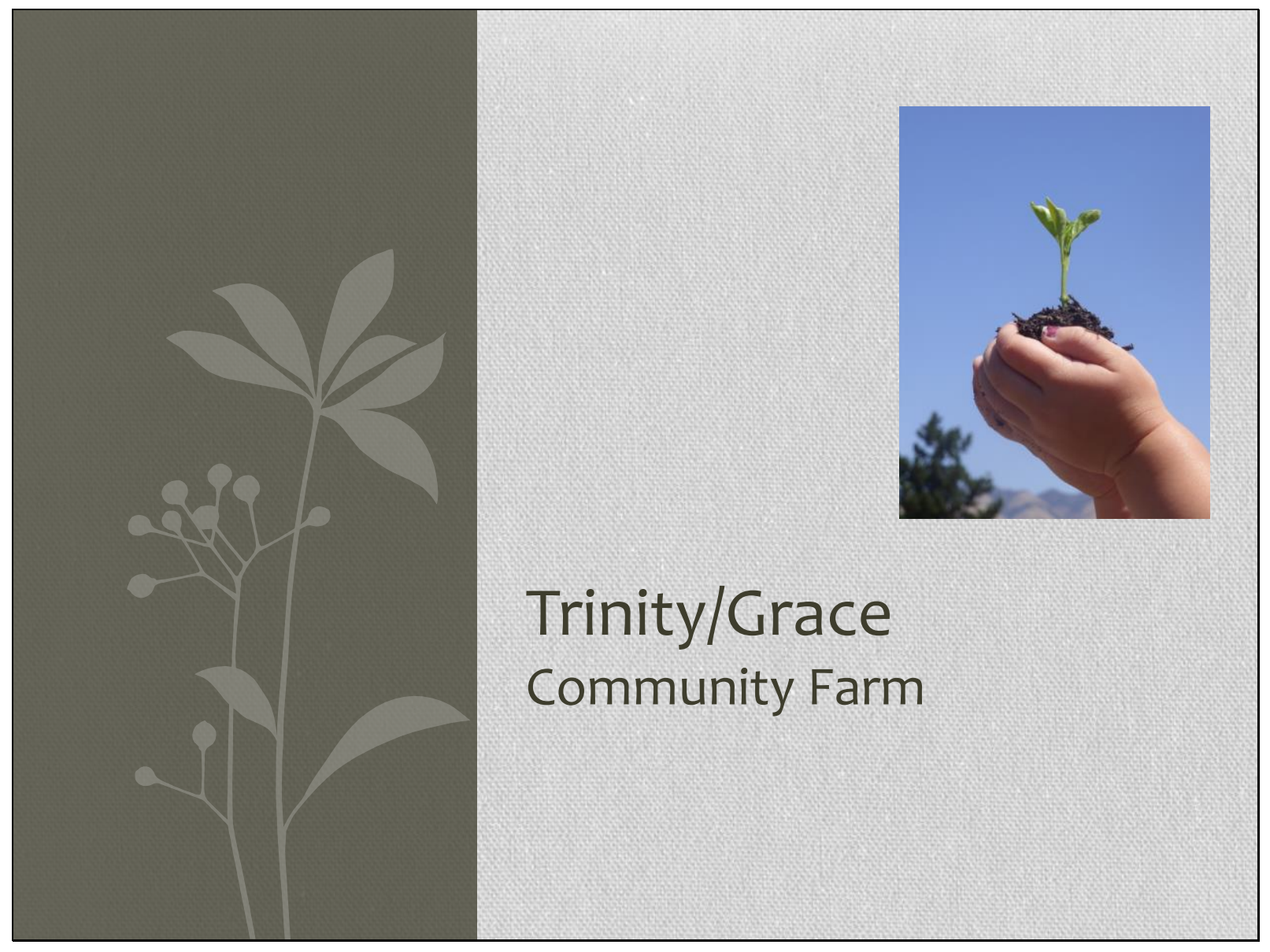

Welcome!

(BTW we need to come up with a name for this little farm!) 


\section{Why a Farm?}

- Provide: Healthy, Fresh, Local, Sustainably Grown, Top Quality produce for God's Storehouse and other outlets

- Working Together to Grow Healthy Food can Nourish: Body, Mind, Spirit, Relationships, Community, Earth

- A Step Toward Building Systemic Justice, Health, and Food Security

- Education: Reconnect people with the knowledge of how food is produced
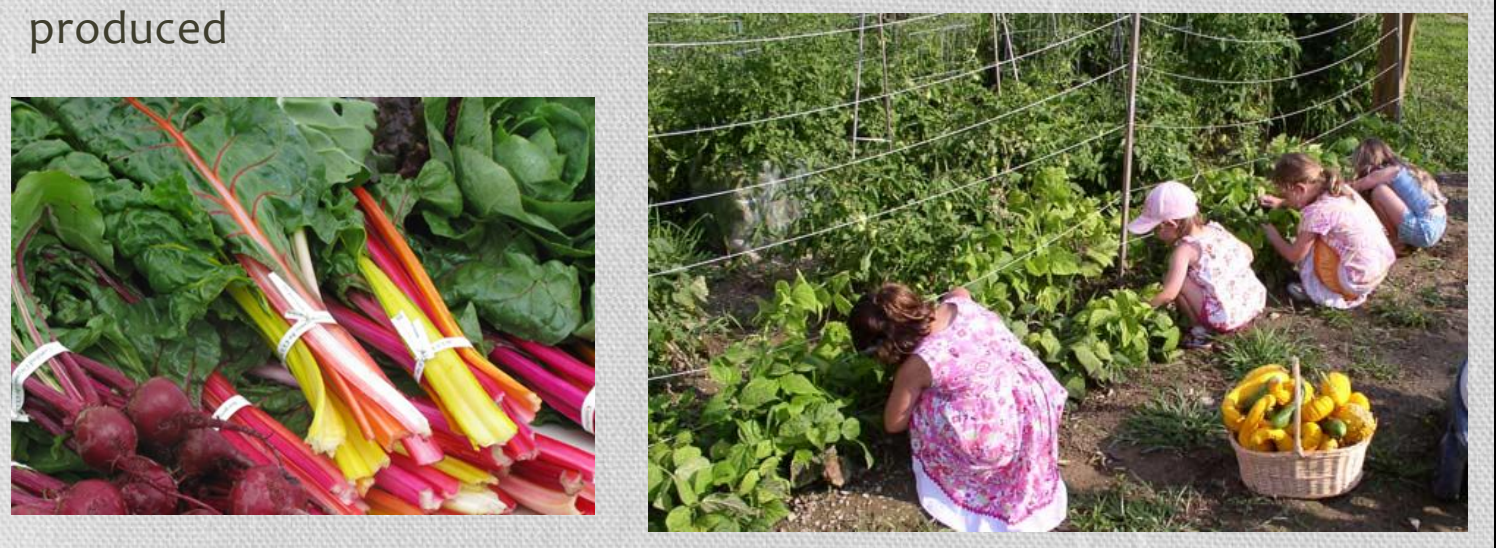

- Currently, the quality of most of the donated produce is not exceptional. It is the leftovers, the seconds, the throw-aways. We can change that...and offer our best, first fruits. There are regularly anywhere from 150-200 families who gather across the street on Saturday mornings to receive food. We can give them an even better offering.

- Working together growing healthy food will help us to care for individuals, the community and creation.

- We can help build community, improve health, and enhance food security. Many of us our completely disconnected from the production of the food we eat. This will help reconnect us. 


\section{The Setting}

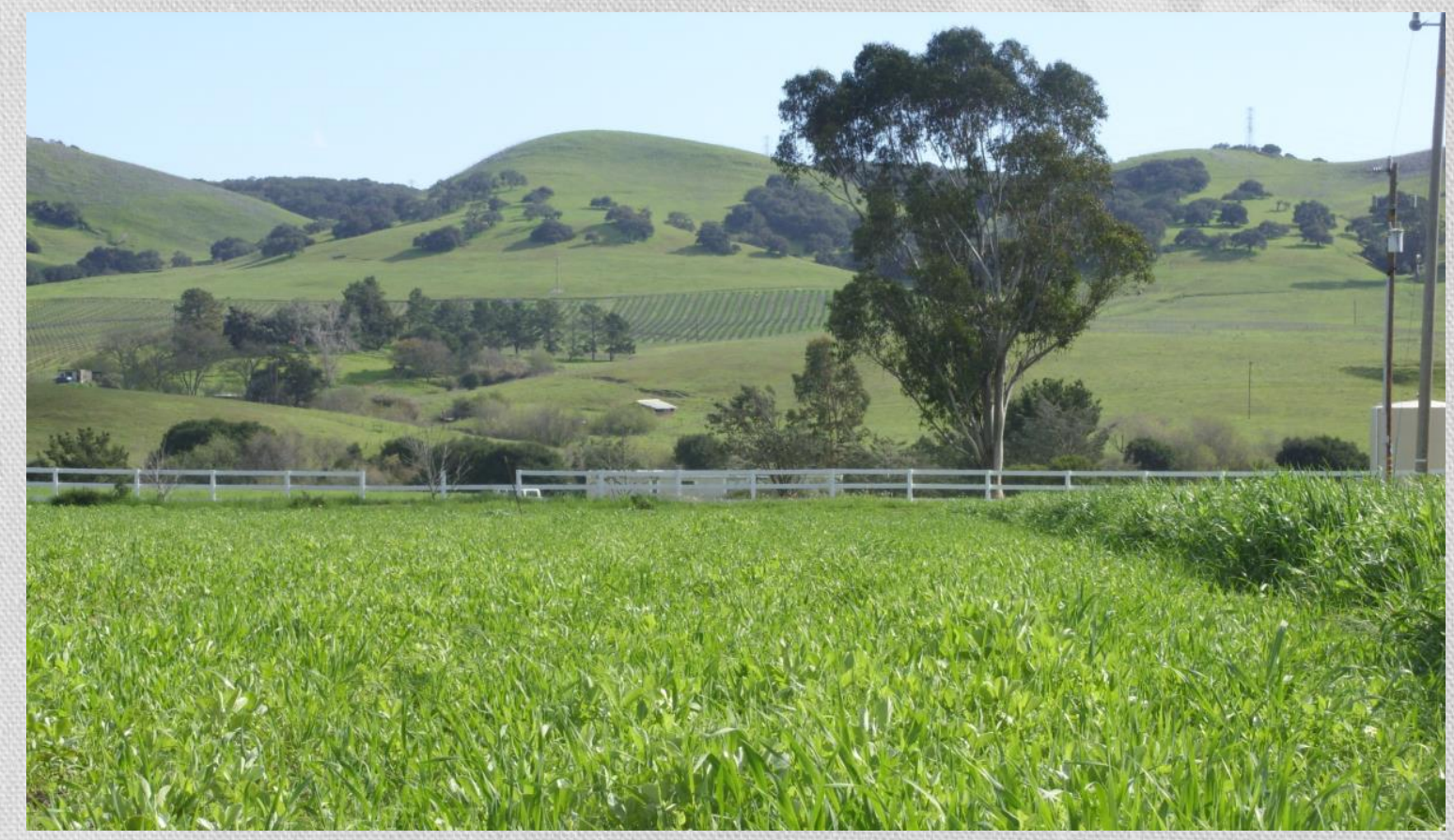

- Beautiful, quiet, open country side just south of the airport off of Buckley Rd. and Davenport Creek Rd.

- 2 acres of gently sloping, south-facing, productive soil.

- This picture is looking south from the top of the field to the bottom, and was taken in early 2009 when the cover crop was really starting to take off. 


\section{Current State}

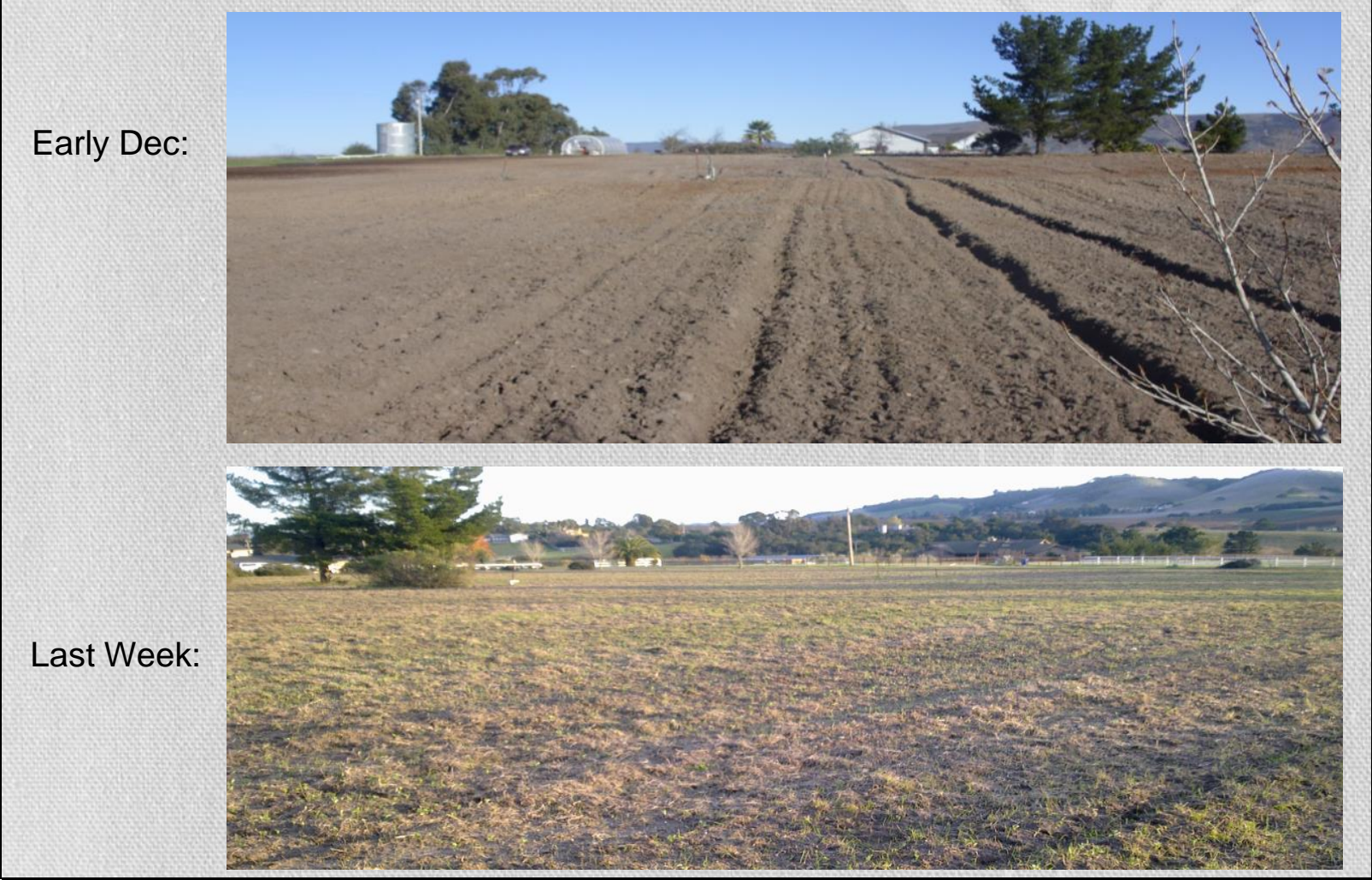

- Top Picture: Looking up from the bottom of the field to the top, this is what it looked like in early December after tractor work.

- Bottom Picture: Looking from the top of the field to the bottom, showing the newly seeded cover crop starting to emerge.

- Cover crops are specially selected species that do wonders for invigorating the soil and preparing it for the growing season. It also protects (covers) the soil from wind and erosion during the winter months (hence the term "cover crop"). 


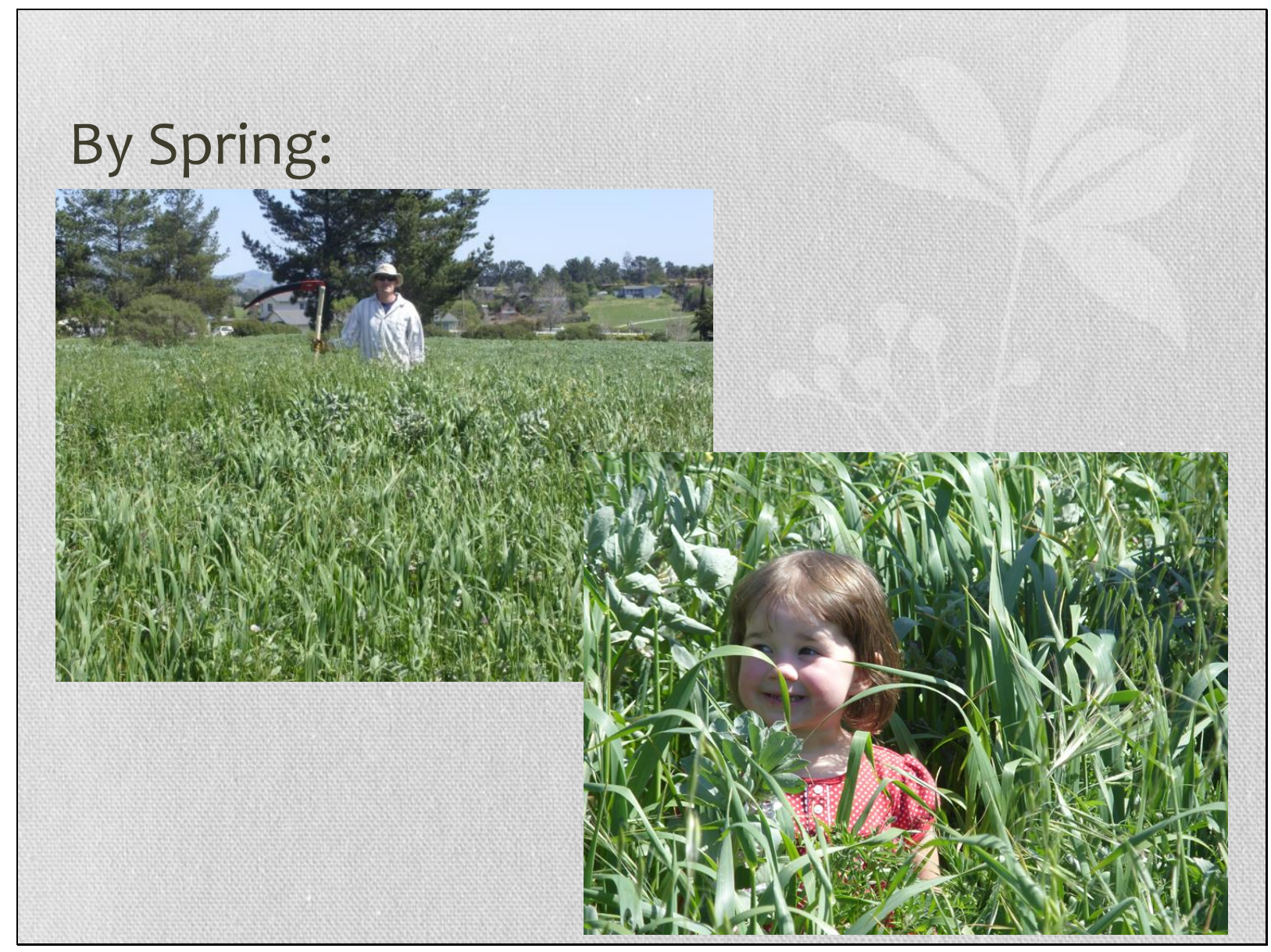

- Those little sprouts will hopefully look like this again by Spring! Once they've started to blossom, they will have reached their peak nitrogen fixation, and we will be then cut it down and turn it into the soil to feed the soil microbial life. This investment will yield incredible results!

- These pictures were taken after the last cover crop was planted and were reaching their peak growth. Caedra was 3 at the time and it towered over her head. The vegetables that came out of the field after this cover crop was turned in, were unmatched in quality. 


\section{What will it take?}

- People!

- Time

- Commitments

- Resources
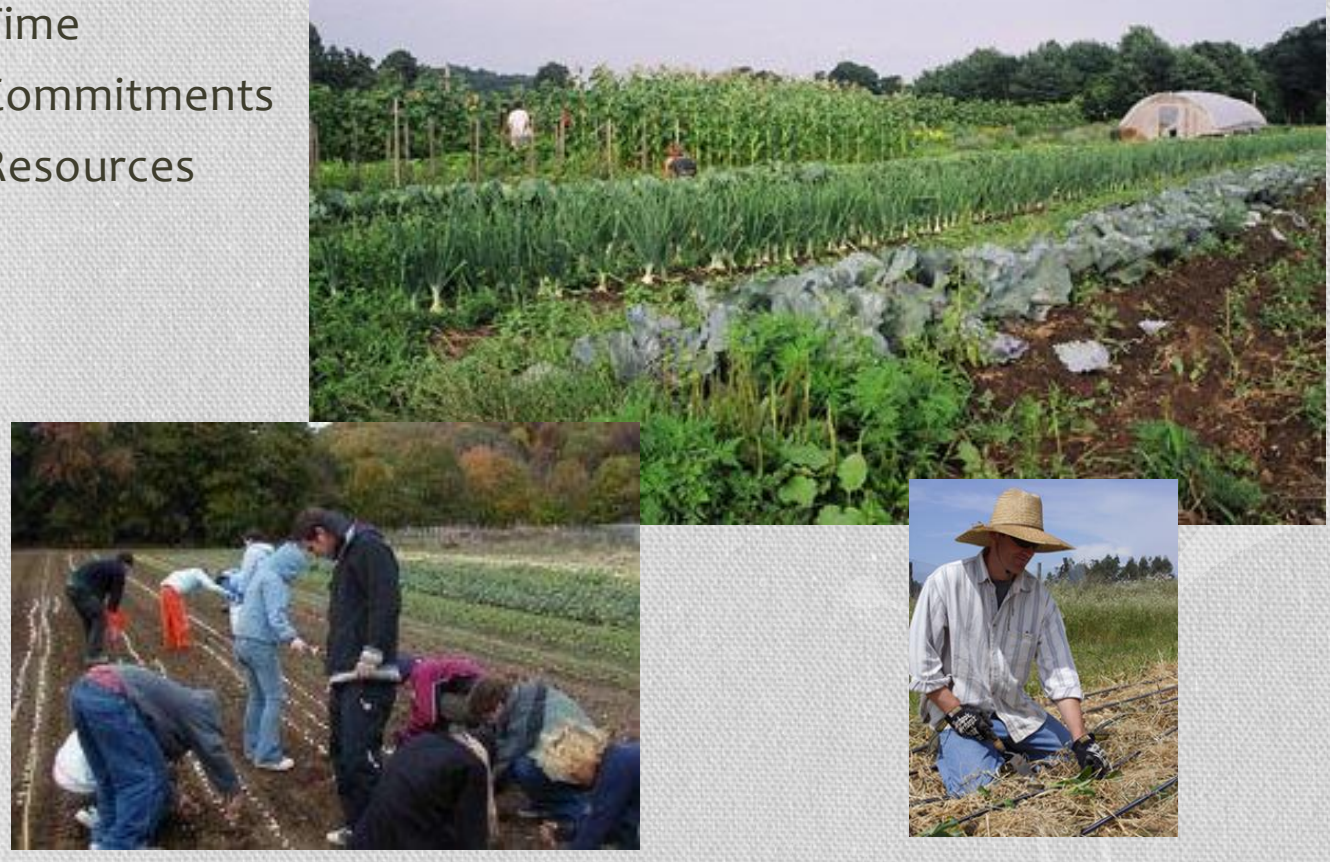

- What will it take to pull this off?

- People-That's You!

- Time - For some of you that might be 1 hour a month, for others it might be several hours per week. For this to be successful we'll need at least 40-50 man-hours per week.

- Commitments - We would hope that you could commit to a growing season (which we'll consider March-October)...and beyond.

- Resources - We'll need donations or finances to acquire key items: seeds, fertilizers, tools, equipment. We currently have only the barest essentials to get something started. Over the next few months, we'll need to gather resources to get ready for the growing season. FYI, we have already received several verbal commitments for donations of key items. But we have a lot of work to do in this area. 


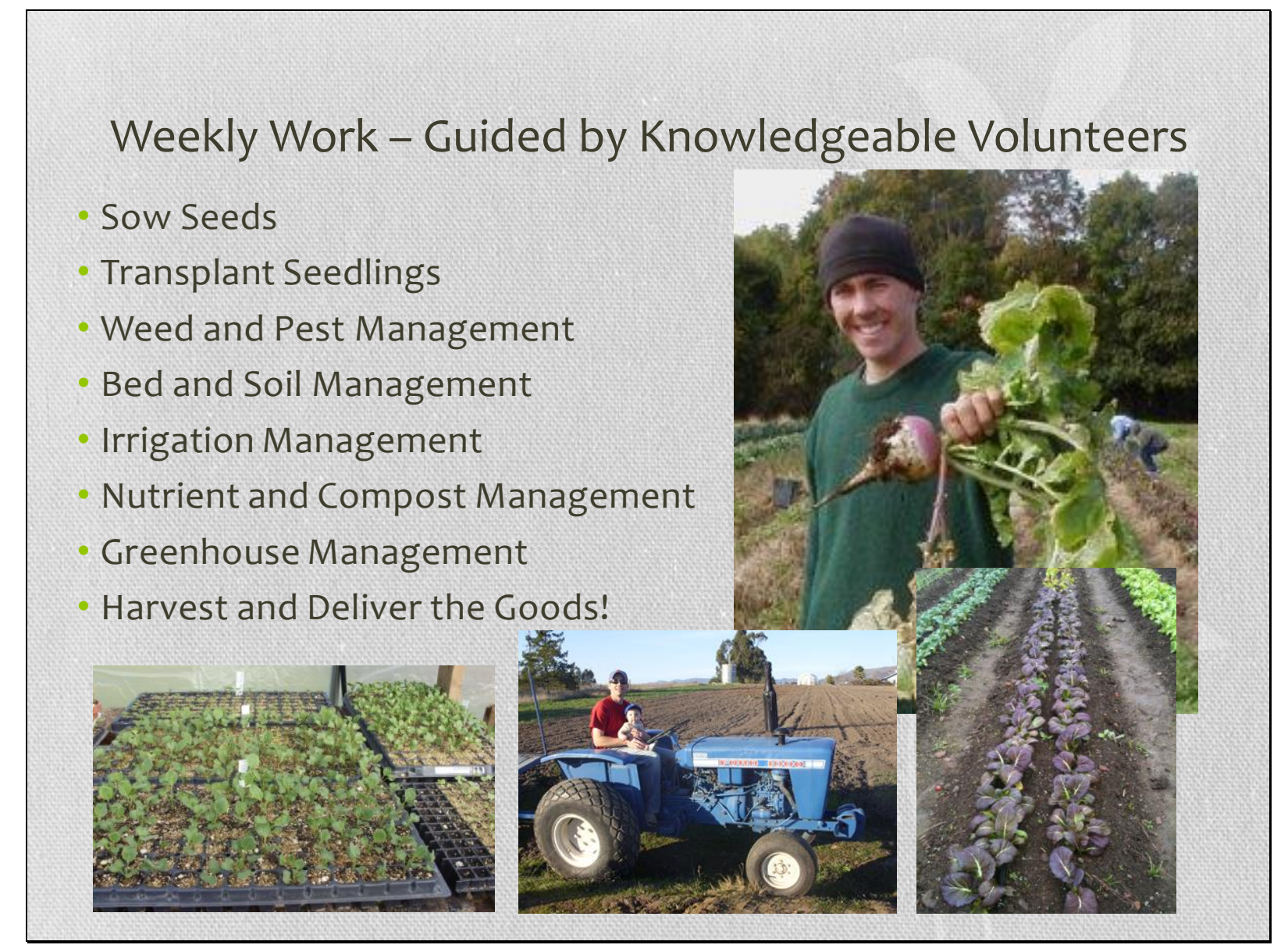

- Ok, so for the majority of you who have no farm or garden experience...you've got one question on your mind: Will someone show us what to do???

- The short answer is, Yes! This list reflects the daily and weekly work that will need to be accomplished each week. None of it is rocket science, but all of it requires skill development. You will get that.

- We don't want to repeat a mistake from a couple of years ago when a volunteer hoed up an entire row of newly germinated carrots thinking they were weeds! 


\section{Projects}

- Greenhouse

- Shed

- Fruit Trees

- Hedgerow

- Land Beautification

- Others???
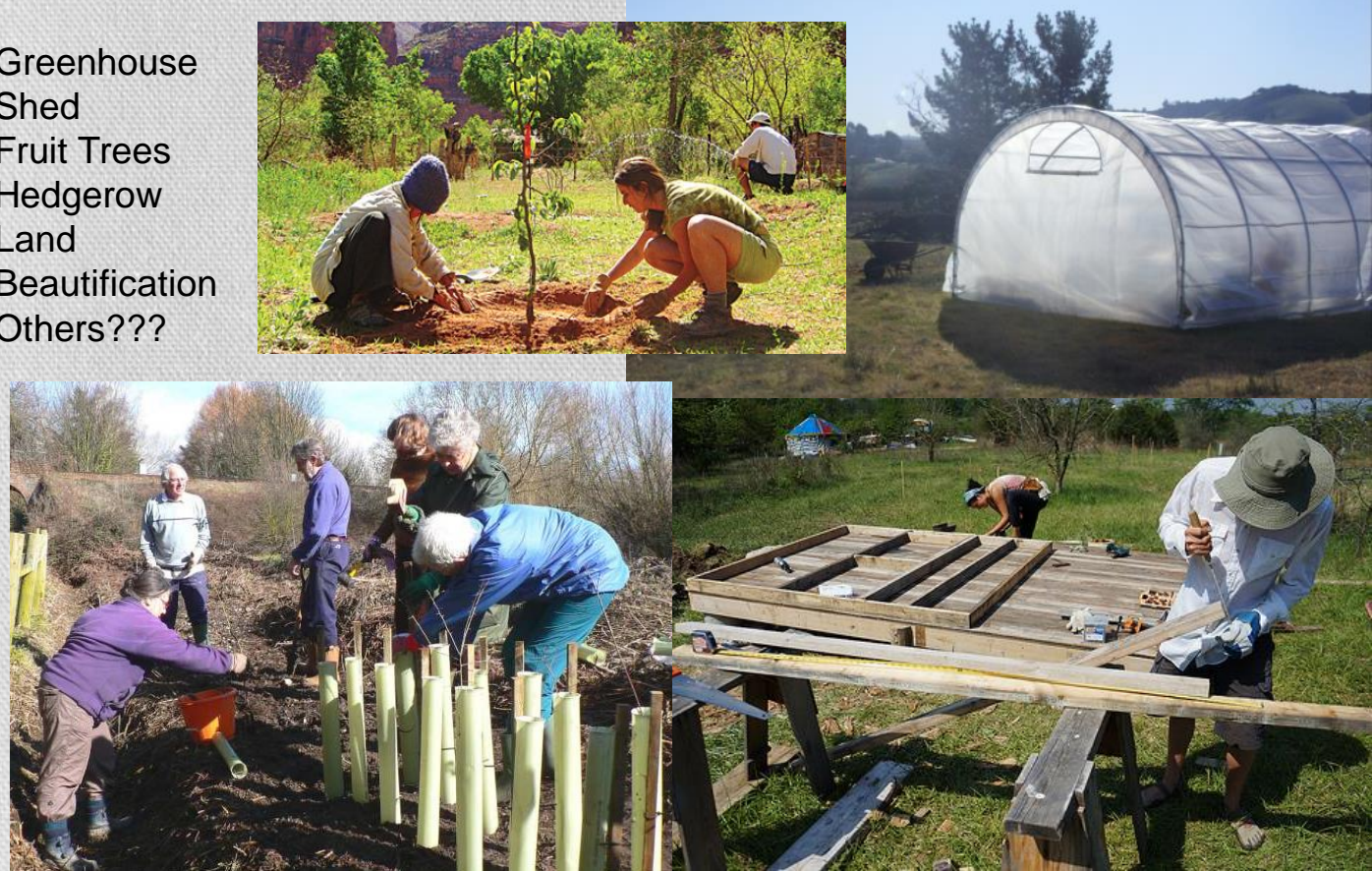

- Over the next months, we'll have special project days to accomplish some key objectives. Some of you have construction or carpentry skills, others are master gardeners. We'll need you to get these projects done. 


\section{What's Next?}

\section{- Form a Dedicated Team to:}

- Coordinate Volunteers

- Manage Resources and Finances

- Seek Donations

- Manage the Farm

- Project Days:

- Assemble Greenhouse

- Build Workbenches and Storage Shed

- Tractor/Equipment Maintenance

- Prepare for the Growing Season:

- Sow seeds

- Care for seedlings

- Turn in the cover crop

- Prepare growing beds and irrigation

- Transplant seedlings and GO!

- If this is going to happen, we need to form a dedicated team of people who have the time and passion to commit to making this succeed. This leadership team is a key determinant on whether we can move forward. If we have a motivated and committed leadership team, this project can succeed.

- As a reference: God's Storehouse has a leadership team of 16 people who ensure that the ministry carries on. We may need something similar.

- Some of the ongoing responsibilities that will be essential for success are listed above: coordinate volunteers, manage resources/finances, seek donations, manage the farm. I think we have a sufficient number of people that are interested in doing the work.

- But we have a great need to coordinate and communicate with these volunteers to ensure the right work gets done at the right time. The leadership team will ensure this happens.

- In the coming months we'll have some project days, and we'll prepare for the growing season.

- So the question for you is.... 


\section{Will You Own It?}




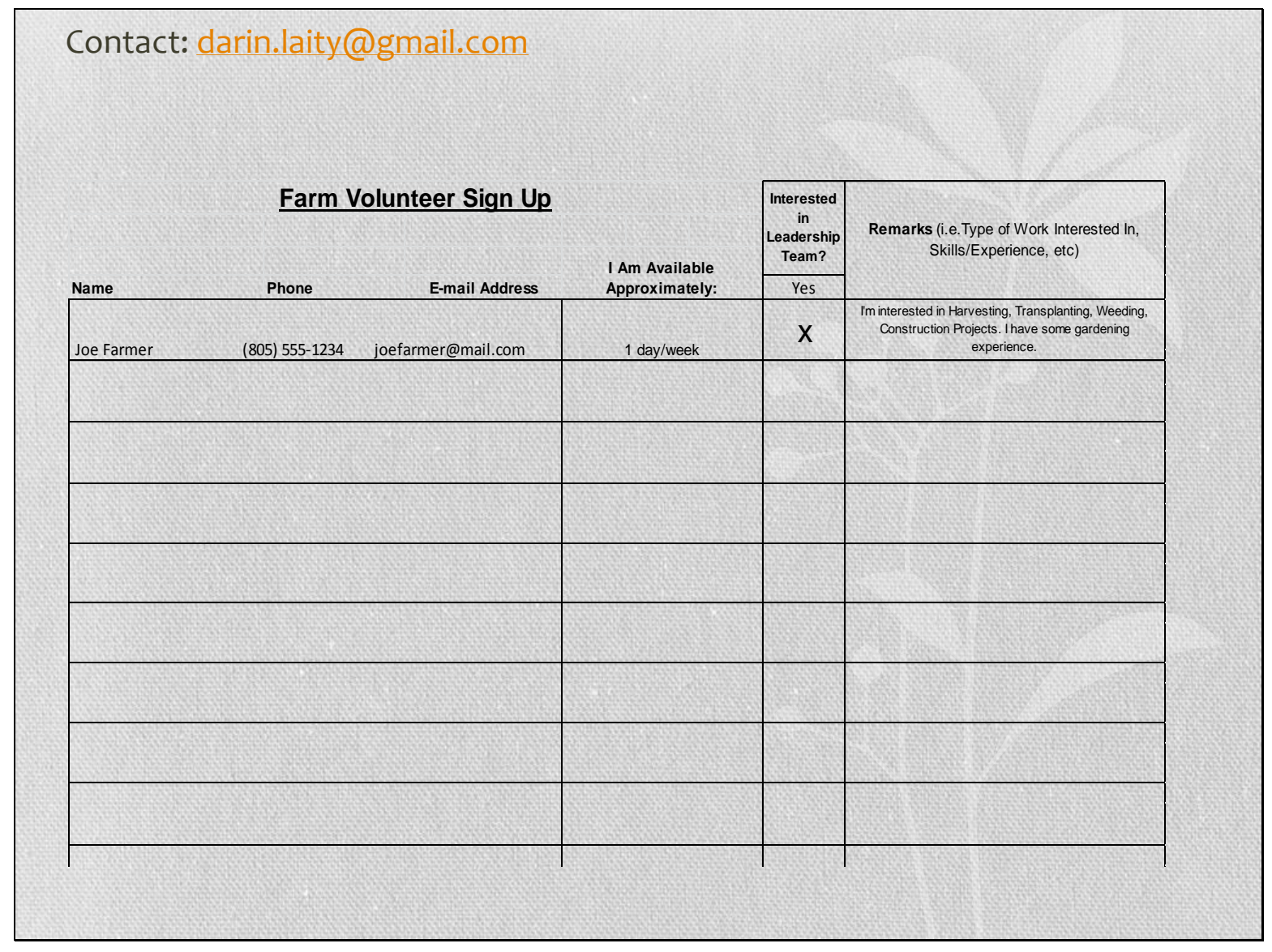

Sign-up sheet, and my contact info. 


\section{Formation of a Leadership Team}

The presentation resulted in about 40 people signing up to participate in the development of the operation, with a number of them expressing interest in joining a leadership team. To keep the momentum going, we scheduled a meeting to form a leadership team, assign roles, solicit ideas, and build ownership. As mentioned before, we were unable to hold any farm workdays before the first leadership team meeting. However, before the meeting, I did ask for a few key people to brainstorm and share their thoughts with me about their ideas for success. One of the individuals, who would later become our special events coordinator and one of our donations coordinators, shared the following list of ideas. It was encouraging to see that many of our ideas were in common and/or complimentary:

\section{Farm Brainstorm Sample \\ (Contributed by Leadership Team Member)}

1. Need Church POC's \& or Church rep

2. God's Storehouse POC's \& or Storehouse Rep

a. Coordinate recipient participation

b. Determine recipient participation requirement $\&$ or track participation

c. Transportation if needed

3. Farming Experts:

a. Develop overall plan

b. Layout

c. Long term plans

d. Decide what to grow

e. What Store House uses, requests

f. What grows best in the area

g. Develop written material S.O.P.

h. Water requirements for each area/ plant group

i. What \& when to fertilize

j. When (time of year) to plant what

4. Structure Manager

a. What structures would be needed /short \& long term immediate/would be nice to have:

i. Green house

ii. Shed for tools, instruction materials, supplies

iii. Security

iv. Play structure (for children of working volunteers)

v. Bathroom

vi. Water

1. For plants

2. For drinking

vii. Wind barrier

viii. Seating (bench to rest, pray, etc)

5. Man Power coordinator 
a. Develop a schedule (i.e. time a skilled volunteer will be available to direct others)

b. Document, track, coordinate skill sets

c. Determine a guideline for number of labor hours needed for in garden

d. Advise the time it takes for a given task to help develop schedule correctly

6. Teacher: train unskilled workers; manage a kids program while parents work; speak at schools......

7. Public Affairs: be a face for the project

a. Visit businesses for:

i. project support

ii. report on progress

iii. thank \& or entice to get involved

iv. investigate other areas of need (other food banks, shelters ect)

8. Media POC

9. Event coordinator

a. Social gatherings to encourage volunteers, business, general public to join us on/off site (i.e. harvest party)

10. Historian: pictures, web/technical, video

a. Ways to remember

b. Communicate with others what project is

11. Finance

a. Someone to manage funds $\$ \&$ in-kind donations

b. Tax letters

c. Operating costs

d. \$ value of goods produced

e. Help advise what to do if excess exists

f. Sell at farmers market? (person to man booth)

g. Allow volunteers access (maybe based on hours)

12. Prayer

a. Coordinate prayer team

b. Visit farm to pray

Before the leadership team meeting, I prepared several documents to provide each member: a meeting agenda, a list of job descriptions and accompanying tasks for each team member to undertake, a contact list (Figures 3,4), and a list of farm needs. The contents of the documents are included here: 


\section{Farm Leadership Meeting Agenda}

1. Introductions

2. Project Updates

3. Ongoing Coordination Needs

4. Organization of Core Team: Decide on Sub-Teams/Roles/Team Leads

Possible Sub-Team Ideas:
a. Volunteer Coordinators
b. Finance Coordinators
c. Donations Coordinators
d. Public Relations Coordinators
e. Special Projects Coordinators
f. Farm Managers

Possible Special Roles:

g. Special Events Coordinator

h. Historian

i. Storehouse POC/Liason

j. Beneficiary Liason

k. Prayer Team

5. Rotation of Responsibilities (weekends/weekdays per month)

6. Commitment Period of Core Team Members

7. Communication Methods

8. Coordination of Volunteers

9. Strategies for Success

10. Upcoming Projects and Growing Season Timeline

11. Taskers for Each Sub-Team

12. Closing 


\section{Coordinator Job Descriptions and Near-Term Taskers}

\section{Volunteer Coordinators}

Description: Responsible for coordinating and scheduling volunteers to help out with weekly farm work and special projects. May also serve as a central point of contact for all activities related to the project.

\section{Near-Term Taskers:}

- Collect contact info of willing farm workers/volunteers

- Decide on, and establish communication method (e-mail, Facebook, website, etc)

- Develop a template for communication to ensure consistency

- Work with Farm Managers to balance volunteer help with farm needs (weekly work cycles, seasonal timelines, and special project plans will be needed for this)

\section{Finance Coordinators}

Description: Responsible for developing a working budget for farm needs and managing financial resources to ensure accountability.

\section{Near-Term Taskers:}

- Work with church leadership (deacons, elders, pastors, God's Storehouse team) to determine possibility of special collection for farm needs

- Develop a farm budget (will need to work with Farm Managers to establish an estimate of annual needs)

- Seek grant money or other outside financial contributions for projects and ongoing expenses

- Make purchases of key resources (fertilizers, seeds, tools, equipment)

\section{Donations Coordinators}

Description: Responsible for seeking donated resources from businesses and organizations in the community who may be interested in contributing to the farm project.

\section{Near-Term Taskers:}

- Communicate farm project to key businesses and organizations in the community that may want to contribute to the cause and develop a resource network for the farm

- Plan and communicate with Finance Coordinators to balance financial expenses with donated items

- Coordinate delivery of donated resources

- Work with Public Relations Coordinators to build interest in donating to the farm 


\section{Public Relations Coordinators}

Description: Responsible for developing and managing a means to publicize information about the farm to the community and the media.

\section{Near-Term Taskers:}

- Decide on, and develop a means to publicize the farm (website, Facebook, Blog, etc)

- Plan and disseminate press releases or updates about the farm to local media as necessary

- Communicate updates about the farm to church leaders and congregation

- Plan special events for farm support and awareness

\section{Special Projects Coordinators}

Description: Responsible for planning and managing the construction and/or installation of special projects necessary for farm operations.

\section{Near-Term Taskers:}

- Build a project team contact list for future projects and determine skills and experiences among team members

- Install Port-a-Potty for farm volunteers

- Plan and construct a storage shed for the farm

- Build work benches for harvest preparations

- Install sinks for vegetable washing

- Build greenhouse and install automatic sprinklers

\section{Farm Managers}

Description: Responsible for planning growing season, training volunteers to accomplish farm work, overseeing ongoing operations to ensure continued production and quality assurance.

- Plan growing season

- Decide on, and communicate resource needs

- Decide on, and plan weekly, monthly and seasonal work cycles

- Provide training seminars on basics of farm work

\section{$\underline{\text { Special Roles }}$}

- Prayer Team

- Special Events Coordinator (PR Coordinator?)

- Historian

- Storehouse POC/Liaisons 


\begin{tabular}{|c|c|c|c|c|c|c|c|}
\hline \multicolumn{8}{|c|}{ First Fruits Farm Contact Info } \\
\hline Name & E-mail & Phone & Leadership Team? & Interests & Skills & Availability & Other \\
\hline An -.......ns & $=$ & $\ldots-\ldots$ & $Y$ & Farm Manager & Farming & $5 \mathrm{hrs} / \mathrm{wk}$ & Works at Transitions Farm \\
\hline Ma-.......ns & $\ldots$ & $\ldots-\ldots$ & $\mathrm{Y}$ & Farm Manager/PR/Historian & Farming & $5 \mathrm{hrs} / \mathrm{wk}$ & Photographer \\
\hline To-......-nz & $=$ & $\cdots+$ & $\mathrm{N}$ & Learning to farm & & At least 1 day/wk & \\
\hline $\mathrm{Be}-\cdots-\cdots \mathrm{nz}$ & $\ldots$ & $\ldots-\ldots$ & $\mathrm{N}$ & Learning to farm & & At least 1 day/wk & \\
\hline Da-.......er & $=$ & $\ldots-\ldots$ & ? & Learning to farm & & About 1 day/wk & Cal Poly professor \\
\hline El-......er & $=$ & $\ldots+\ldots$ & ? & Learning to farm & & About 1 day/wk & Cal Poly professor \\
\hline Di-......-aj & $=$ & $\ldots+\cdots$ & $\mathrm{N}$ & & & $3 \mathrm{hrs} / \mathrm{wk}$ & Teacher at Classical Academy \\
\hline $\mathrm{Na}-\ldots-$-...as & $=$ & $\ldots-\ldots$ & ? & & Project Organizing & ? & Boy Scout Leader \\
\hline To -......-on & $=$ & $\ldots-\ldots$ & $\mathrm{Y}$ & Organization & Strategist & ? & Finance Coordination Team \\
\hline Da-......es & $=$ & $\ldots-$ & ? & Farming/Projects & Landscape Maint. & 1-2 days/wk & Special Projects Team \\
\hline St-......rd & $\ldots$ & $\ldots+\ldots$ & ? & Physical work/admin & Administration & ? & Former pastor \\
\hline $\mathrm{Ni}-\ldots-\ldots-\mathrm{er}$ & $=$ & $\ldots-\ldots$ & $\mathrm{N}$ & Anywhere needed & & 1 day/wk & Will have more time soon \\
\hline To-n-..-er & $\cdots$ & $\ldots-\ldots$ & $\mathrm{N}$ & Special Projects & Construction & weekends & Can make hawk roosts \\
\hline We--..-.-er & $=$ & 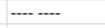 & $\mathrm{Y}$ & Farming/Projects & Carpentry & 1-2 days/wk & Special Projects Team - Chairperson \\
\hline De-.......ng & $=$ & $\ldots-\ldots$ & $\mathrm{Y}$ & Anywhere needed & Organization & 1 day/wk & \\
\hline De--..--ly & $=$ & $\ldots-\ldots$ & $\mathrm{N}$ & Farming & Gardening & ? & Lots of gardening and holistic health experience \\
\hline Bo-......ms & $=$ & $\ldots-\ldots$ & $\mathrm{Y}$ & Donations/Finances & Computer/Spreadsheets & $1-2 \mathrm{hrs} / \mathrm{wk}$ & Finance Coordinator - Chairperson \\
\hline Ba $\ldots . .-\ldots$ th & $\ldots$ & $\ldots-\ldots$ & $\mathrm{Y}$ & Farming & Organic Gardening/Bees & 1-2 days/wk & Very experienced, may need transportation help \\
\hline $\mathrm{Fa}-\ldots-\ldots$ on & $\ldots$ & $\ldots-\ldots$ & $\mathrm{Y}$ & & & 2 days/wk & \\
\hline We-c-..-on & $=$ & $\ldots-$ & $\mathrm{N}$ & & & 1-2 days/month & \\
\hline Ba-.....-re & $=$ & $\ldots+. .$. & ? & Farming & Organizing/Communication & 1 day/wk & Open to helping wherever needed \\
\hline Sh-....-.ing & $=$ & $\ldots-\ldots$ & ? & & Gardening & $1 \mathrm{day} / \mathrm{wk}$ & Interested in learning about farming \\
\hline $\mathrm{Ky}-\cdots-\ldots-\mathrm{ey}$ & $=$ & $\ldots-\ldots$ & ? & Farming & Gardening & ? & Works for SUSTAIN SLO / AmeriCorps \\
\hline Su-z...-ra & $=$ & $\ldots-\ldots$ & ? & Farming & Gardening & 1 day/wk & \\
\hline $\mathrm{Br}-\ldots-\mathrm{ks}$ & $=$ & $\ldots-\ldots$ & $\mathrm{N}$ & Farming/Projects & Construction/Plans & ? & Engineer \\
\hline Ca-.......er & $=$ & $\ldots-\ldots$ & $\mathrm{N}$ & Farming & Gardening & ? & Has grown lots of different fruits and veggies \\
\hline Ma-..-..-er & $\ldots$ & $\cdots-\ldots$ & $\mathrm{N}$ & Farming & Gardening & ? & Willing to help in many different ways \\
\hline Sh-n-..-er & $=$ & $\ldots-\ldots$ & ? & Anywhere needed & & ? & Schedule a little crazy, but very interested \\
\hline $\mathrm{He}-\ldots \mathrm{rds}$ & $\ldots$ & $\ldots+\ldots$ & $\mathrm{N}$ & Farming & Gardening & 1 day/wk & Green thumb \\
\hline Ma-..-.-.er & $=$ & $\ldots-\ldots$ & $\mathrm{Y}$ & Donations Coordinator & Gardening & 1-2 days/month & Founding member of this project \\
\hline $\mathrm{Fr}-\ldots-\ldots \mathrm{er}$ & $=$ & $\ldots-\ldots$ & $\mathrm{Y}$ & Projects & Maintenance/Construction & 1-2 days/month & Special Projects Team \\
\hline Jo-......ck & $=$ & $\ldots-\ldots$ & $\mathrm{N}$ & Leadership & & & Pastor of Trinity \\
\hline Sc-......on & $\ldots$ & $\ldots$ & $\mathrm{Y}$ & Leadership & Counseling & 1 day/month & Associate Pastor at Trinity/Counselor \\
\hline La -.......ty & $=$ & 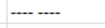 & $\mathrm{Y}$ & Volunteer Coordination & Gardening & 1 day/wk & Volunteer Coordination Team \\
\hline $\mathrm{Da}-\cdots \cdot \cdots \cdot \mathrm{ty}$ & $=$ & $\ldots-\ldots$ & $\mathrm{Y}$ & Farm Manager & Farming & 1-2 days/wk & Primary POC for project \\
\hline Ju-.......et & $=$ & $\ldots-\ldots$ & ? & & & & Wife of -......- would like to be kept in loop \\
\hline $\mathrm{Ke}-\ldots-\mathrm{et}$ & $=$ & $\ldots-\ldots$ & $\mathrm{Y}$ & Leadership & & $1 \mathrm{day} /$ month & Adult Pastor at Grace Church - Owner of Land \\
\hline
\end{tabular}

Figure 3

\begin{tabular}{|c|c|c|c|c|c|c|}
\hline \multicolumn{6}{|c|}{ First Fruits Farm Leadership Team } & \\
\hline \multicolumn{7}{|c|}{ Chairperson? } \\
\hline 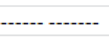 & (-............... & 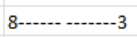 & Volunteer Coordinator & Y & Volunteer Coordinator - Chairperson & \\
\hline 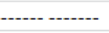 & $\ldots$ & $8-8$ & Volunteer Coordinator & & Volunteer Coordination Team & \\
\hline -........... & 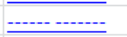 & 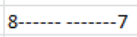 & Volunteer Coordinator & & Lives in Cambria & \\
\hline - n & ב.......... & 7-...--3 & Finance/Donations/PR Coordinator & Y & Finance Coordinator-Chairperson & \\
\hline -.............. & 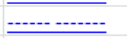 & 8-....-1 & Finance Coordinator & & Accounting Experience & \\
\hline 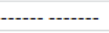 & $\ldots$ & 8-1..--0 & Donations Coordinator & Y & Founding member of this project & \\
\hline -........... & 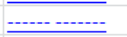 & 8-.-.-.--7 & Special Projects & Y & Carpentry and construction experience & \\
\hline 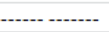 & 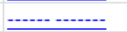 & 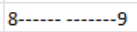 & Special Projects & & Special Projects Team & \\
\hline 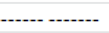 & ב............. & 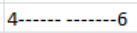 & Special Projects & & Lots of handyman experience & \\
\hline 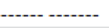 & - & 8--o-n--.--4 & Special Projects & & Can make hawk roosts & \\
\hline 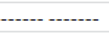 & -............ & & Special Projects & & Use -...-..-.-r's contact info & \\
\hline 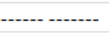 & ב-......... & $8-\cdots$ & $?$ & & Will have more time soon after baby is born & \\
\hline -........... & -............ & 8--..-- - 6 & Farm Management & Y & Primary POC for project & \\
\hline -1.........- & -............ & 4-1...-...-9 & Farm Management & & Works at Transitions Farm & \\
\hline 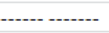 & -........... & 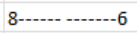 & Farm Management/PR/Historian & & Photographer & \\
\hline -1........... & 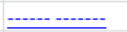 & $8-\cdots$ & Farm Management & & Very experienced, may need transportation help & \\
\hline 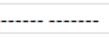 & 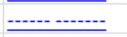 & $8-1-8$ & Special Events Coordinator/PR & Y & Will manage Facebook page & \\
\hline -...- -...- & $\overline{y-\cdots+\cdots}$ & 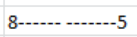 & ? & & Wants to be included in leadership communication & \\
\hline 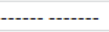 & $\ldots$ & $8-1$ & ? & & Wants to be included in leadership communication & 1 day/wk \\
\hline -....- & 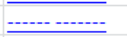 & 4-1--.--6 6 & Volunteer Coordinator/Special Events & & Experienced with volunteer coordination & \\
\hline 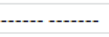 & ב.......... & $8-1-0$ & $?$ & & Wants to be included in leadership communication & \\
\hline -.............. & 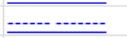 & $8-\cdots-1$ & $?$ & & Wants to be included in leadership communication & \\
\hline -1...-. & $\ldots$ & 7-1-...--5 & $?$ & & Wants to be included in leadership communication & \\
\hline -...- n & (-............. & 8-...-1 & & & Pastor of Trinity & \\
\hline (n).............. & ב.......... & $8-\cdots$ & & & Associate Pastor at Trinity/Counselor & \\
\hline -.......... & $\overline{y-\cdots+\cdots+\cdots}$ & 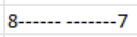 & Land Owner & & Wife of -..--.--t - Would like to be kept in loop & \\
\hline -..-- -..-. & - & 8--o---6 & Land Owner & & Adult Pastor at Grace Church - Owner of Land & \\
\hline
\end{tabular}

Figure 4 


\section{Urgent Farm Needs (as of 2/10/13)}

$\underline{\text { Item }}$

Qty

\section{Equipment}

- Bed shaper (tractor drawn)

1

- Wheelbarrows

2

Tools

- Hand Trowels (for transplanting) 6-10

- Stirrup Hoes/Hula Hoes (for weeding) 2-3

- Fork Spades 2-3

- Shovels (round edged, flat edged) 2 each

- Watering wand 1

- Watering nozzle 1

- Hoses (safe for drinking water - 50ft) 3

\section{Growing Supplies}

- Organic Fertilizer (OMRI listed - no synthetics please)

Farm Managers will advise

- Seeds

- Potting Soil

- Mushroom compost

- Floating fabric row cover (Agribon)

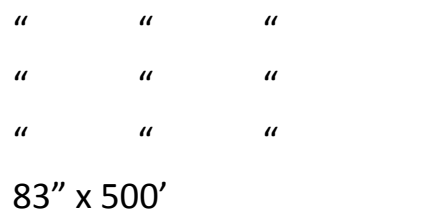

\section{Structures}

- Storage shed (for tools, supplies, etc) 1

- Work benches

2 (depending on size)

- Stainless steel deep sink (pair) 1

- Outhouse (Port-a-potty) 1

- Shade house (for shelter on hot days) 1

- Greenhouse/Nursery 1

- Greenhouse tables (for seedlings) 4 (depending on size) 
By the end of the meeting, ideas were explored, the leadership team roles were filled, jobs were assigned, decisions were made, and future meetings were planned. Below is a summary of the meeting written by one of our Volunteer Coordinators.

\section{Summary and Recollections of Last Night, Friday Feb.15, 2013}

(First Farm Leadership Meeting - Contributed by one of our Volunteer Coordinators who took notes. Edited to protect privacy of team members.)

"Forgive me if I got wires crossed-this is all impressions.

First off, a big thank you to the (unnamed)'s for opening the (unnamed) House to us farmers. (Unnamed), thank you, and please convey our appreciation to your parents for serving us on short notice such good food.

First Fruits Farm is off and running! Darin, it was very helpful for us all to see the farm sites. I now have a better grasp of what it will be like when we work there.

As for organization, the structure I saw coming out of the meeting was a bunch of rocks (persons) shaped in a pyramid with lots of links between them. We all answer to top rock, Darin.

The committees under him are:

a. Farm Management, with (unnamed) and (unnamed);

b. Volunteer coordination, led by me, helped by (unnamed) and (unnamed);

c. Finance, led by (unnamed) who also has lots of experience in P.R. She too will work with (unnamed), and with (unnamed) and (unnamed).

d. Then there is Special Projects, led by (unnamed), helped by (unnamed), (unnamed), and (unnamed).

e. Working in P.R. along with (unnamed) will be (unnamed) and hopefully "a guy in our church" who would be (unnamed)?

f. Donations coordinating will be run by (unnamed) and (unnamed).

g. (unnamed) will spearhead Events.

h. (unnamed) volunteered to help as Historian

i. Remind me who volunteered to be the Liaison?

Kyrie Eleison be praised for giving us purpose, and strength, and resources, and high morale.

I am sending this out as a chance for you to chip in. I have neglected to mention a couple of people: (unnamed) and (unnamed) and other kind folk.

I think the best way to communicate is by using Listserve; I am open to learning about Google doc, and am new to social networks. For the time being, reply to me about your available hours and skills and interests and please cc Darin. Feel free to "Reply All" if you like. 
Thank you again, Darin. First Fruits Farm (or is it Firstfruits Farm?) is a noble idea. Let me know what the Volunteer coordinator needs to tackle next. Keep up your good work."

- Unnamed (Volunteer Coordinator)

\section{Behind the Name: Firstfruits Farm}

One of the first accomplishments at the leadership meeting was deciding on a name for the farm: Firstfruits Farm. The idea came from a biblical reference: "The best of the firstfruits of your ground you shall bring to the house of the Lord your God." - Exodus 34:26. The team members agreed that the name complimented one of our goals for the farm: to provide our best offerings to our neighbors in need.

\section{Gathering Resources}

Within a few weeks of the leadership meeting, our Donations Coordinators had secured key resources for the farm, including: a large donation (40 cubic yards) of high quality compost from Central Coast Landscape Products; a \$1000 cash donation from Grace Church for building supplies; key supplies (tools, hoses, nozzles, potting soil, wheelbarrow, etc) from Home Depot and Miner's Ace Hardware; seedling donations from Greenheart Farms, Speedling Inc., and Ball Tagawa Growers; drip irrigation lines from Farm Supply and Andros Engineering, and a tractor that we could borrow as needed from a farm neighbor. Before approaching these businesses and organizations, we prepared a Tax Deduction Letter so any donations could be recorded as tax-deductible. A copy of the letter is included in Figure 5.

The efforts of the Donations Coordinators really paid off for the farm. But we needed several more items to get ready for the production season. We also wanted to include the congregation of Trinity Presbyterian Church in the process and create a sense of ownership for the farm. So we decided to do a fundraiser after church service one Sunday in April 2013, and I prepared sign-up sheets with descriptions of each item needed for congregants to peruse before making a decision on which item they'd like to contribute (included below). The idea was to give people a tangible idea of exactly how they were contributing to the farm project. At the end of the day, we had received donations for: 2 action (hula) hoes, a 100 foot hose, a picnic table, a dozen vegetable crates, a complete supply of drip irrigation valves, a year's supply of organic fertilizer, 4 shovels, and a year's supply of potting soil. These contributions filled many of the gaps left on our Farm Needs List.

There were only a few items left, and this list was presented to the Trinity deacons for their consideration for providing funding to the farm. The remaining needs were detailed with costs estimated and provided to the deacons. (See Figure 6.) 


\section{Tax Deduction Letter for Donors}

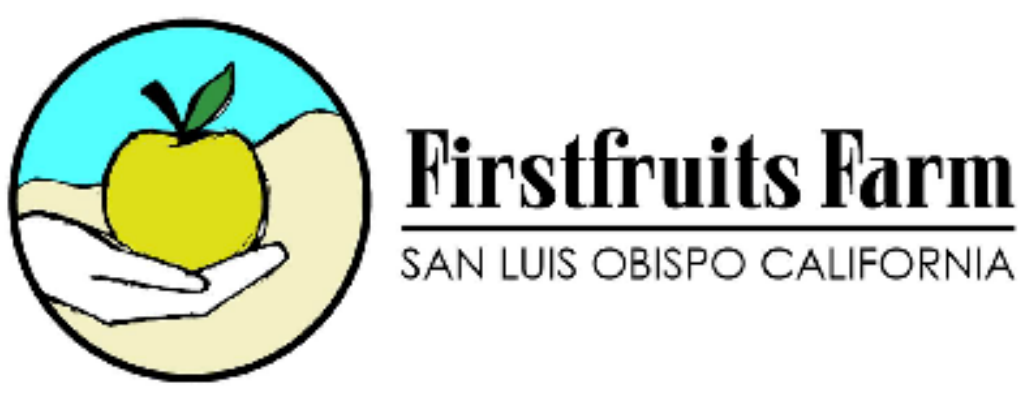

Firstfruits Farm is dedicated to growing the freshest, organically grown fruits and vegetables for the SLO Veteran's Services Center, the Food Bank, the Women's Shelter, and low income senior citizens in San Luis Obispo, California. The operation is accomplished entirely by dedicated volunteers made up of members from Trinity Presbyterian Church, Grace Church, community members, and the food recipients themselves. These volunteers gain farm work experience and agricultural education as they work together to keep the farm productive. The farm generates no income, and is completely non-profit, donor-driven, and volunteer-run.

There are many generous donors who provide food to the economically disadvantaged in the community. Often, however, the food that is donated is "seconds", leftover, expired, or wilted. Additionally, much of the donated food is packaged and processed. The need for fresh, wholesome, organically grown fruits and vegetables is readily apparent. We decided that our fellow veterans and neighbors who may be struggling to make ends meet should have our "firstfruits" the best our land can provide. So we set out to do something about it. We now grow, harvest and deliver hundreds of pounds of the highest quality, fresh produce every week to hundreds of families and individuals in our community. All of our produce is provided at no cost to the recipients.

We strive to keep our costs low, but we do have expenses. We must seek donations to cover these costs to keep the farm in operation. Your tax-deductible contribution will directly impact the lives of hundreds of families in this community.

Contact us at firstfruitsfarmslo@gmail.com or visit us on Facebook: https://www.facebook.com/firstfruits.farm

Firstfruits Farm, as a ministry of Trinity Presbyterian Church (a member of the Presbyterian Church in America), is recognized as a tax exempt organization from the Internal Revenue Service, according to IRS Revenue Procedure 80-27, $1980-1$ CB 677. Employer Identification Number 77-0461512. Federal Group Exemption Number: 8534 


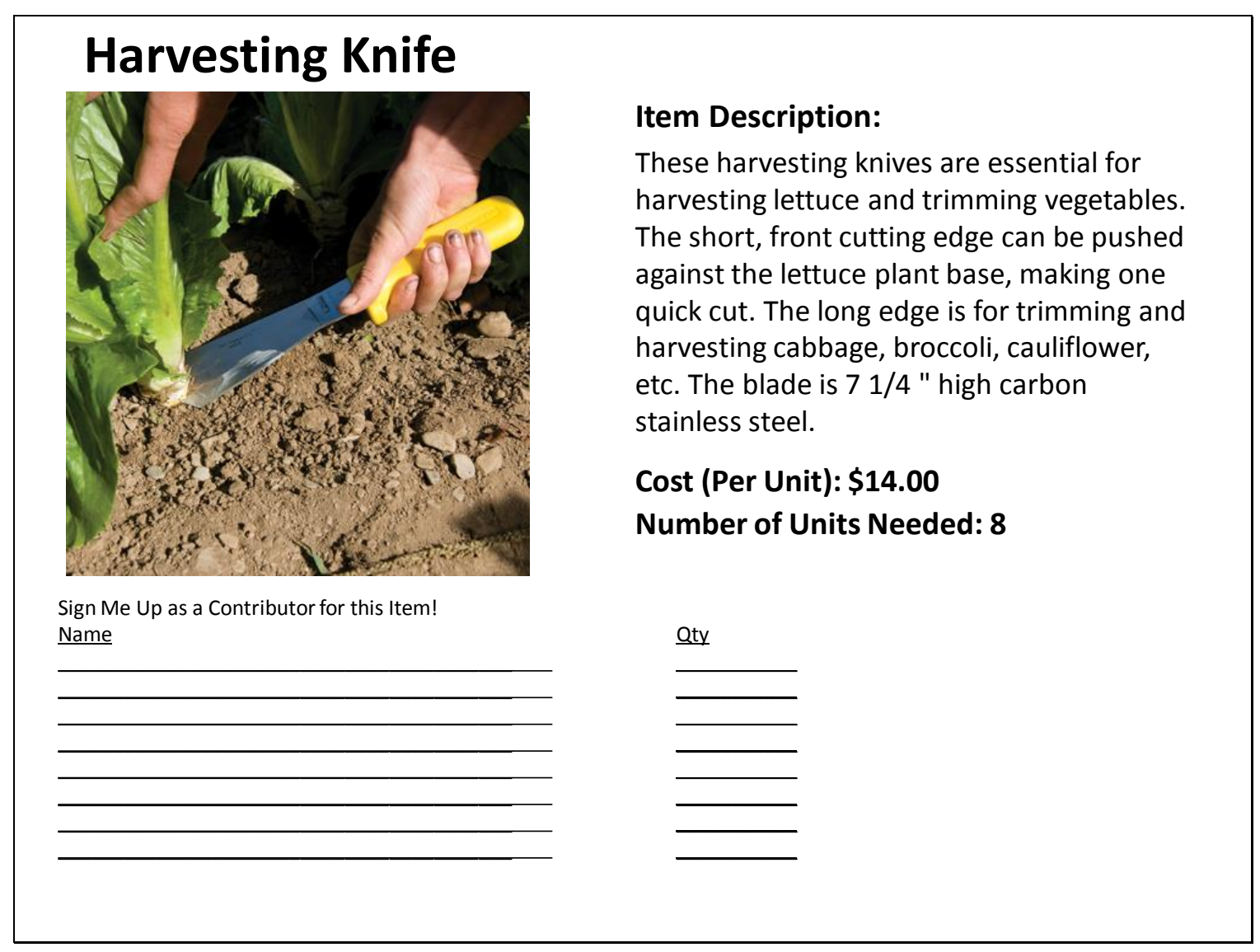




\section{Action Hoe (Hula Hoe)}

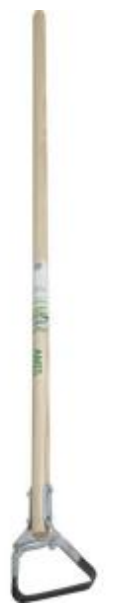

\section{Item Description:}

The Action Hoe is great for weeding and cultivating around live growing plants. It works by using a back and forth push-pull motion to cut weed roots deep under the surface. This tools cuts weeding in half the time.

Cost (Per Unit): \$16.00

Number of Units Needed: 4

Sign Me Up as a Contributor for this Item!

Name

$\underline{\text { Qty }}$

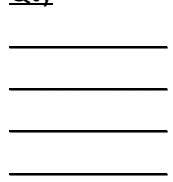




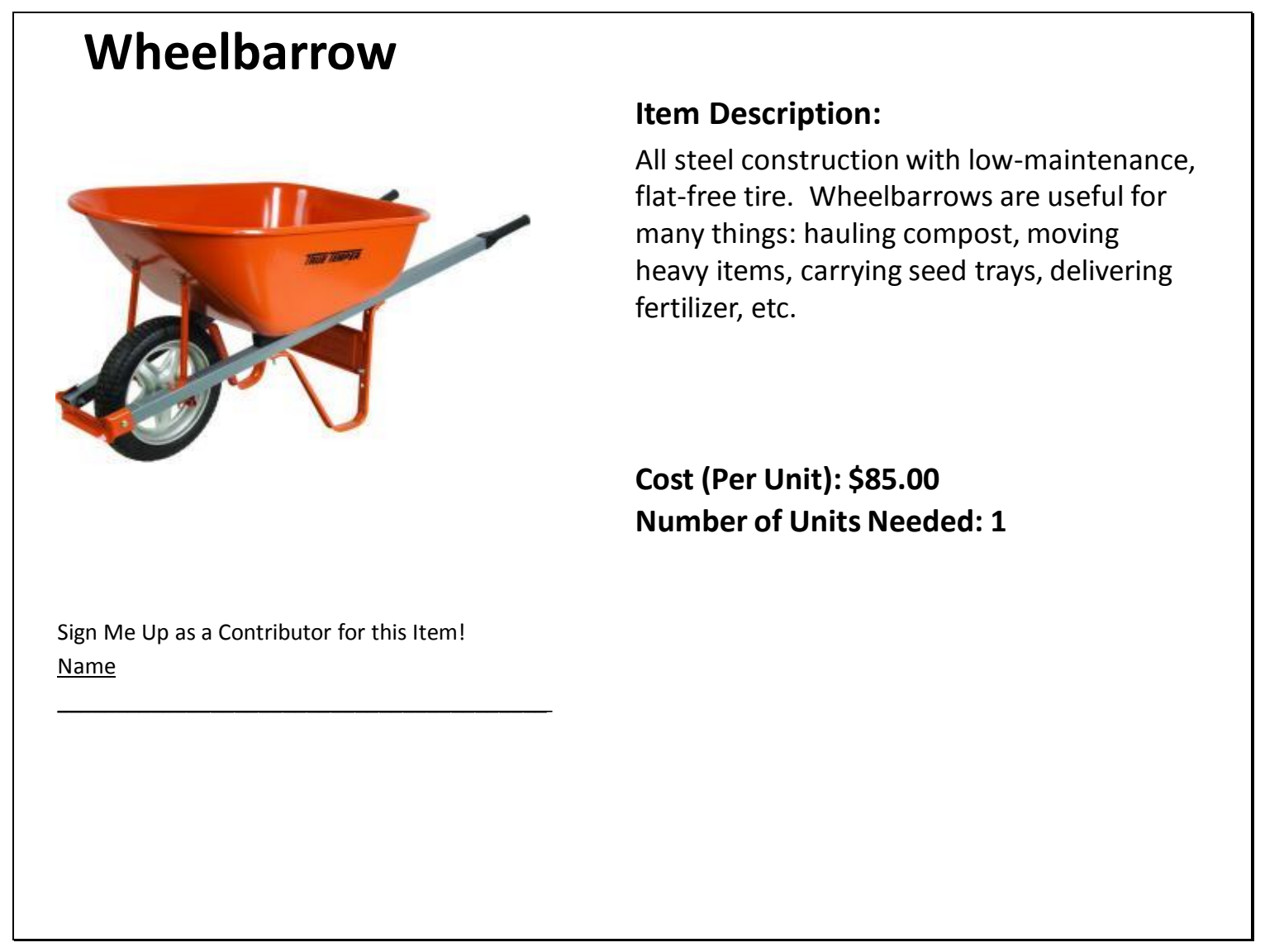




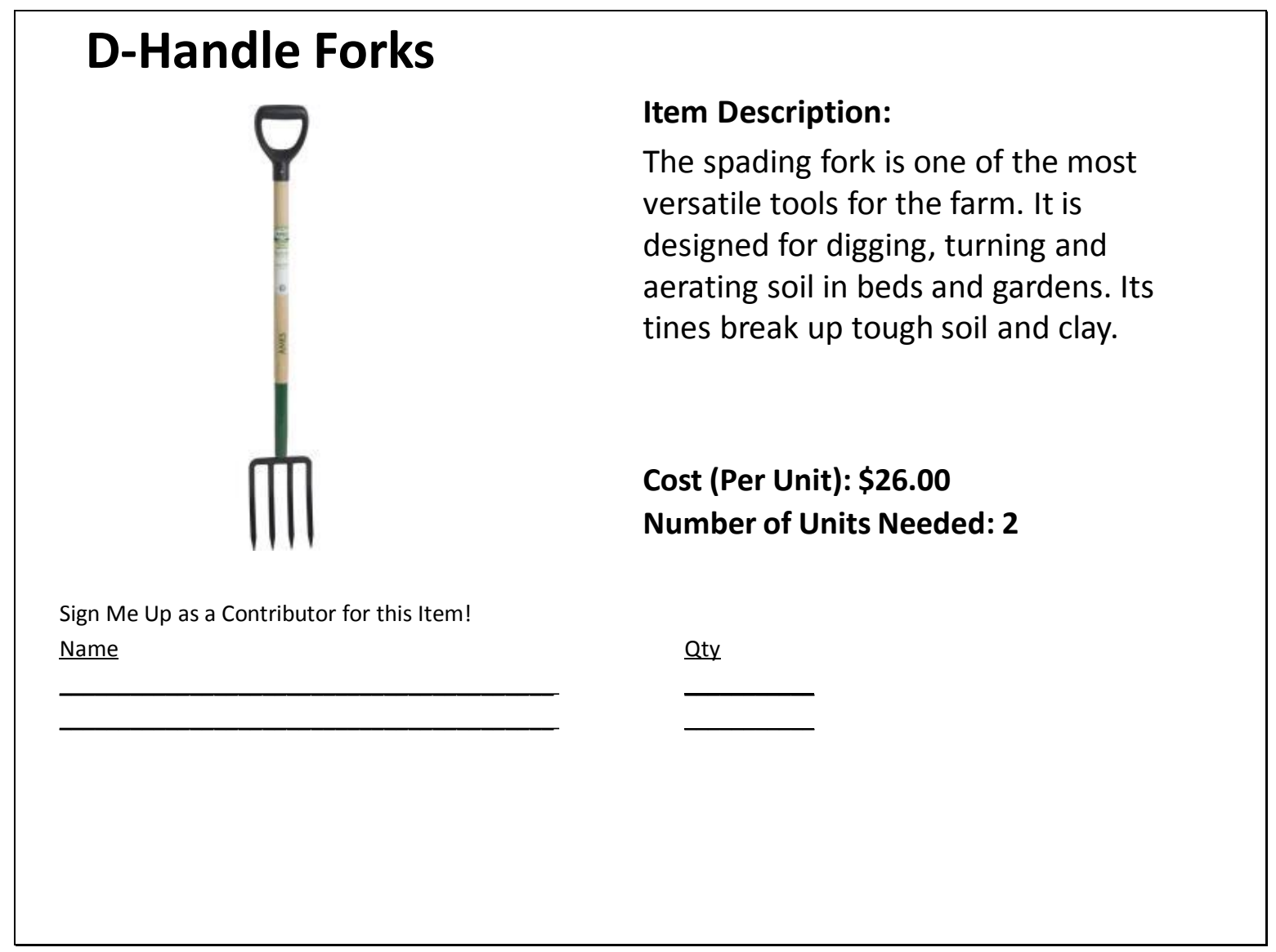




\section{Shovel}

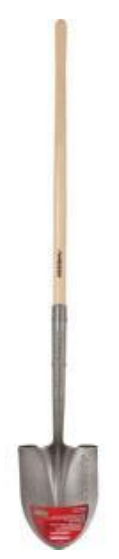

Sign Me Up as a Contributor for this Item! Name

\section{Item Description:}

A good digging shovel can be used for all sorts of farm work, including shoveling compost, cutting roots, or turning soil. This one is made of high quality tempered steel with an ash handle.

\section{Cost (Per Unit): $\$ \mathbf{2 6 . 0 0}$}

Number of Units Needed: 2
Qty 


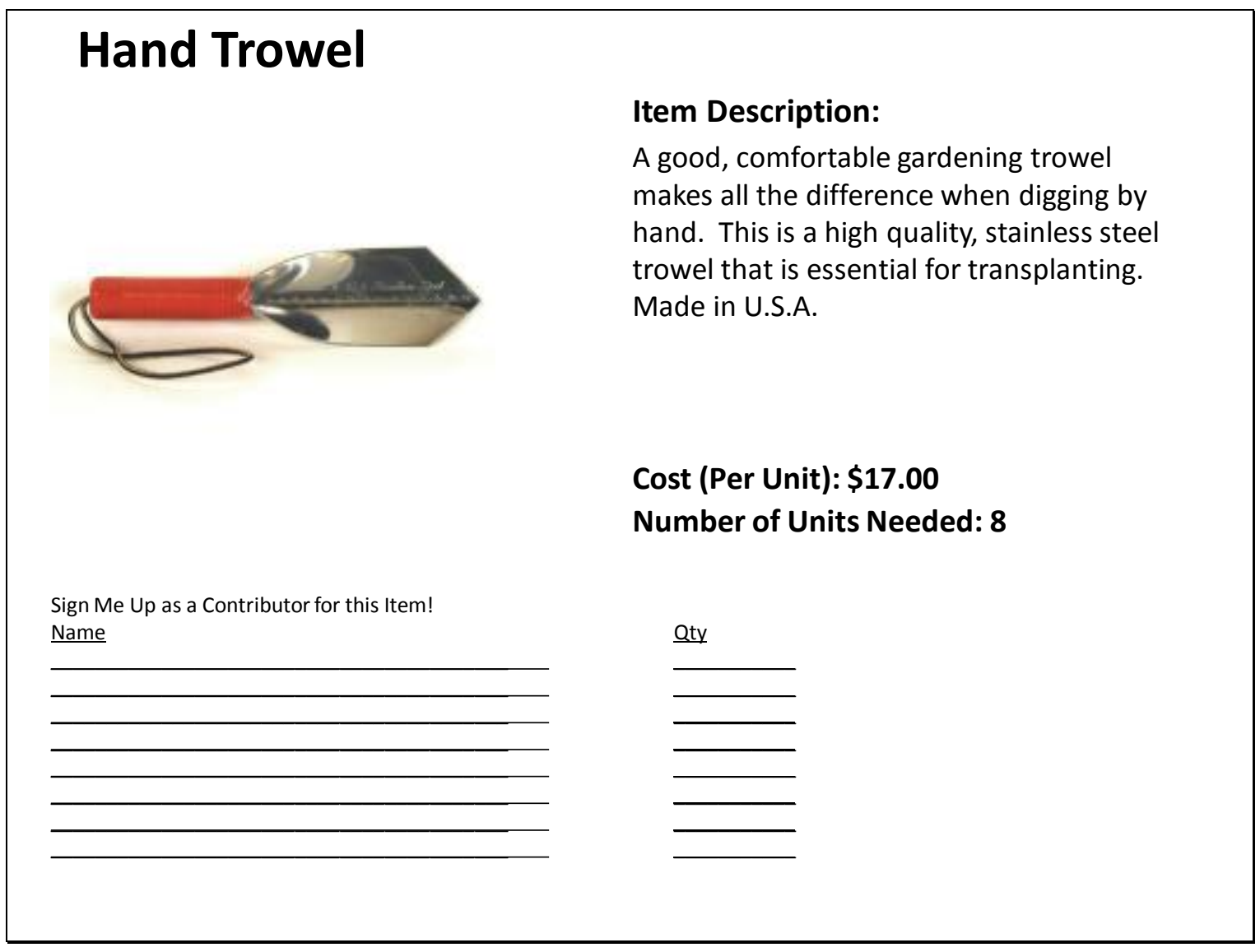




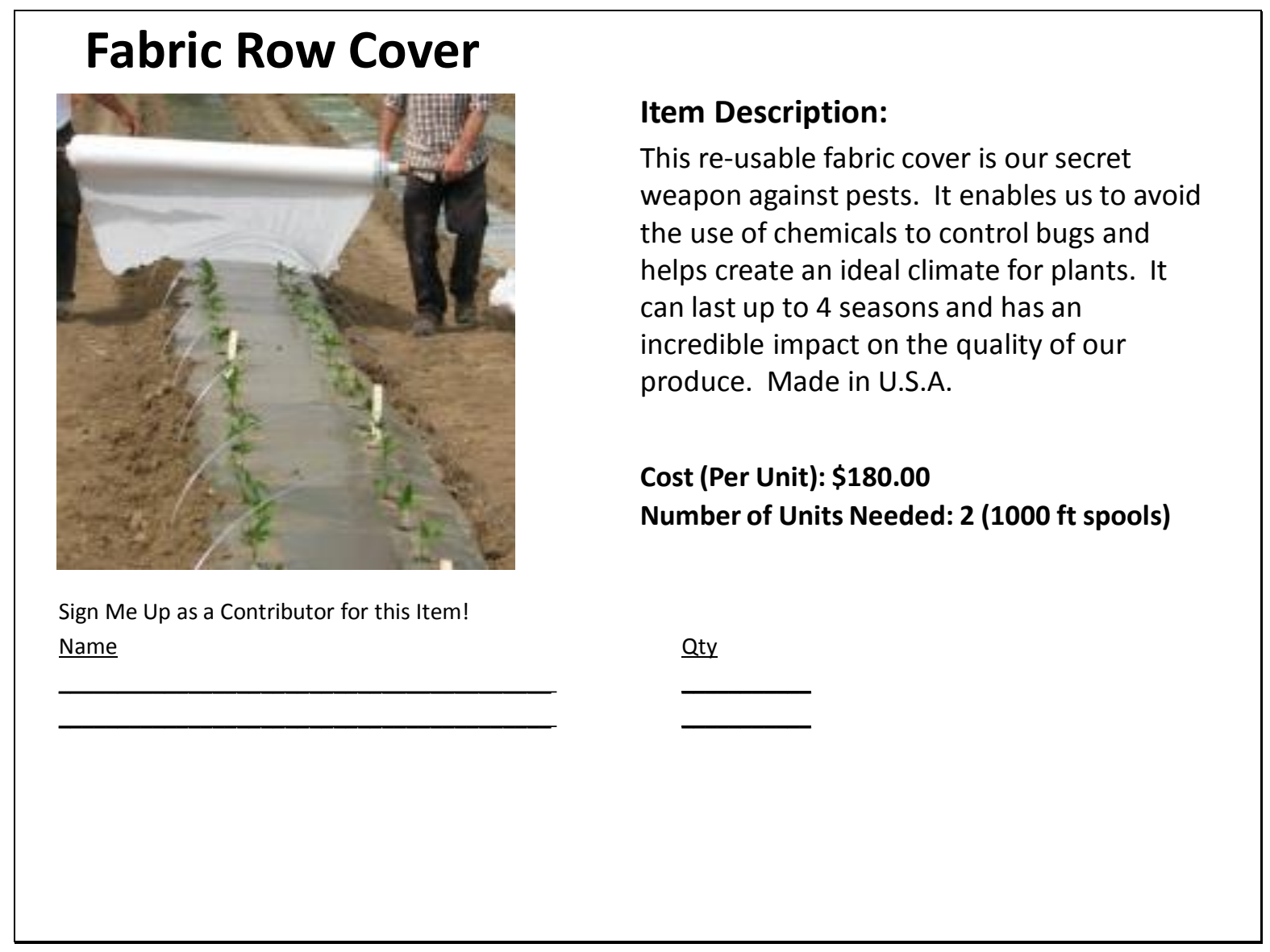




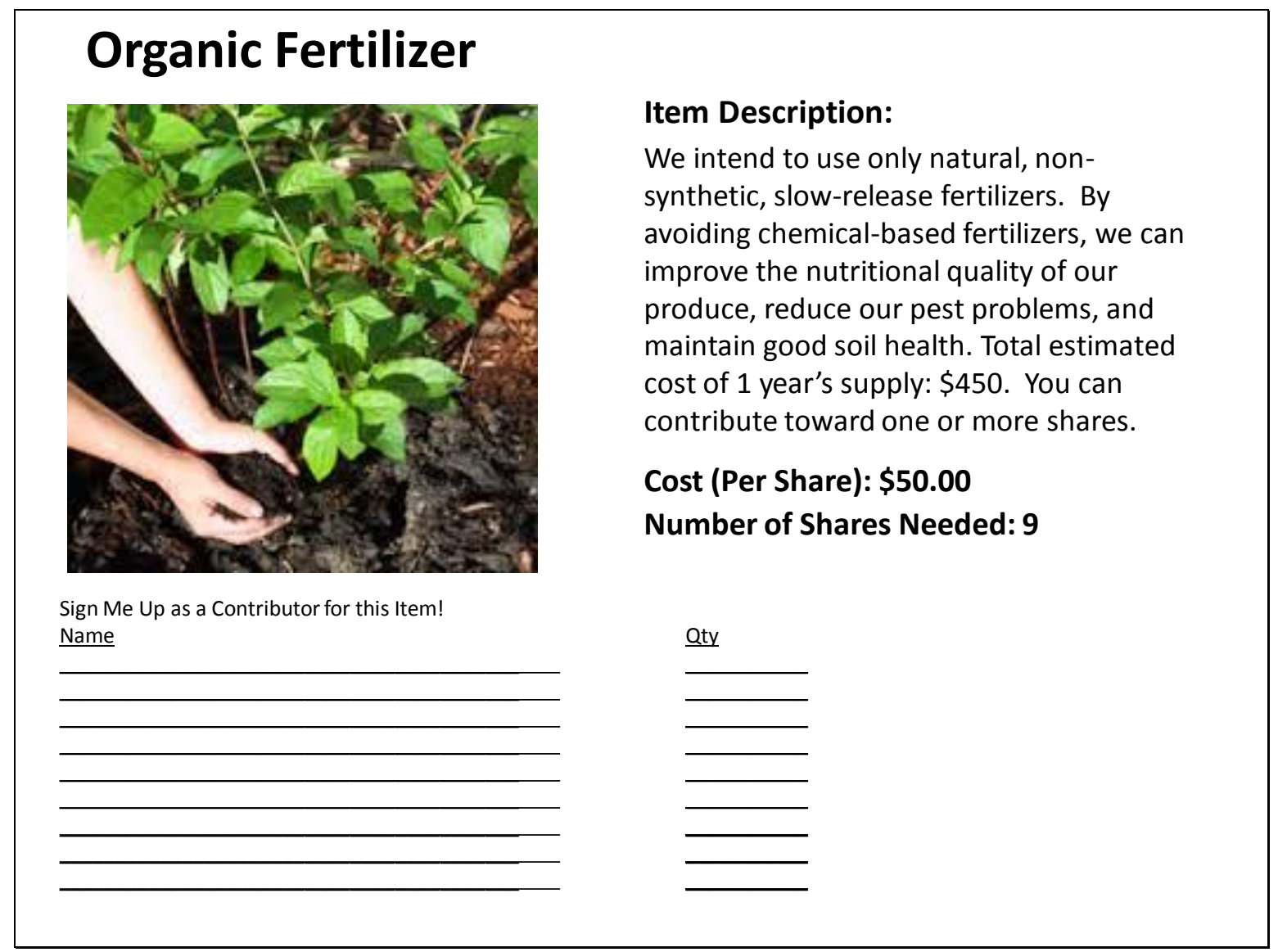




\section{Storage Shed}

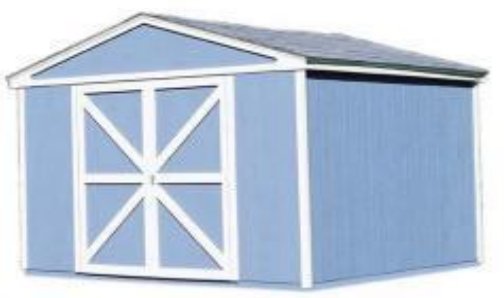

Name

Sign Me Up as a Contributor for this Item!

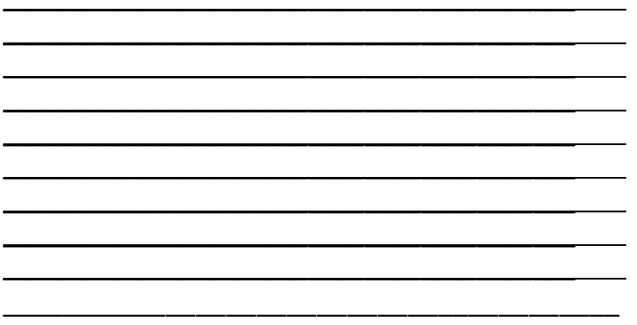

\section{Item Description:}

Keeping our tools and supplies secure and out of the weather is essential for longevity. This shed will be all wood, durable and will last for many years. It will be approximately 100 sq. ft. Total cost will be about $\$ 1000$. You can contribute toward one or more shares.

Cost (Per Share): $\$ \mathbf{5 0 . 0 0}$

Number of Shares Needed: 10

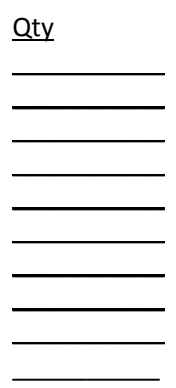




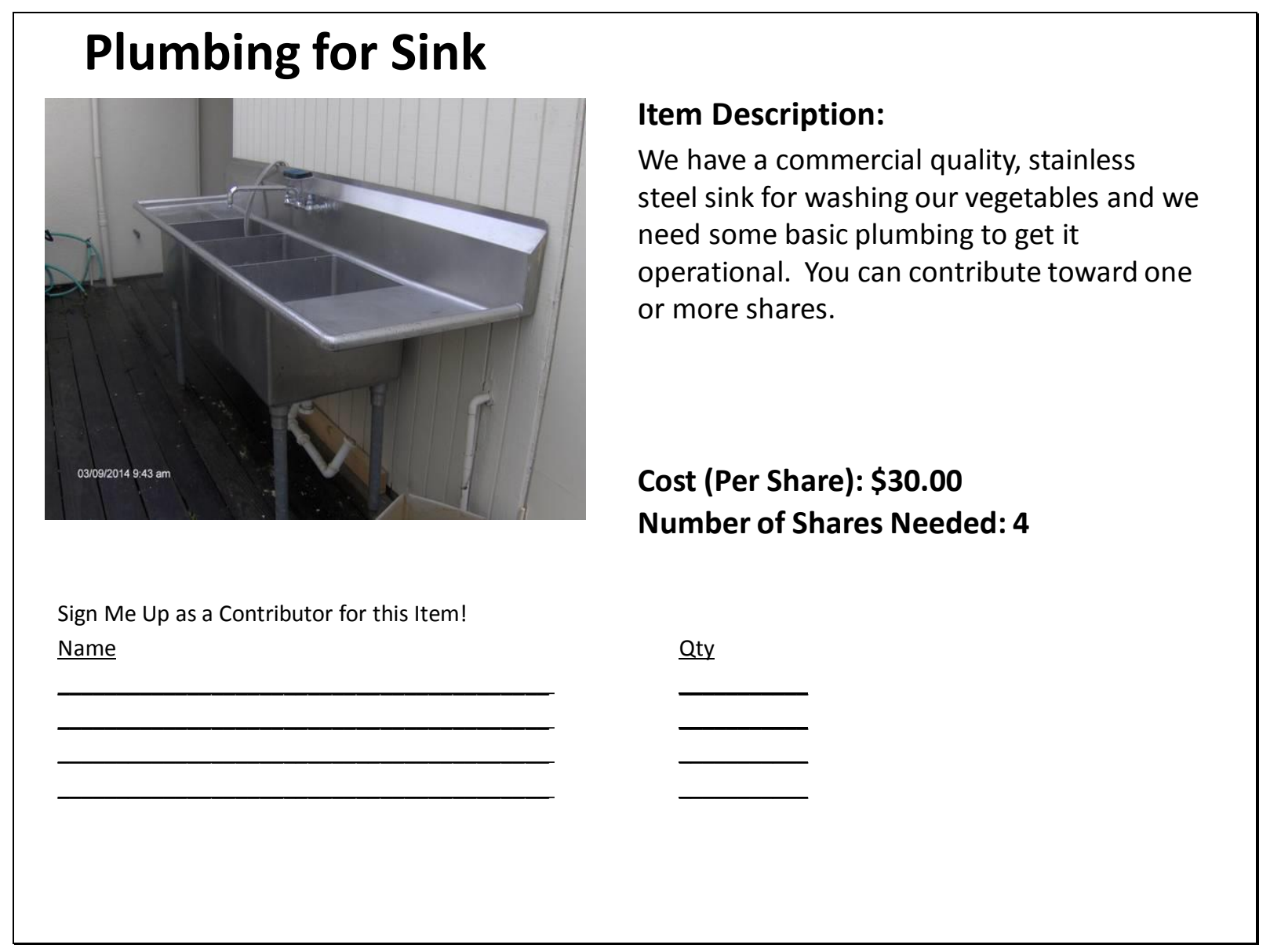




\section{Vegetable Crate}

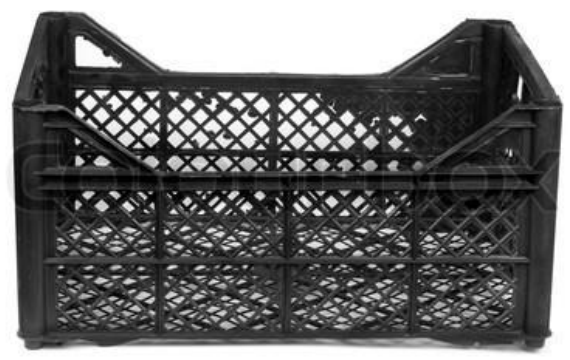

\section{Item Description:}

Our freshly harvested produce will be delivered to God's Storehouse in these crates. We already have 10 , but we need at least 10 more.

\section{Cost (Per Unit): $\$ \mathbf{5 . 0 0}$}

Number of Units Needed: 10

Sign Me Up as a Contributor for this Item!

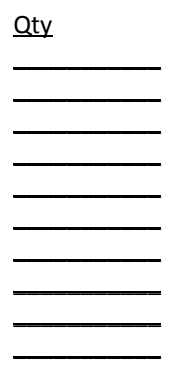




\section{Drip Irrigation Valves}

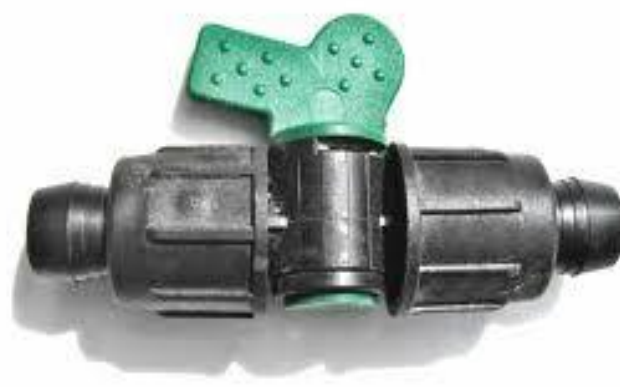

\section{Item Description:}

Conserving water by using drip irrigation is one of our key goals. We need control valves and connectors to the main water manifold to make it work. $\$ 20$ will buy 5 valves/connectors (1 unit).

\section{Cost (Per Unit): $\$ \mathbf{2 0 . 0 0}$}

Number of Units Needed: 10

Sign Me Up as a Contributor for this Item! Name

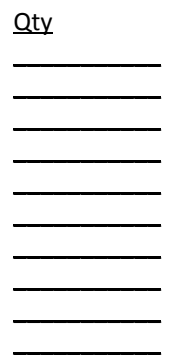




\section{Picnic Table}

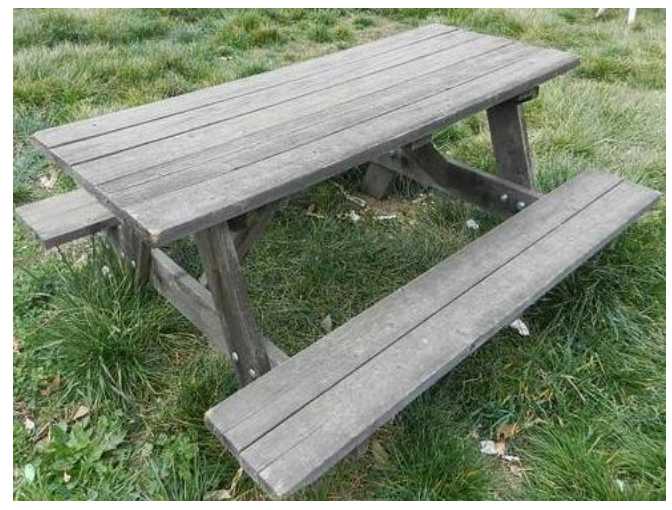

Sign Me Up as a Contributor for this Item! Name

\section{Item Description:}

After working hard in the field, our volunteers will need to take a break. These picnic tables will be placed under the shadehouse to provide a break area for our hard workers.

Cost (Per Unit): $\$ \mathbf{1 0 0 . 0 0}$

Number of Units Needed: 2

Qty 


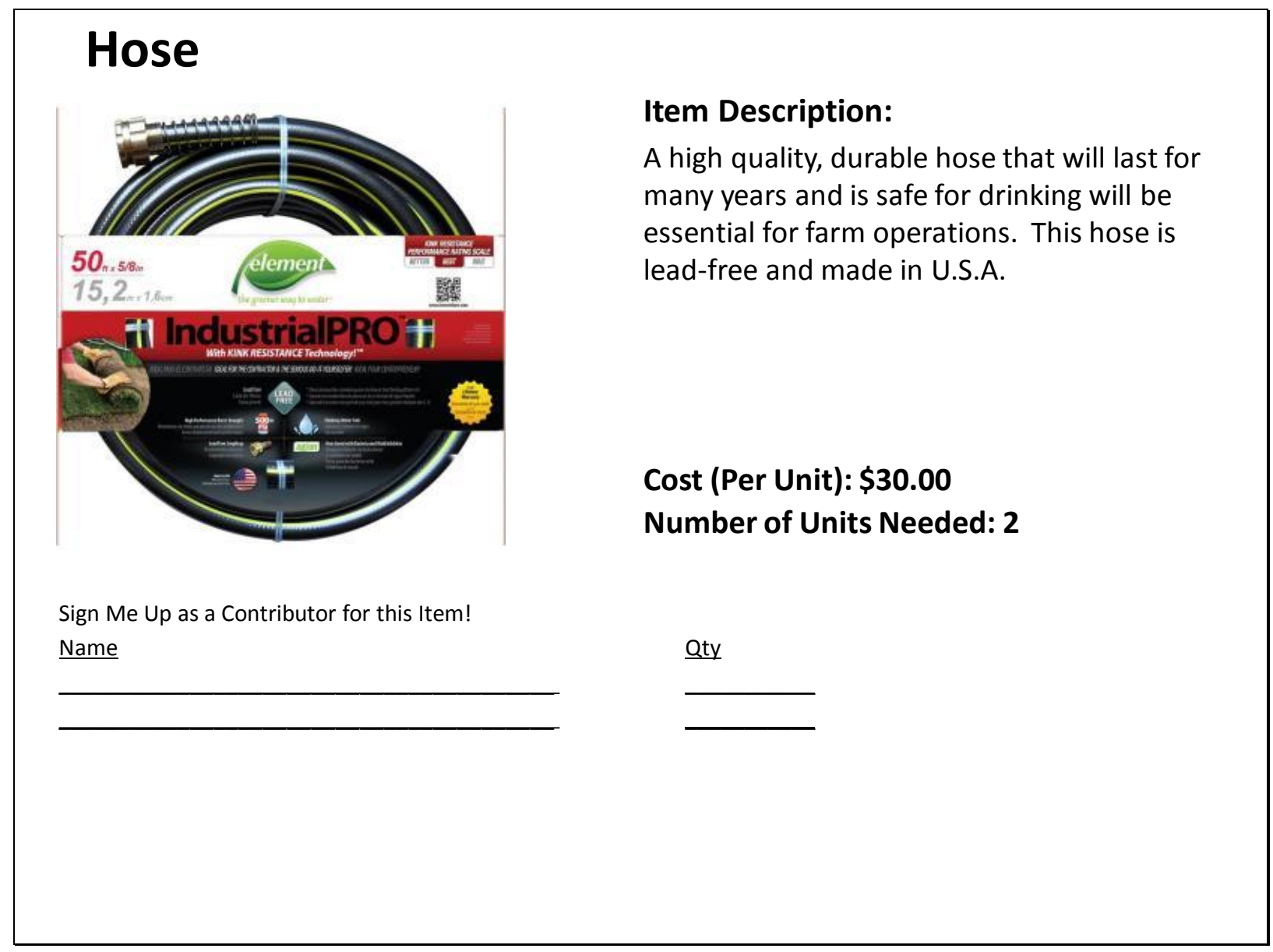




\section{Farm Needs List Provided to Trinity Deacons}

\begin{tabular}{|c|c|c|c|c|c|c|c|}
\hline \multicolumn{7}{|c|}{ (Updated as of 4/24/2013) Urgent Farm Needs - Startup 2013} & \\
\hline Item & Qty & & t. Cost. & & ill Need & Notes & \\
\hline Stainless Steel Sink & 1 & $\$$ & 450.00 & $\$$ & - & donated & \\
\hline Misc Plumbing to Connect Sink & - & $\$$ & 100.00 & $\$$ & 100.00 & & \\
\hline Misc Irrigation Parts for Greenhouse & - & $\$$ & 100.00 & $\$$ & 50.00 & Mostly finished & \\
\hline Materials for 2 Work Benches & - & $\$$ & 150.00 & $\$$ & - & donated already & \\
\hline Materials for Shade House & - & $\$$ & 250.00 & $\$$ & - & Finished & \\
\hline Materials for Storage Shed & - & $\$$ & $1,000.00$ & $\$$ & $1,000.00$ & maybe less \$, depending on donated materials & \\
\hline Harvesting Knives & 5 & $\$$ & 35.00 & $\$$ & 35.00 & total for 5 & \\
\hline Action Hoes & 3 & $\$$ & 50.00 & $\$$ & 50.00 & total for 3 & \\
\hline Wheelbarrow & 1 & $\$$ & 80.00 & $\$$ & 80.00 & & \\
\hline D-Handle Forks & 2 & $\$$ & 50.00 & $\$$ & 50.00 & total for 2 & \\
\hline Garden Trowels & 8 & $\$$ & 75.00 & $\$$ & 75.00 & total for 8 & \\
\hline Vegetable Crates & 12 & $\$$ & 40.00 & $\$$ & 40.00 & already have 12 , need 12 more & \\
\hline Drip Irrigation Valves/Parts & - & $\$$ & 200.00 & $\$$ & - & donated already & \\
\hline Port-a-Potty & 1 & $\$$ & 600.00 & $\$$ & 600.00 & total per year (\$50/mo.) - Harvey's Honeyhuts has offered to dd & it at cost \\
\hline Fabric Row Cover & 1 & $\$$ & 150.00 & $\$$ & 150.00 & 1 spool for the year & \\
\hline Potting Soil (bags) & 8 & $\$$ & 100.00 & $\$$ & - & donated already & \\
\hline Fertilizer (approx. year supply) & 40 & $\$$ & 450.00 & $\$$ & - & donated already & \\
\hline Tractor Fuel & & $\$$ & 100.00 & $\$$ & - & donated already & \\
\hline Total & & $\$$ & $3,980.00$ & $\$$ & $2,230.00$ & & \\
\hline
\end{tabular}

Figure 6 


\section{Projects}

Within a few weeks of the fundraiser, we had a Special Projects Team building a greenhouse, seedling benches for the greenhouse, workbenches for processing crops, and a shadehouse for hardening off seedlings and providing shaded shelter to volunteers. Additional projects included installing a stainless steel sink (donated by one of our team members) for washing freshly harvested crops, installing an automatic sprinkler system in the greenhouse, creating a break area with picnic tables in the shadehouse, creating a children's play area with a sandbox, and establishing a native bee garden to attract pollinators.

\section{Newly Constructed Greenhouse}

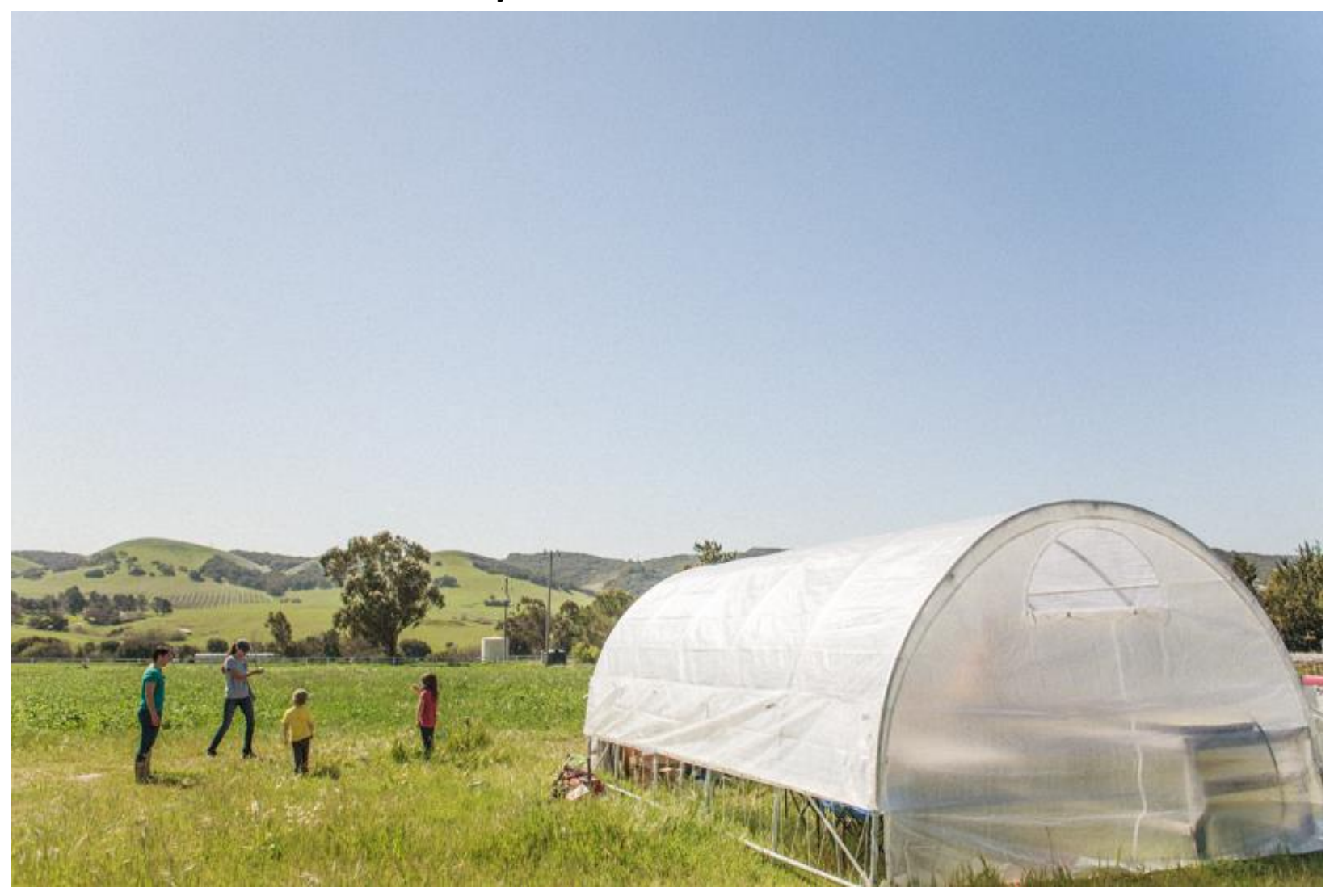




\section{Newly Constructed Shade House \& Break Area}

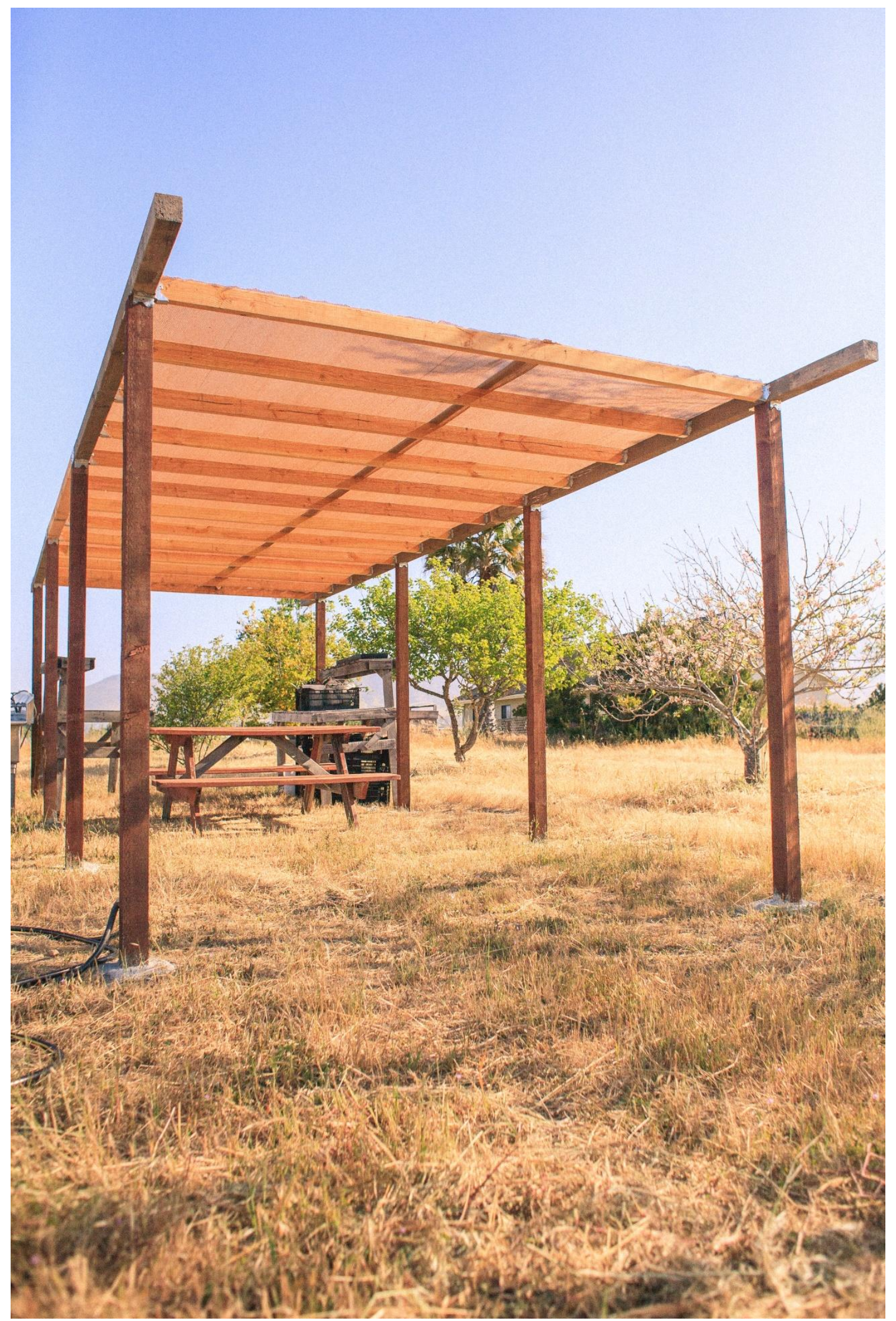




\section{Shade House and Break Area}

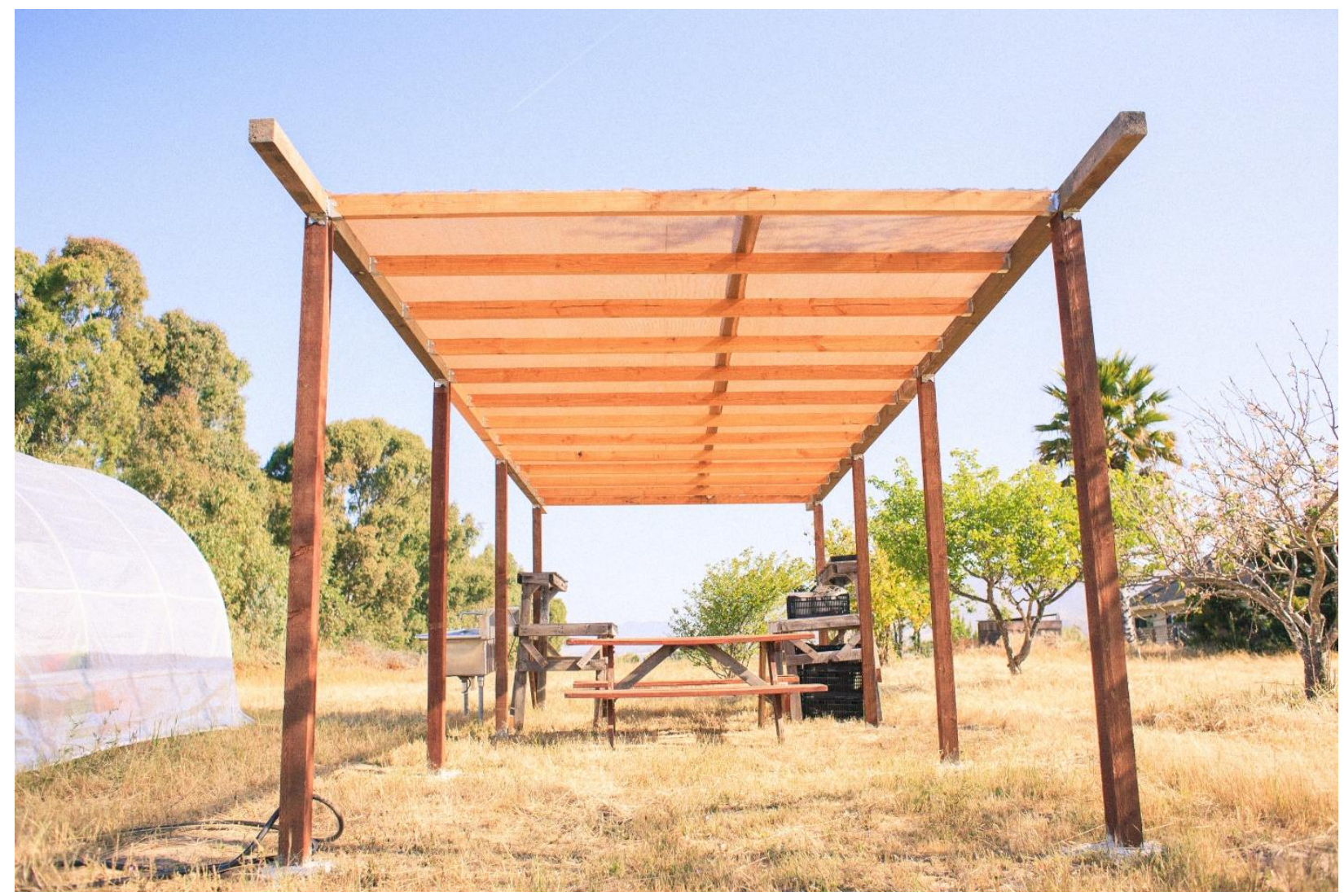

\section{Crop Planning}

Simultaneously, the farm management team, which included me and 3 other members, began planning our crops for the first year of production. In choosing our crops, we followed several agreed upon guidelines:

1. The crop should be in demand by the recipients

2. Particular attention should be given to produce items that are considerably expensive in the grocery stores (to provide the maximum benefit to the recipients)

3. The crop should be well-suited to our climate and soils

4. If possible, the crop should not require an inordinate amount of resources or effort to grow and harvest

For the first year of production, we sought to keep the number and variety of crops to a manageable level. We weren't exactly sure about the sustained level of volunteer help, nor the demand for the produce. We also sought to reduce or eliminate high-maintenance crops that would require extra care. A partial list of the crop selection is shown in Figure 7 . In addition to the items listed, we added several varieties of melons, cucumbers, basil, and hot peppers. 
A significant portion of the seeds used to start our seedlings were donated by the San Luis Obispo Seed Saver's Exchange. Additionally, as mentioned before, large donations of seedlings by Greenheart Farms, Speedling Inc., and Ball Tagawa Growers were a great benefit to our first year of production. All together, these donations significantly reduced our seed costs for the first year.

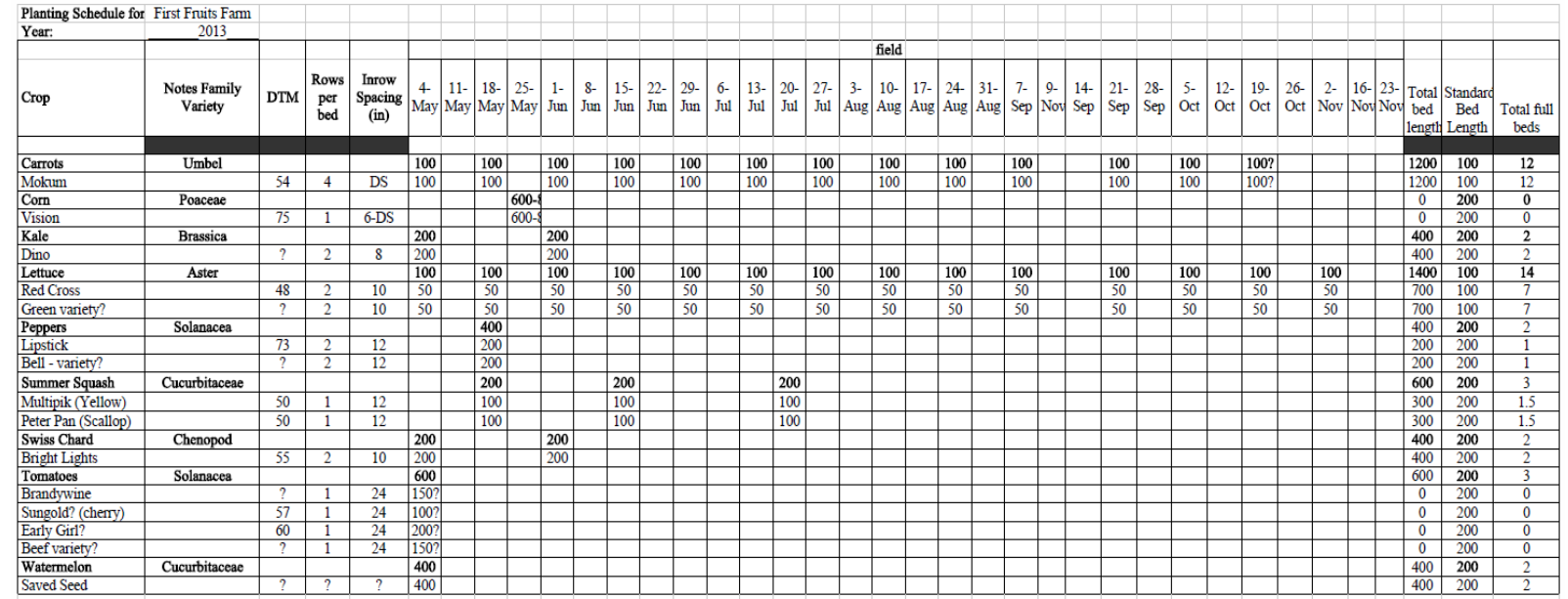

Figure 7

\section{First Farm Workdays}

Spring weather in San Luis Obispo, California can begin as early as January, and by early March our cover crop was reaching maturity. It was nearly time to cut down the cover crop, till it into the soil and start crop production. There was only one problem; we hadn't yet started any seedlings in our greenhouse, so there was nothing ready to plant in the field. Up to this point, so much of our time had been spent on planning, projects, and resource gathering that there had not yet been an opportunity to have a farm work day to start seeds. Having commitments for donated seedlings from several local growers proved to be a huge asset at this point in our development. After collecting on these promises and stocking our greenhouse with thousands of donated mature seedlings (including kale, tomatoes, lettuce, basil), we followed up with our first farm work day in mid-March. This first workday was intended to complete our seedling stock to match our crop plan. There was a lot of enthusiasm on this first work day and we were able to get nearly all of our remaining crops seeded. The following photos were taken on that first seeding day. 
Adults and Children Seeding Trays at First Work Day

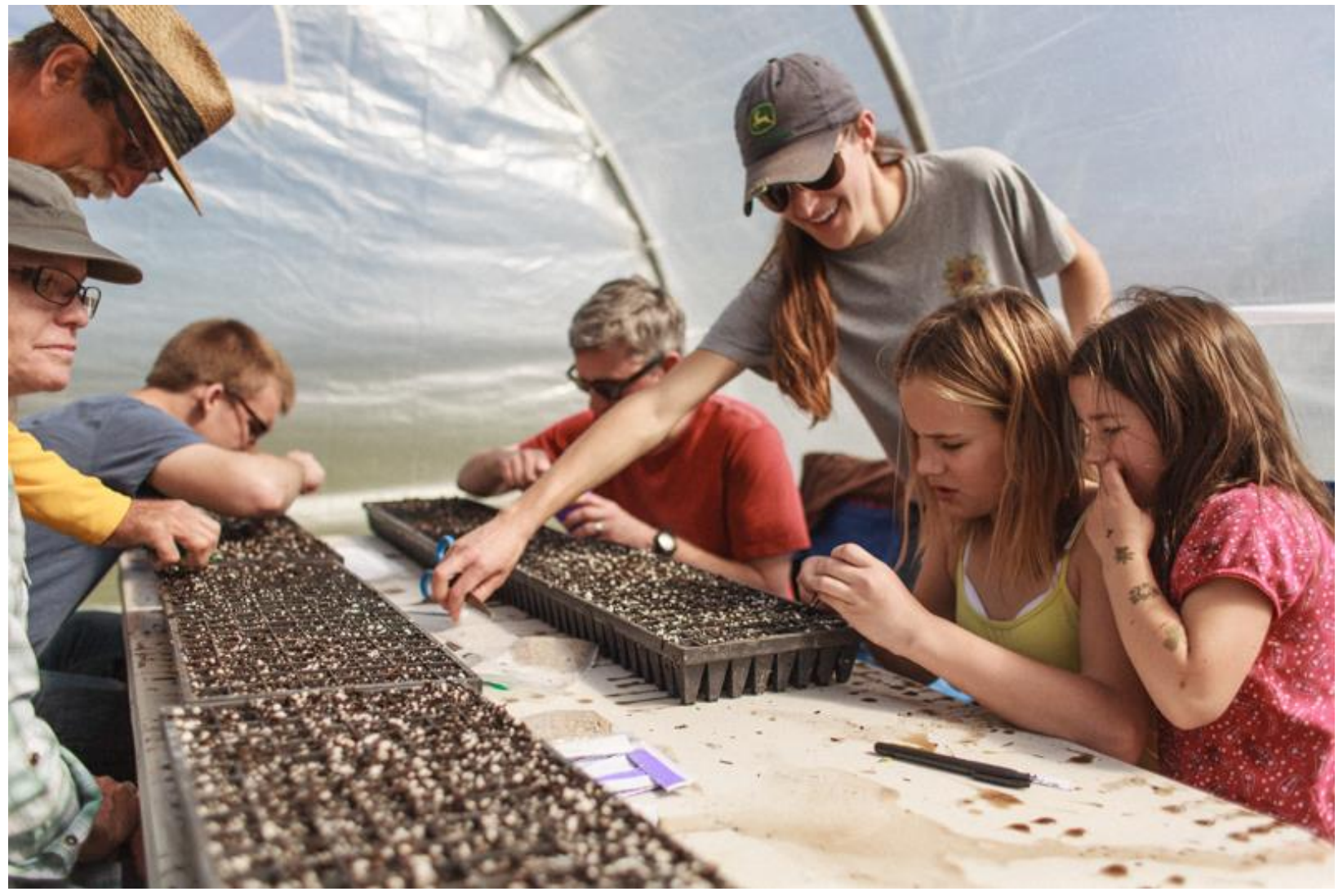




\section{Sowing in Seed Trays}
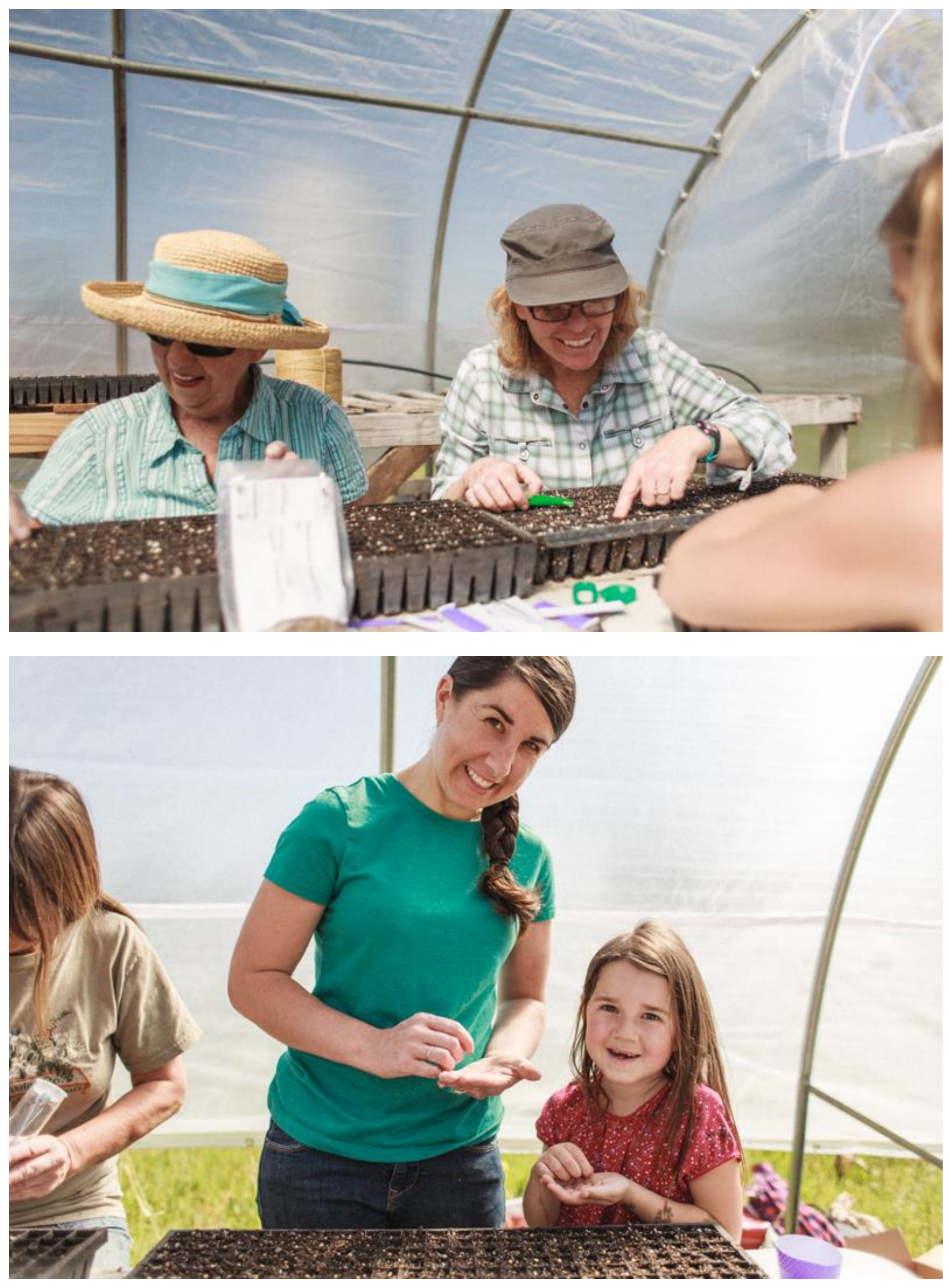

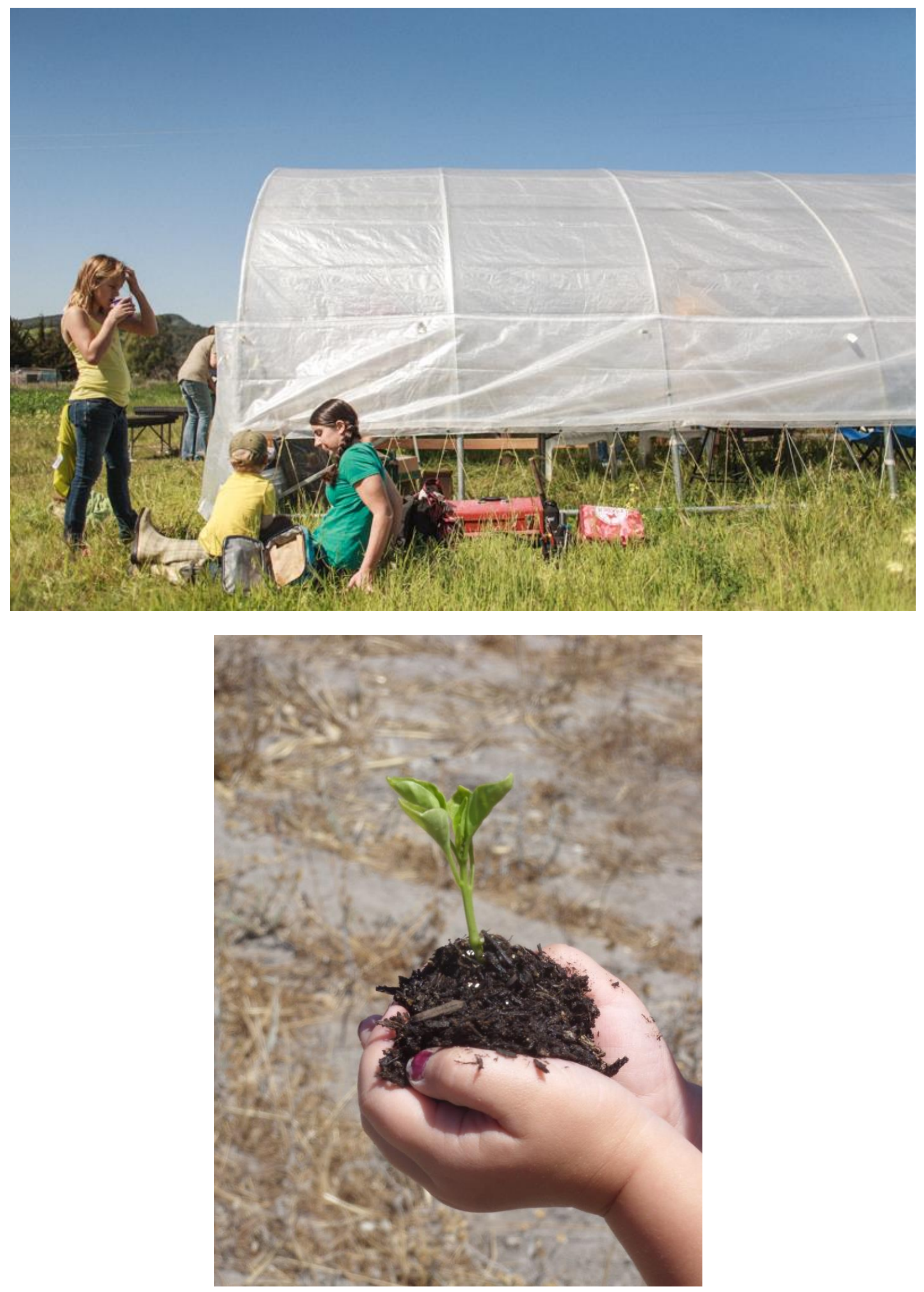


\section{Newly Sprouted Seedlings}
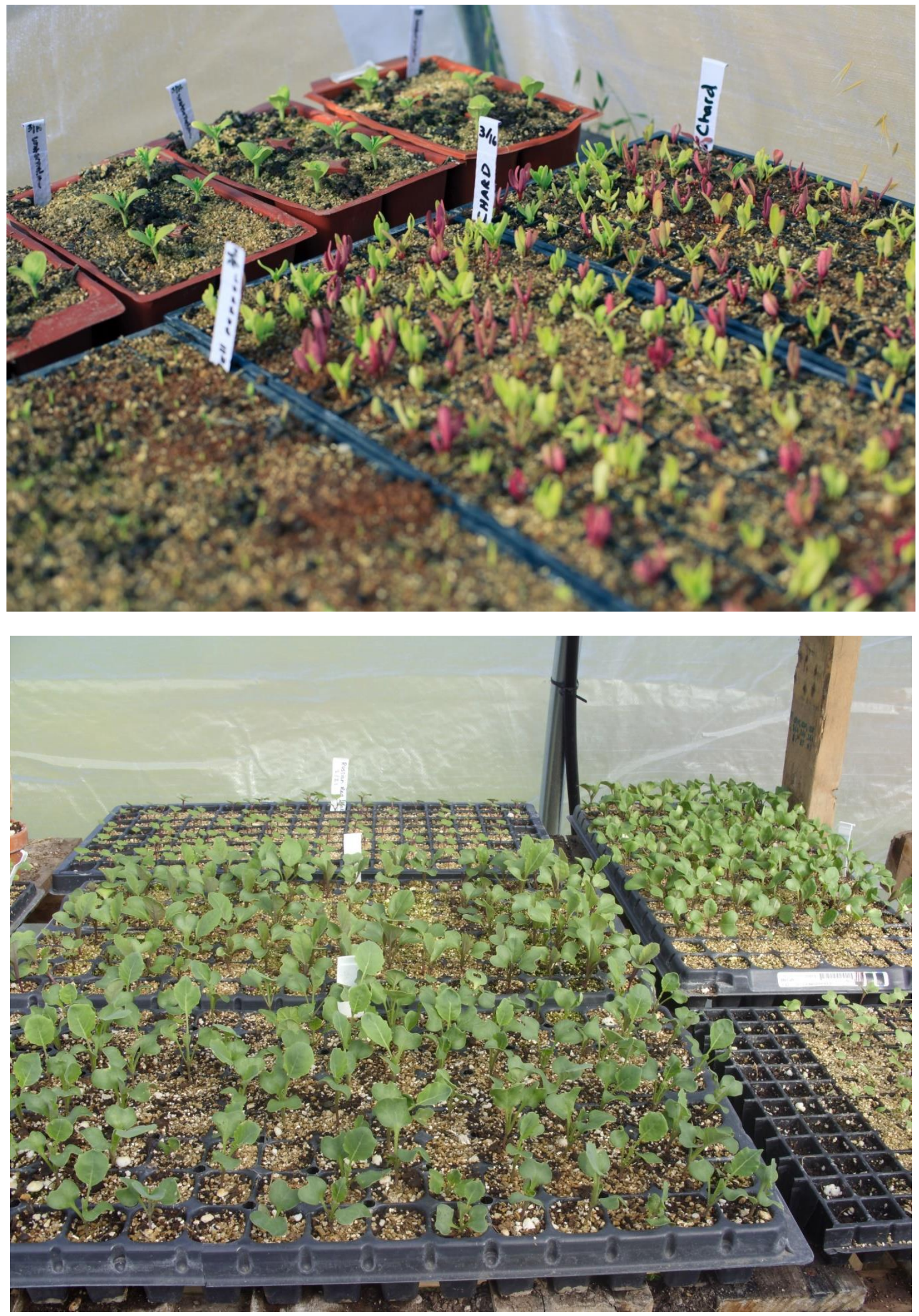
Within a couple of weeks of the first farm work day, I was able to get the cover crop mowed and disked into the ground. I followed this up with rototilling and forming beds for the new seedlings. We were then ready to follow up the seed planting day with a transplanting day. The thousands of donated seedlings needed to get in the ground soon, and this transplanting day was urgently needed. This first day involved spreading compost over the newly formed beds, rolling out drip tape, and transplanting the seedlings in line with the irrigation. Floating fabric row covers were placed over all leafy green transplants to protect them from insects and wildlife (especially deer and rabbits). Once again, this work day was fruitful, rewarding, and enjoyed by all.

\section{Rototilling Field}

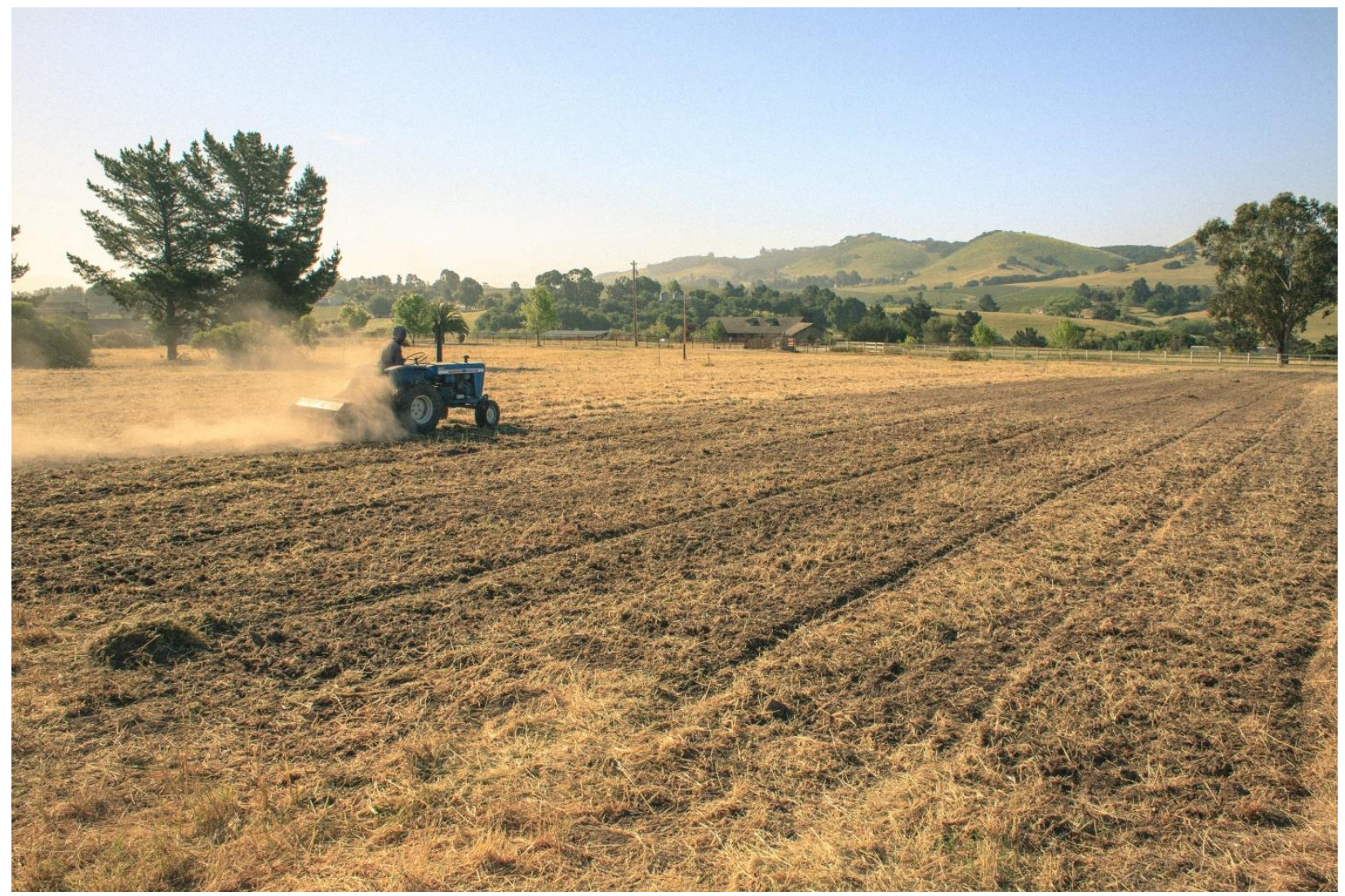




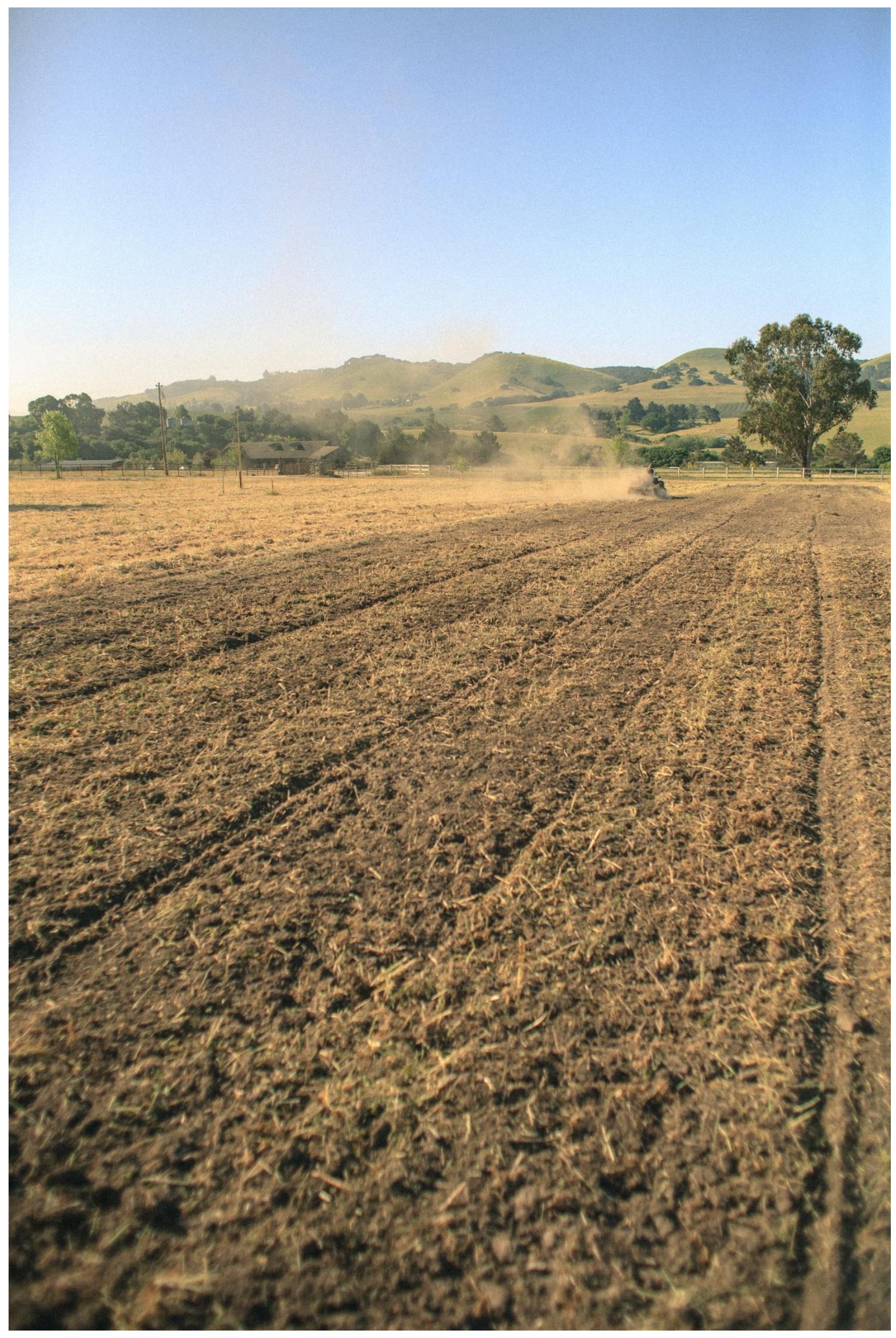



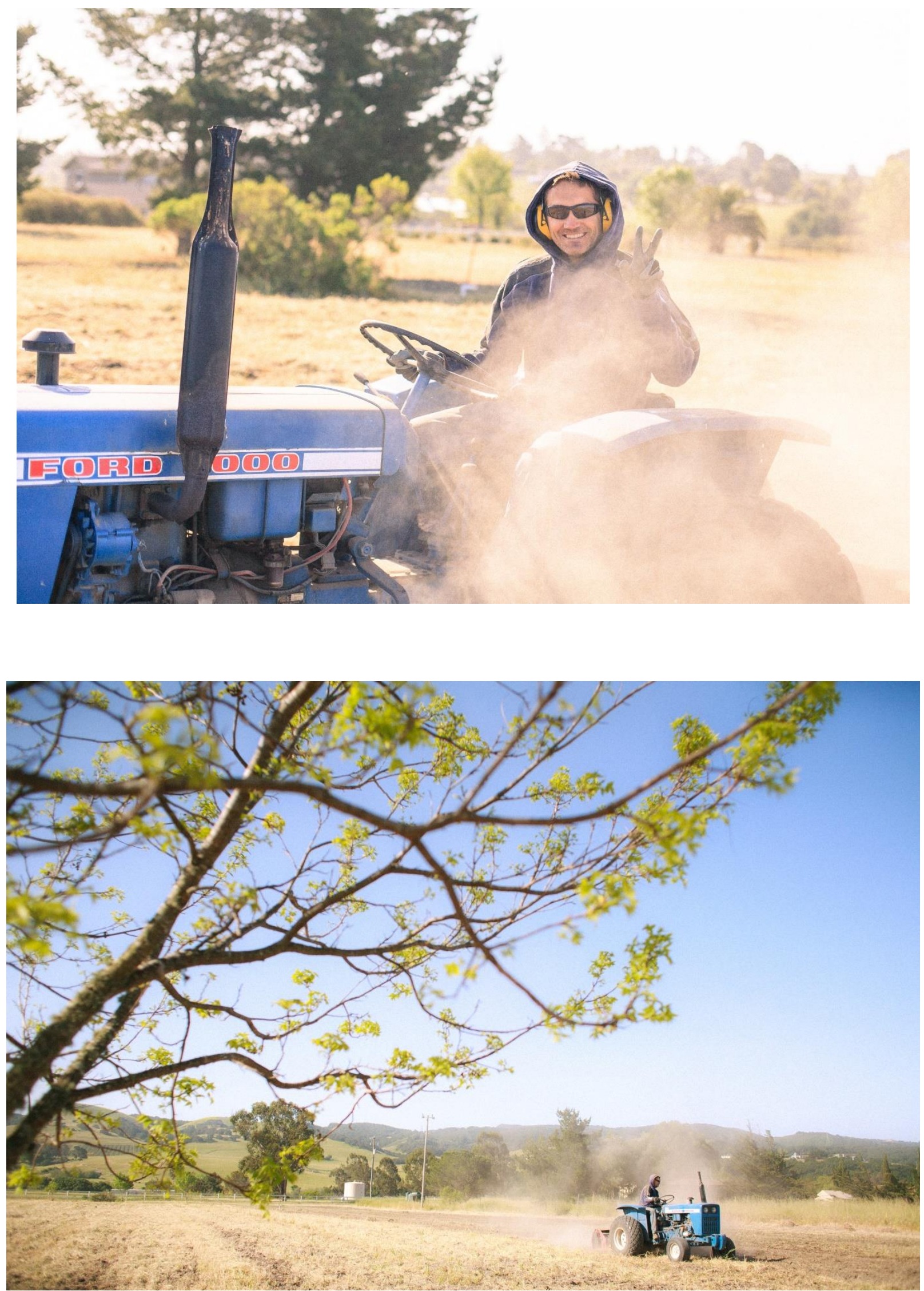


\section{Forty Cubic Yards of Donated Compost}
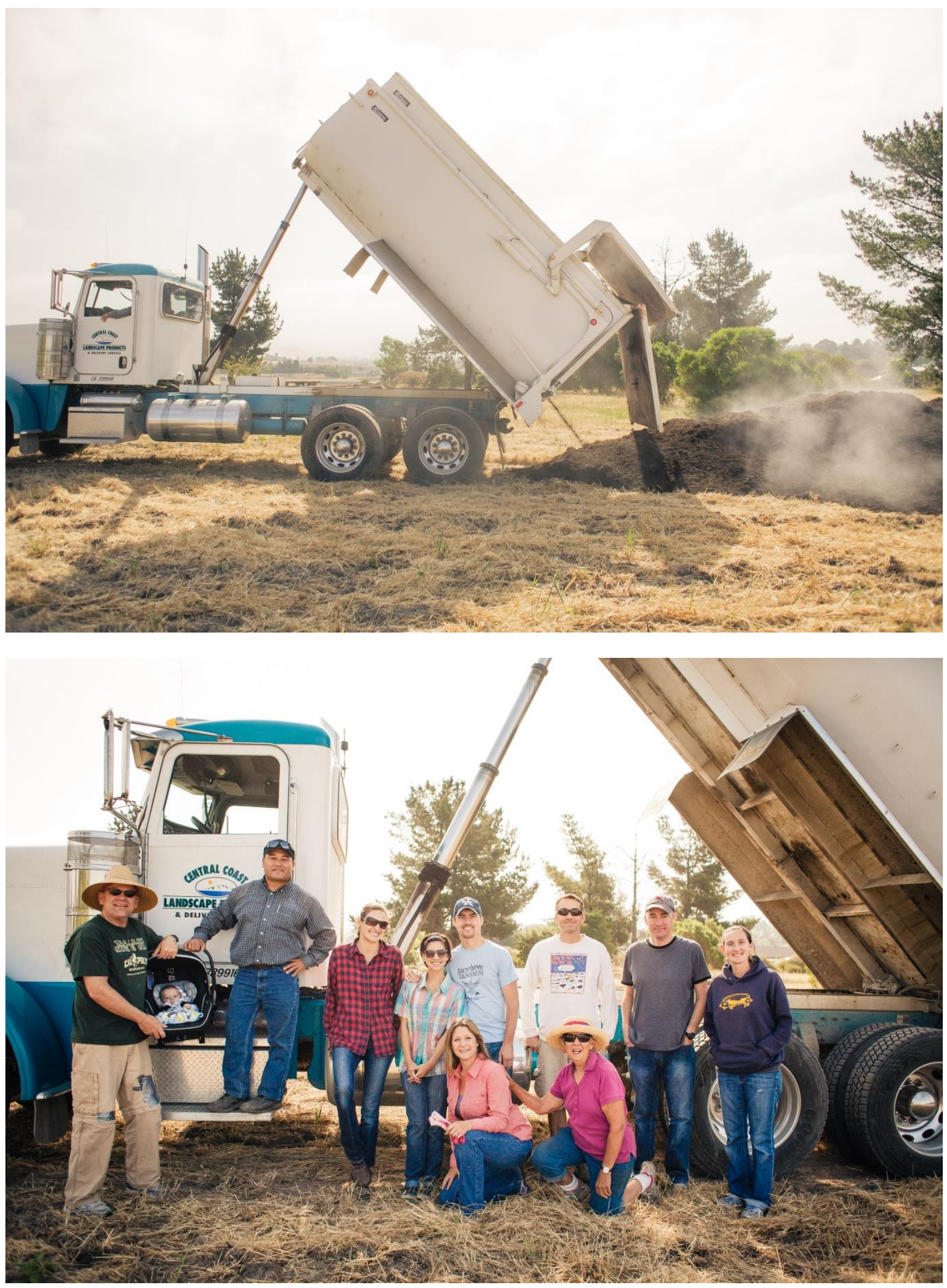


\section{Spreading Compost in Newly Formed Beds}
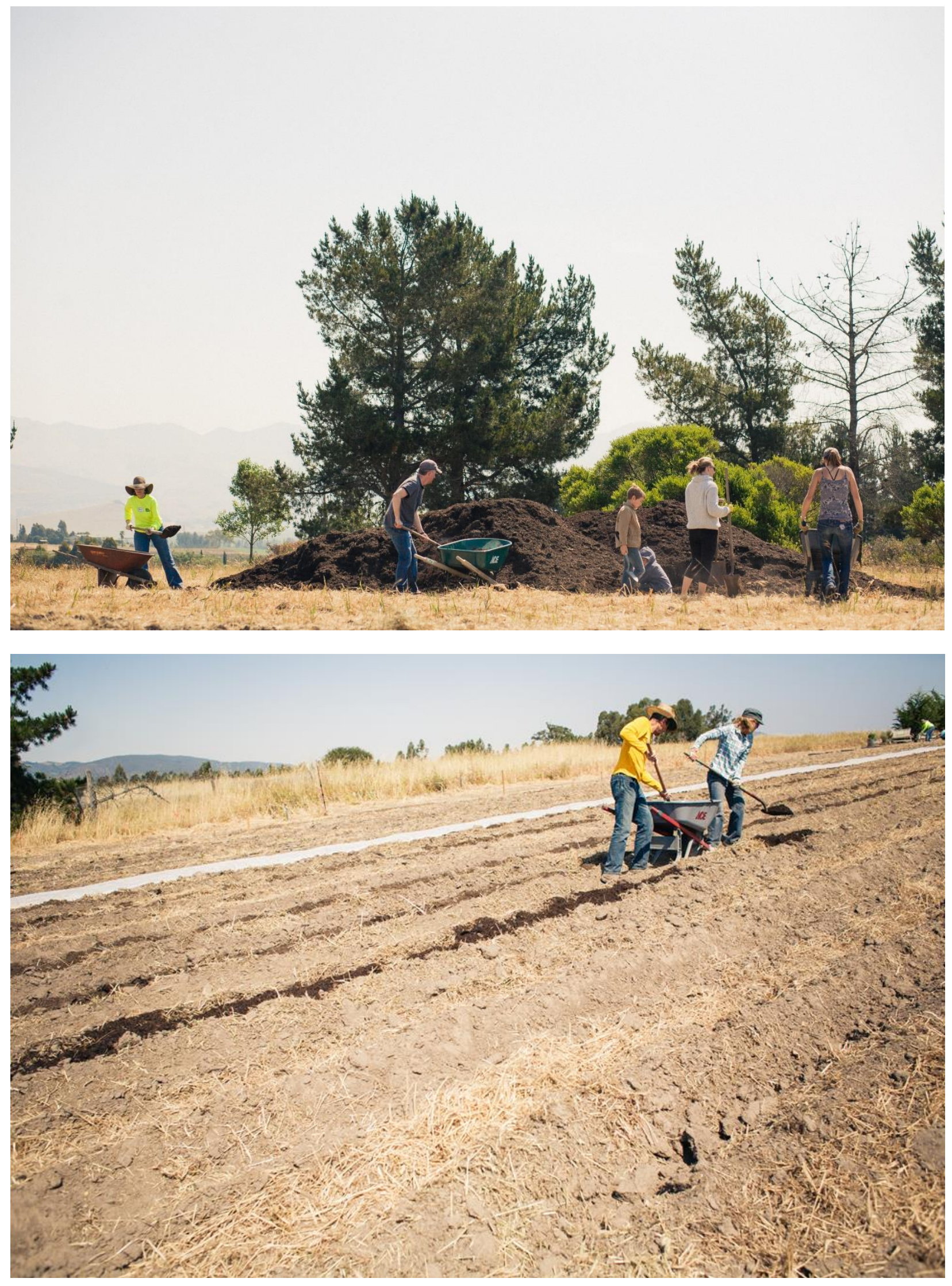


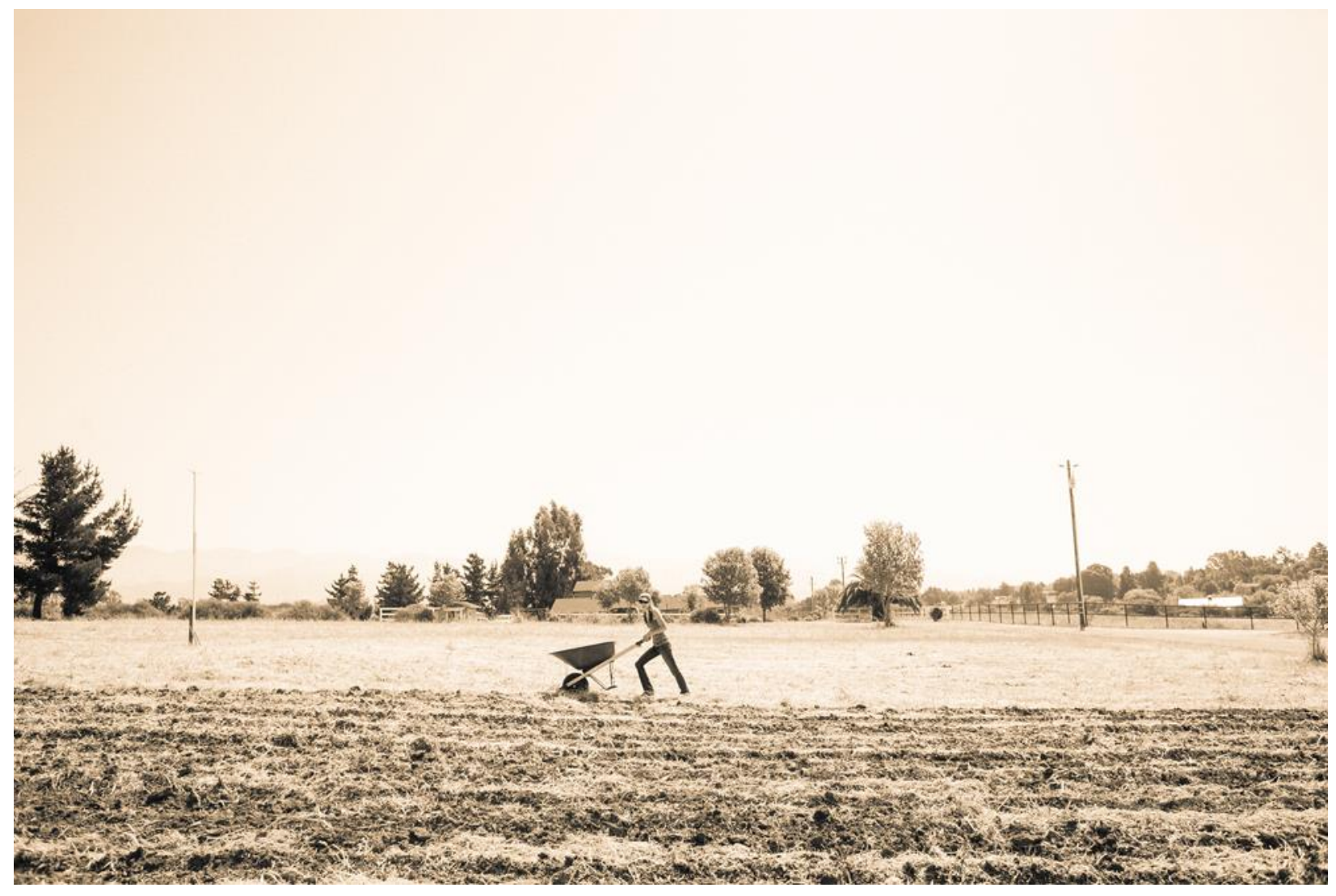




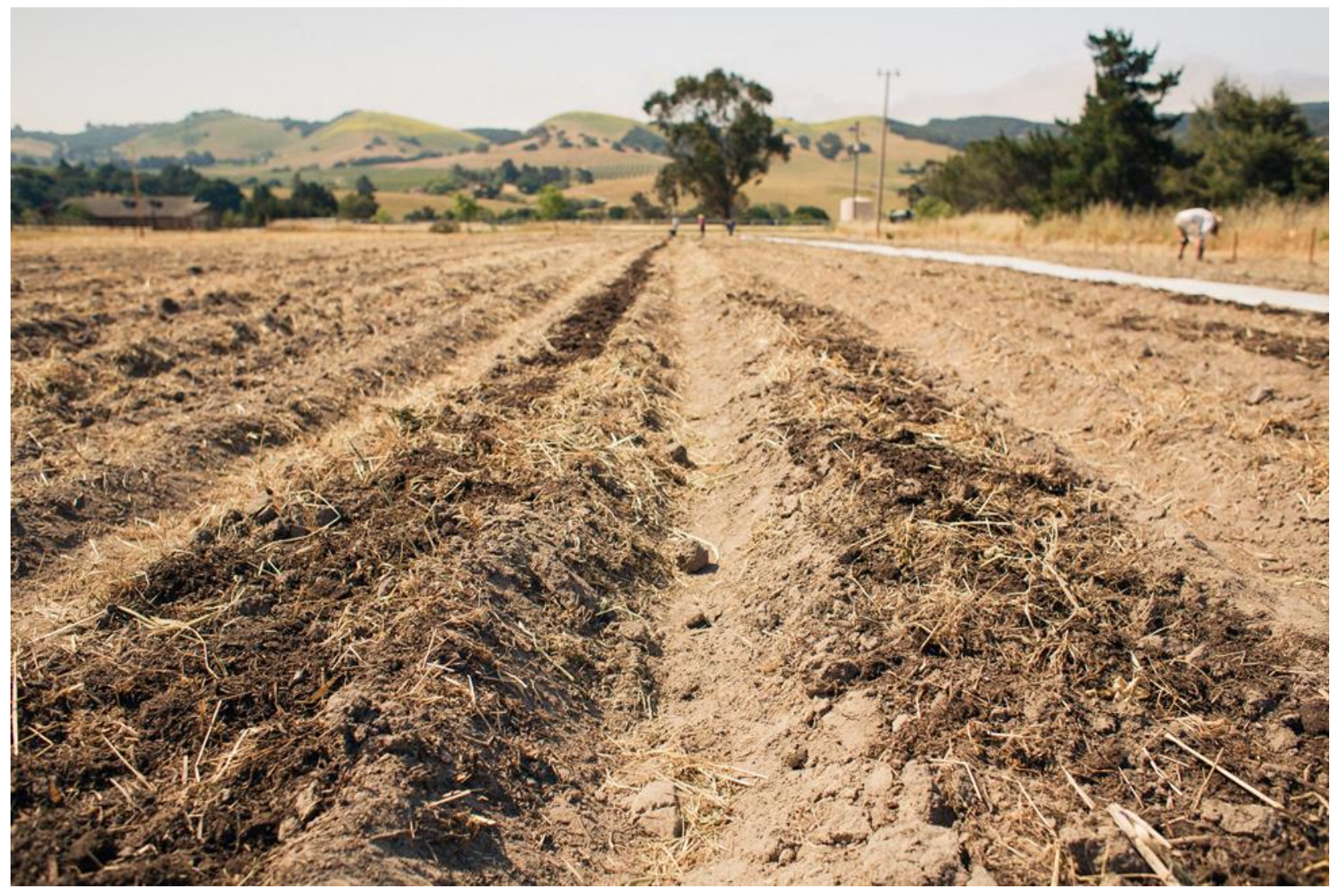




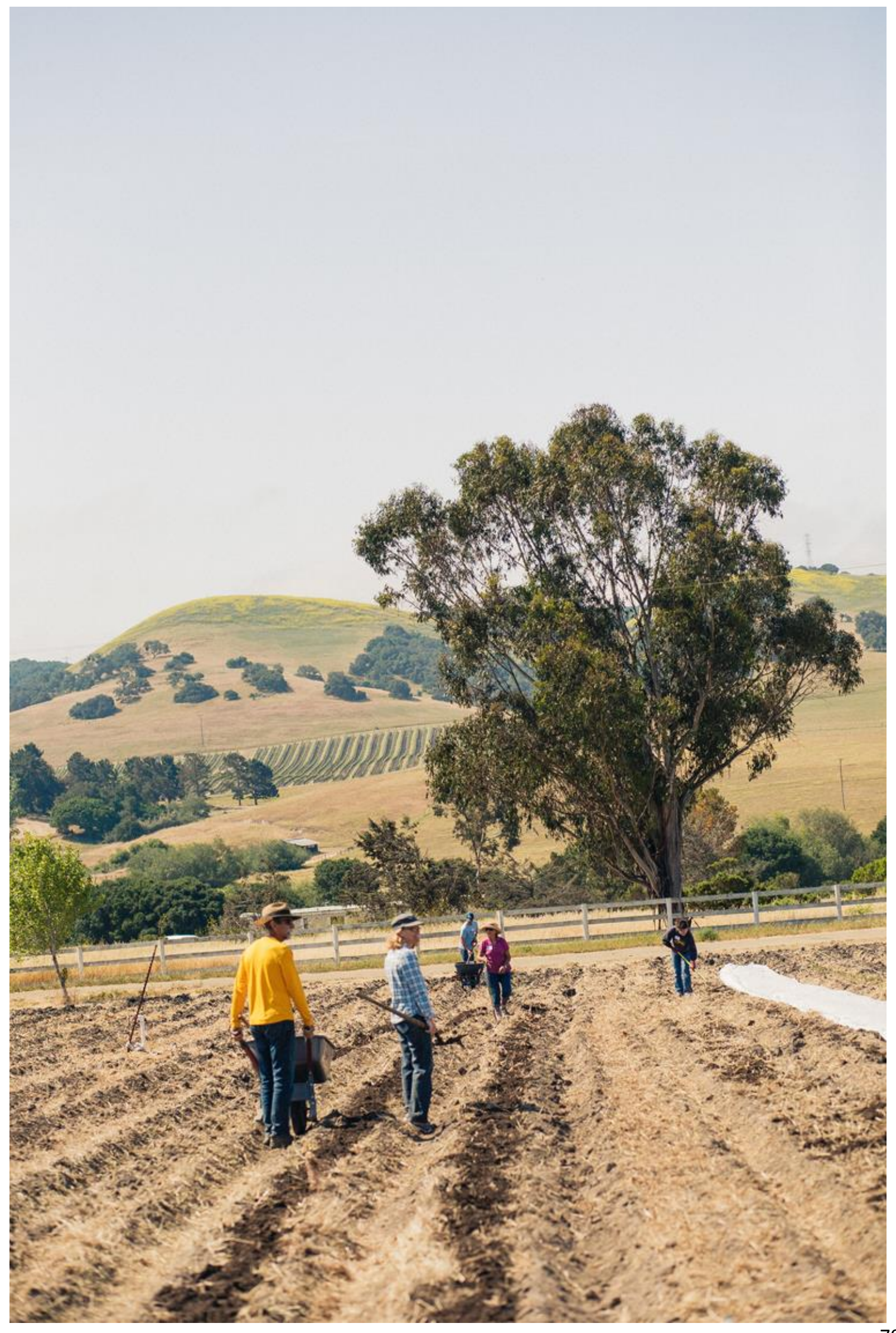




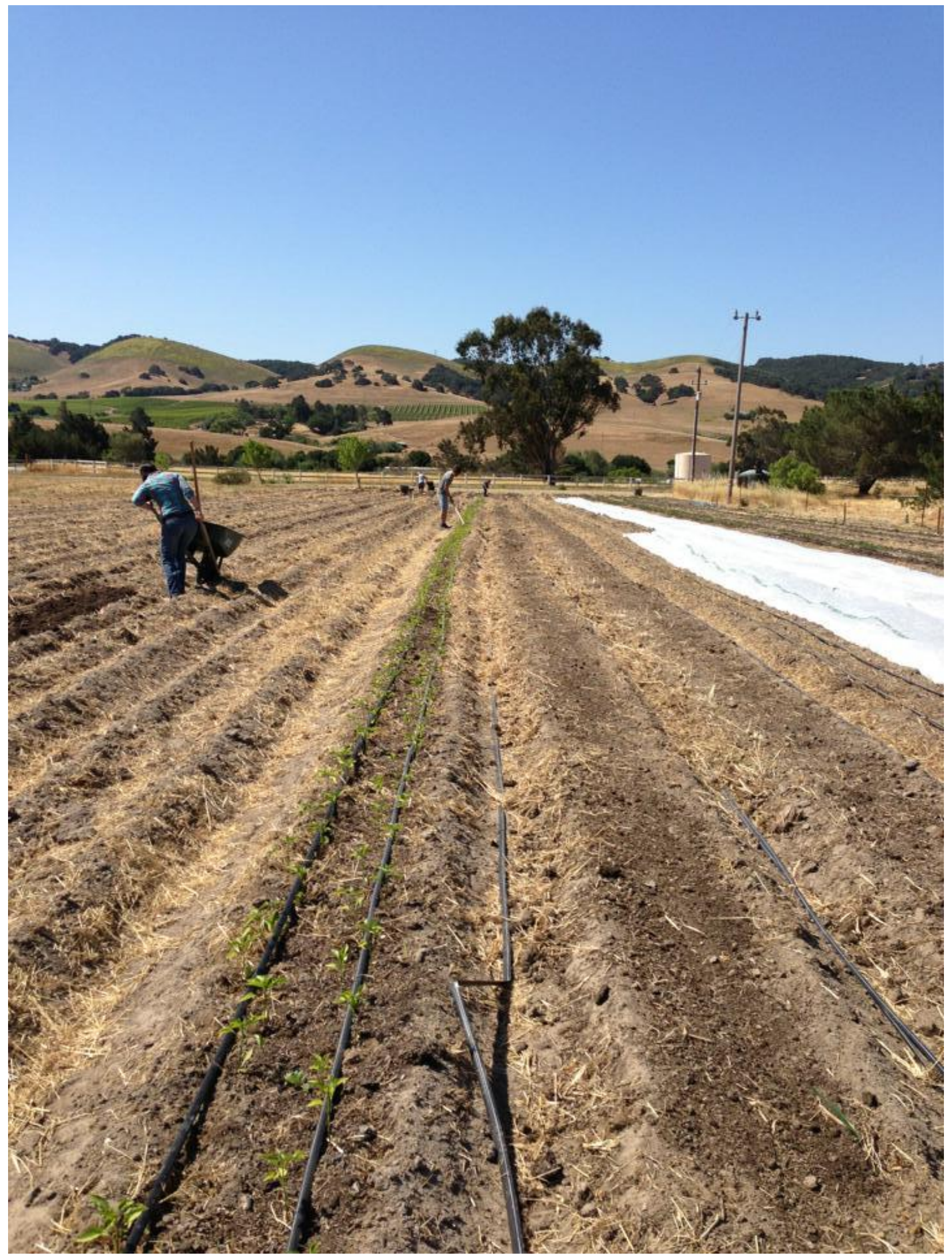




\section{Transplanting Seedlings}

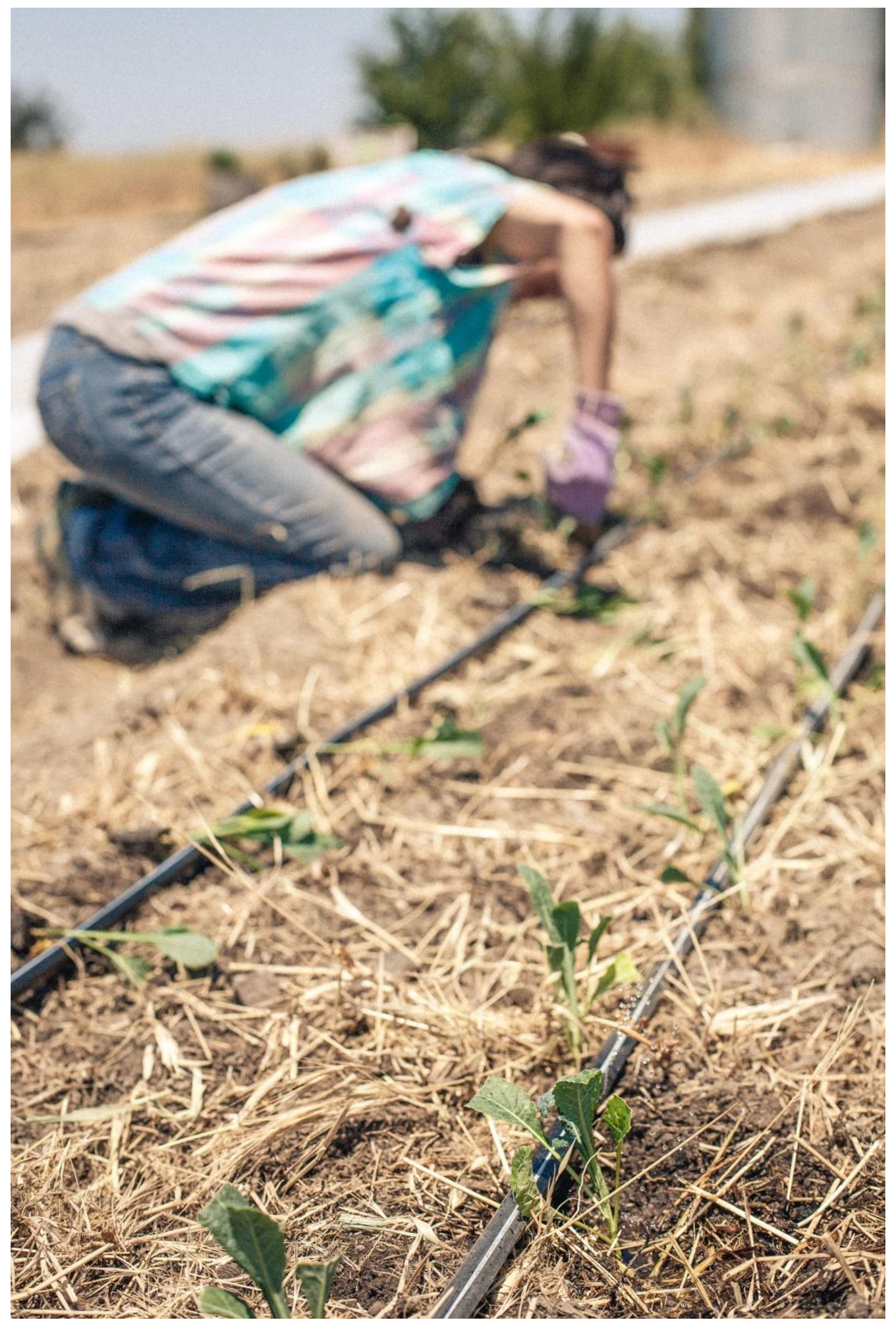


Newly Transplanted Tomatoes (Top) and Leafy Greens (Under Fabric Row Covers)

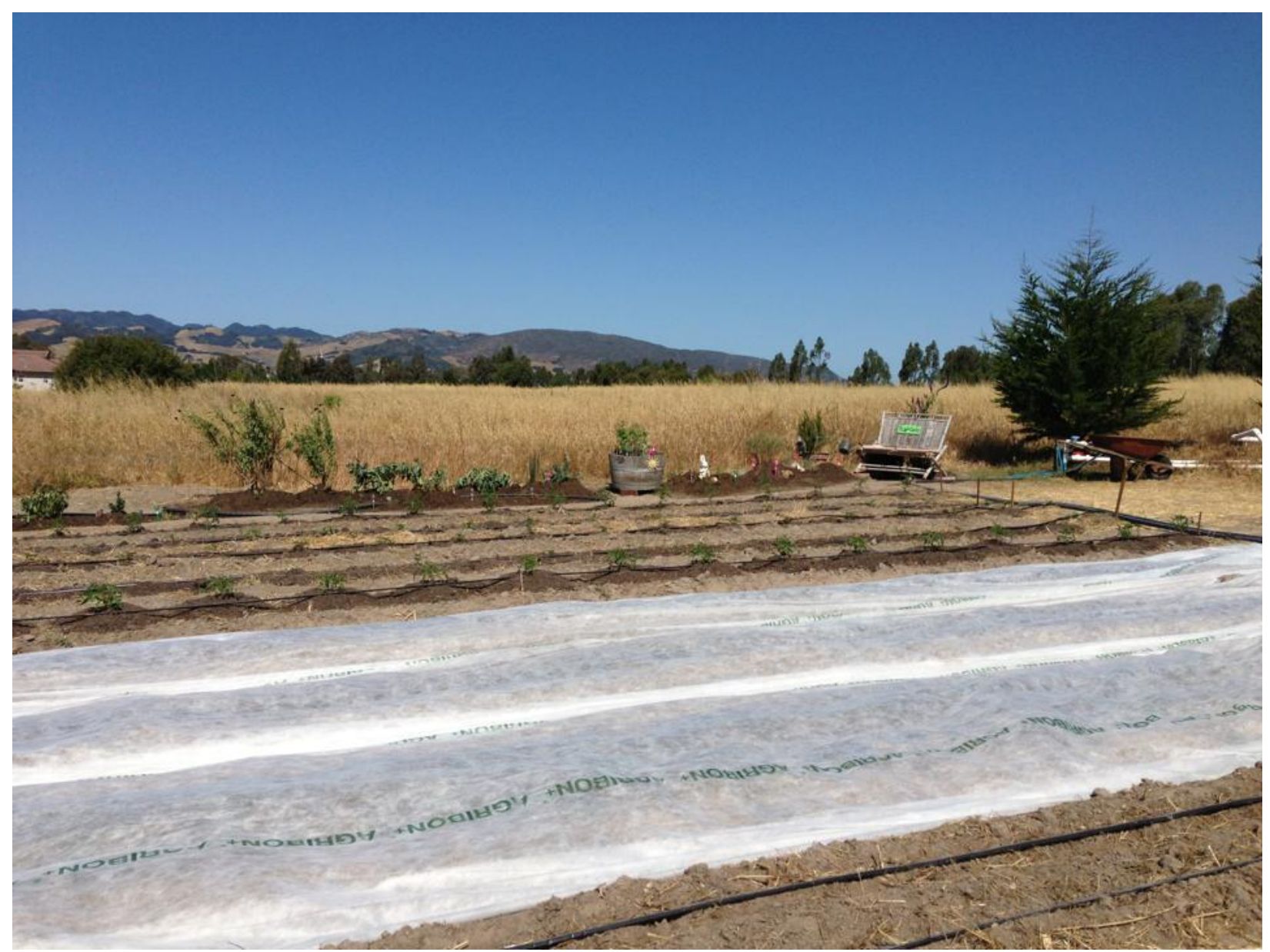




\section{Weeding Recently Planted Rows}

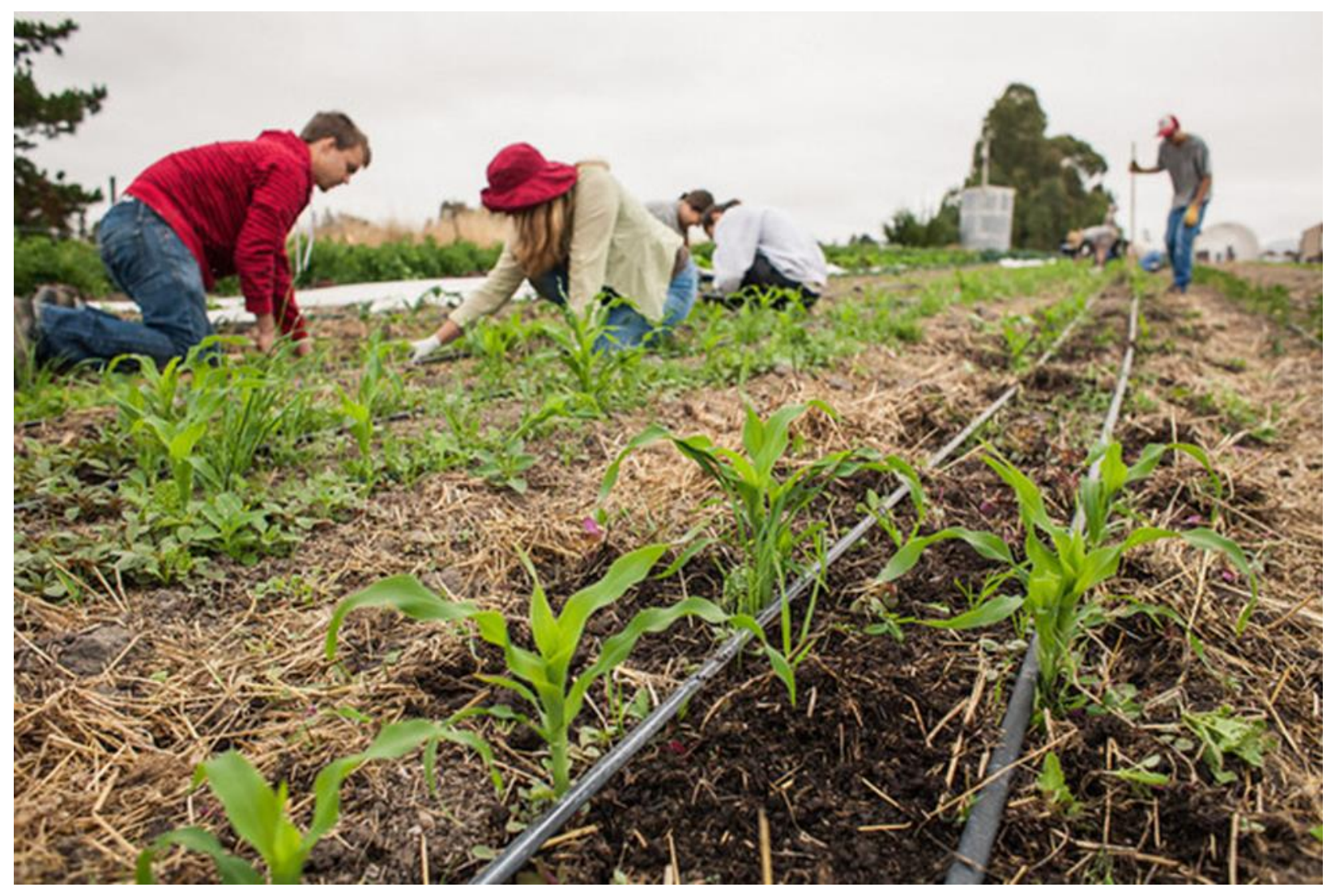




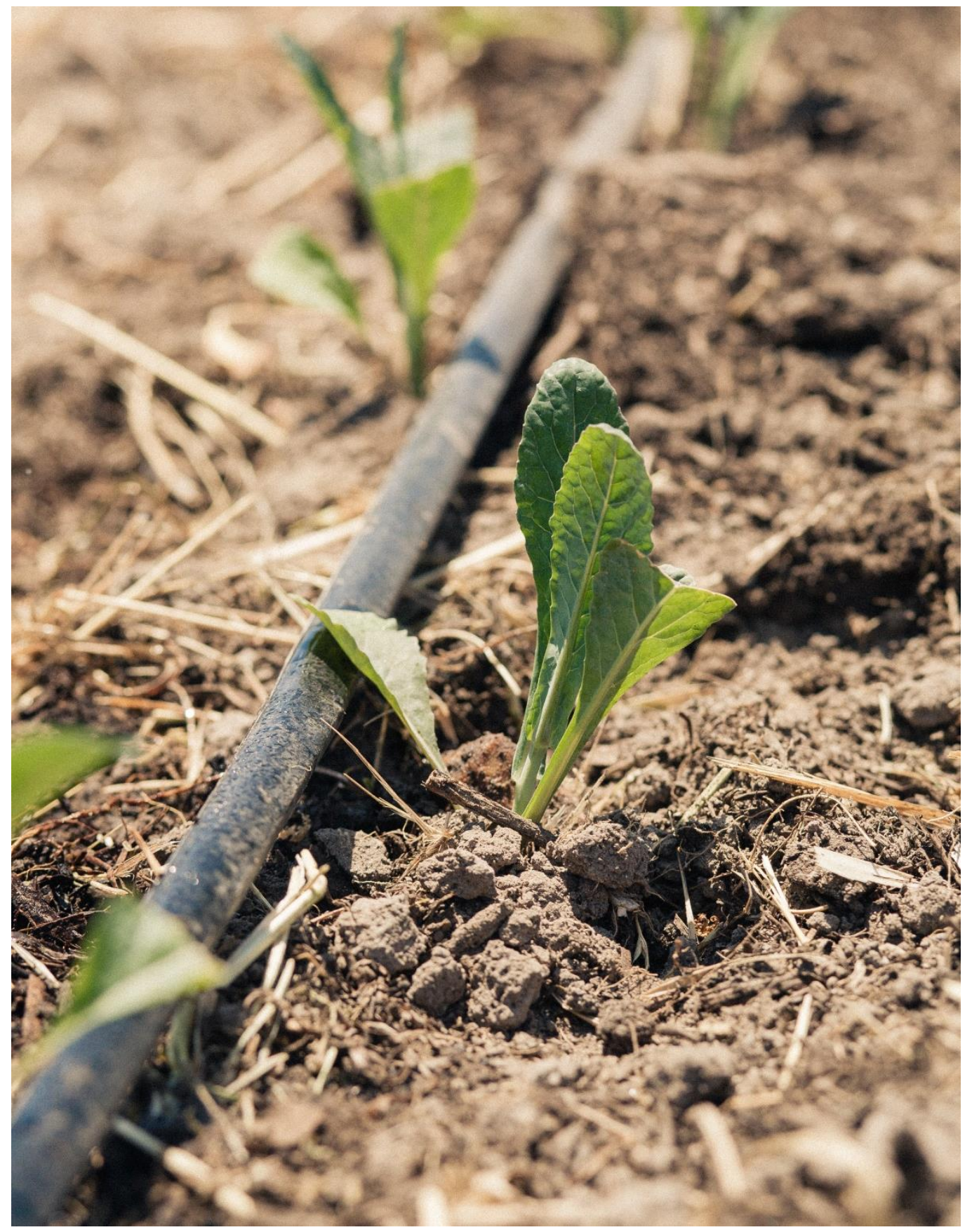




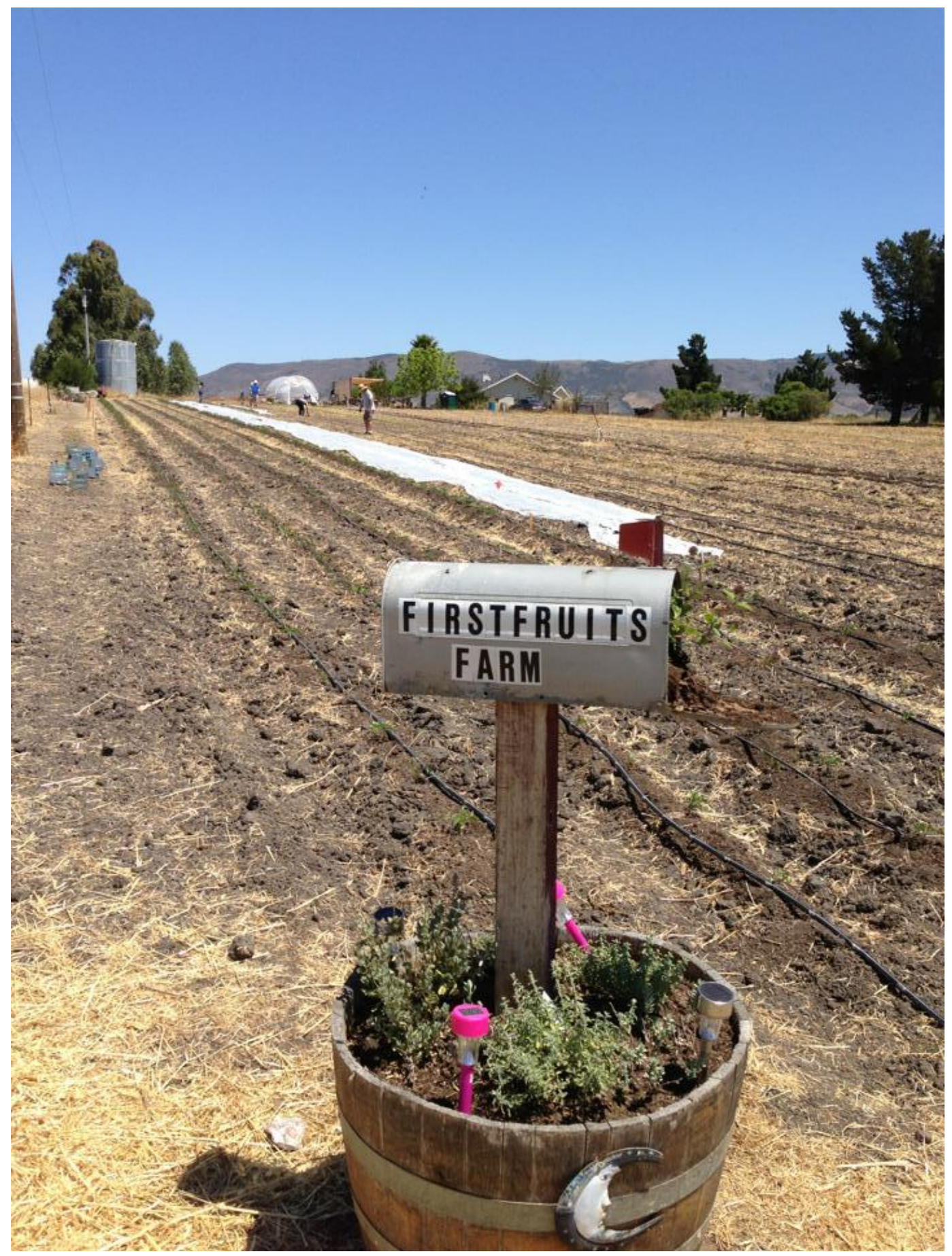

The successes of the early farm work days gave us a big boost in morale and momentum and the project had now reached a defining moment. There were team leaders that were committed to the project, volunteers that were ready to work, crops growing in the field that would need to be harvested, and food recipients that were eager for fresh produce. The bulk of the effort that had, until this point, been spent on project and organizational development would now transition to the ongoing process of sustaining operations. 
"Cultivators of the earth are the most valuable citizens. They are the most vigorous, the most independent, the most virtuous, and they are tied to their country and wedded to its liberty and interests by the most lasting bonds." -Thomas Jefferson

\section{Part 4: Sustaining Operations}

As the seasons change and the months wear on, new challenges emerge for projects such as these. In hindsight, maintaining the operation of the farm over the period of an entire growing season was clearly the most tiring and challenging process. There are no paid positions in this volunteer organization and that means that every task is accomplished by people who either have full-time employment elsewhere, or have other responsibilities (like raising children, or attending college, or caring for loved ones). Most non-profit organizations have a staff of people who keep the operation humming along, but not Firstfruits Farm. It is made up entirely of volunteers. Farm operations require daily upkeep, and ensuring this work is distributed and accomplished by unpaid volunteers is (and was) very difficult, regardless of the level of commitment and enthusiasm.

The founder and director of a project like this must be willing to carry a large burden through the entire development process, otherwise the project will begin to unravel and potentially dissolve. When there is an urgent need and a designated team leader is unable to take responsibility, there must be someone who will assume that responsibility. Ultimately, this may often fall on the shoulders of the founder; because he/she likely has the most at stake (has invested the most time and resources) in the project. To combat this, there must be a continuing effort at building a sense of ownership in all of the volunteer corps. By the end of the first growing season, there was clearly work to be done in this aspect of our organization.

\section{Weekly Work}

In the early weeks of production, we maintained only one delivery point (God's Storehouse) for our harvests and kept our designated work days to one day per week: Saturdays. Our typical Saturday followed this routine and it was closely tied to the schedule of God's Storehouse:

\section{Saturday Work Routine}

8:00am - Harvest Time: First group of volunteers arrive and were greeted. The size of this group ranged from 8-20 individuals (the number of harvesters needed averaged 15-20 and we achieved these numbers less than half the time). Children were welcome. A brief overview of instructions and items to be harvested was given by the on-duty Farm Manager. Volunteers were assigned a crop to harvest, and one or two were assigned to begin washing and packing produce. 
9:00am - Washing and Packing: Once all items were harvested, the harvest crews would move up to the washing/packing area and assist with cleaning produce and packing it into crates to be loaded on the delivery truck.

9:30am - Load and Delivery: Produce was loaded onto a designated volunteer's pickup truck, covered with clean, wet burlap (for evaporative cooling), and delivered to God's Storehouse. Food distribution to food recipients at God's Storehouse began at 10am each Saturday.

10:00am - Farm Maintenance Work: A new group of volunteers would arrive to relieve the harvest crews and begin farm work. Harvesters were welcomed and encouraged to stay longer if they could. This work involved preparing growing beds for transplanting, laying out drip lines in new rows, transplanting seedlings into the field, weeding established crops, direct seeding root crops in the field, spreading compost or mulch around newly planted crops, trapping gophers, repairing damaged drip lines, sowing replacement crops into seed trays in the greenhouse, and other maintenance work.

12:00pm - Lunch Break: Volunteers gathered under the shadehouse for refreshments. Occasionally a volunteer would bring lunch for everyone.

12:30pm - Work resumed in the field.

1:30 - 2:00pm - Work ended.

During the first weeks of the season, the majority of the weekly work accomplished at the farm occurred on Saturdays. With 20 people working three hours on a Saturday, a total of 60 manhours of farm work can be accomplished. The day-to-day maintenance (irrigation, pest control, repairs, etc) were carried out by myself or one of the other farm managers who would make a late-afternoon, early evening trip out to the farm each weekday. This daily maintenance work by the farm managers required about an additional 15 man-hours per week. So, for the first few weeks of the growing season (with production capacity limited to one delivery location, providing produce to about 150-180 families) required an average of 75 man-hours per week.

By the peak of the season, our manpower needs increased greatly. When we started the season, we were only harvesting 3-4 crops per week (lettuce, kale, chard, and carrots). By midsummer we were harvesting 6 varieties of tomatoes, 3 varieties of lettuce, 3 varieties of squash, 3 varieties of melons, 2 varieties of peppers, 2 varieties of cucumbers, kale, chard, carrots, sweet corn, and basil. The increased numbers of crops to harvest demanded a larger number of volunteers to harvest it all in time for delivery. At this point, the number of man-hours needed increased to nearly 120 per week.

Until the routine and farm protocols were established, we asked that volunteers only come out on designated work days. Since this was private property offered by a generous family who lived on the land, we wanted to have a farm manager on site at all times to ensure standard 
operating procedures (S.O.P.S) were followed. There was an early plan to establish written S.O.P.s before farm operations began, but this was another item that we weren't able to accomplish in time for the first production year.

\section{Expanding the Operation}

By mid-June our field crops were exploding with produce and we needed additional drop-off locations to ensure no crops were wasted. With virtually all of the farm work being done by hand, it was a very labor intensive process and wasting any of the premium fruits and vegetables that were growing in the field was not acceptable. So we made contact with four additional outlets to deliver our goods, and we soon were delivering to: The San Luis Obispo Women's Shelter, The Salvation Army, The San Luis Obispo Veteran's Center, and Judson Terrace (a low-income senior citizen's housing facility). This required an additional harvest and work day, and after working with the new delivery locations, we decided on a Wednesday morning harvest and delivery. This work day proved to be a better fit for a number of people on our volunteer list who were not able to make it on Saturday mornings.

At this point in the season, with our production peaking and multiple weekly harvests occurring, the number of man-hours worked per week increased significantly. We now had an additional 10 volunteers working for about 3 hours on Wednesdays to get the additional harvests completed. We also required additional people on Saturdays to keep up with transplanting, weeding and harvesting additional crops. As detailed above, the number of needed man-hours increased to nearly 120 per week. 


\section{Harvesting Crops}

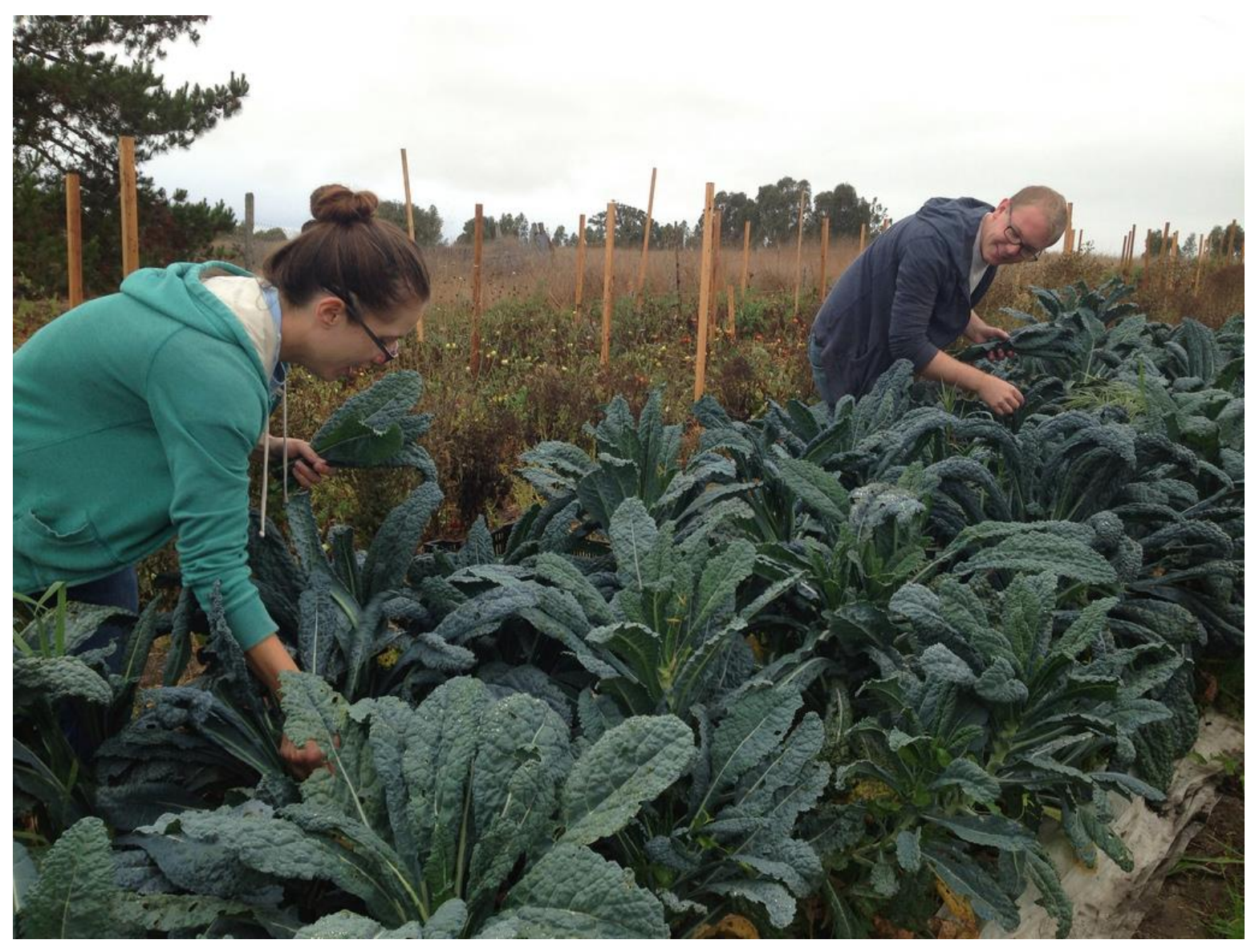



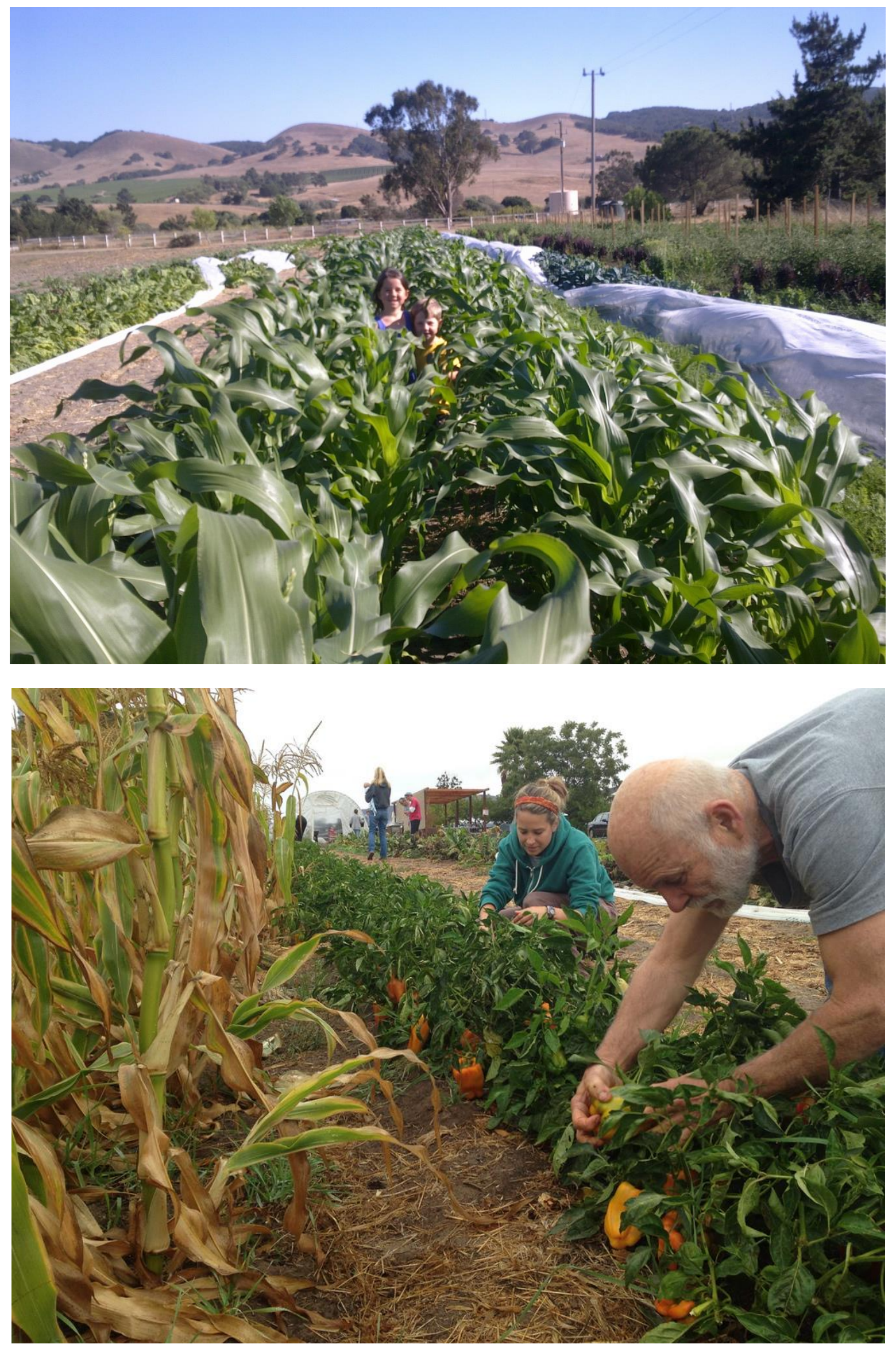

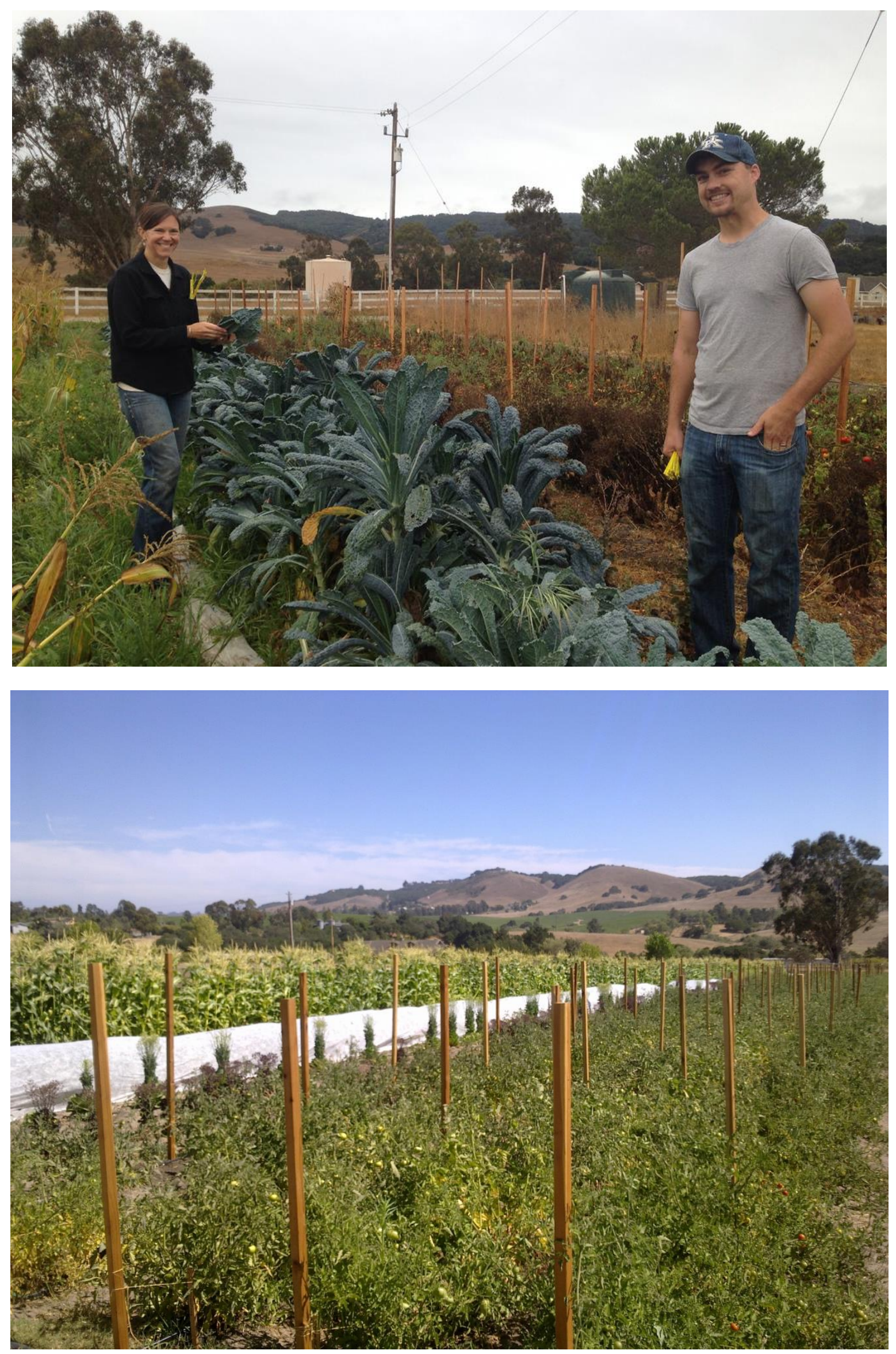


\section{Volunteers and Children}
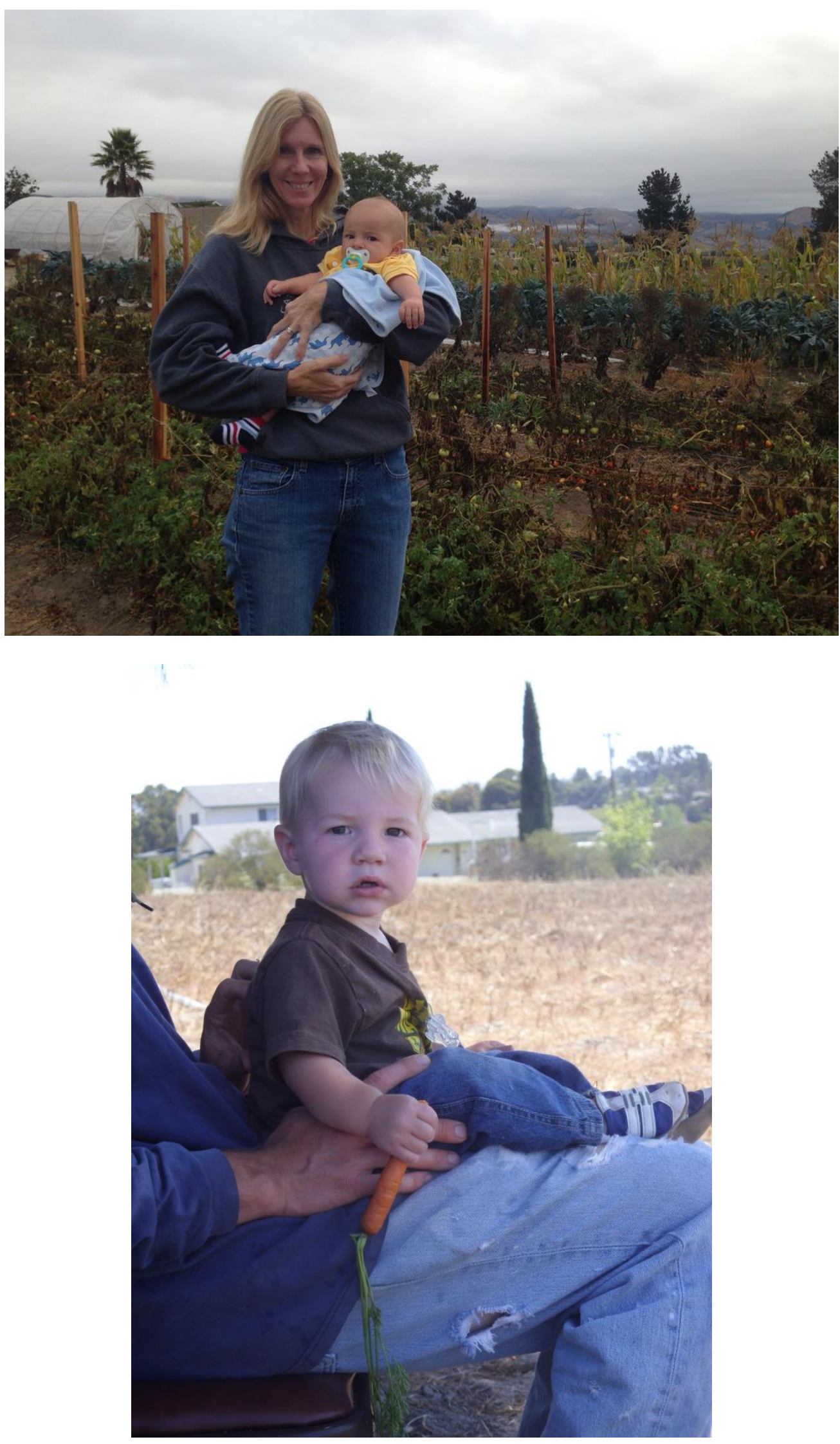


\section{Produce Loaded on Truck Ready for Delivery}
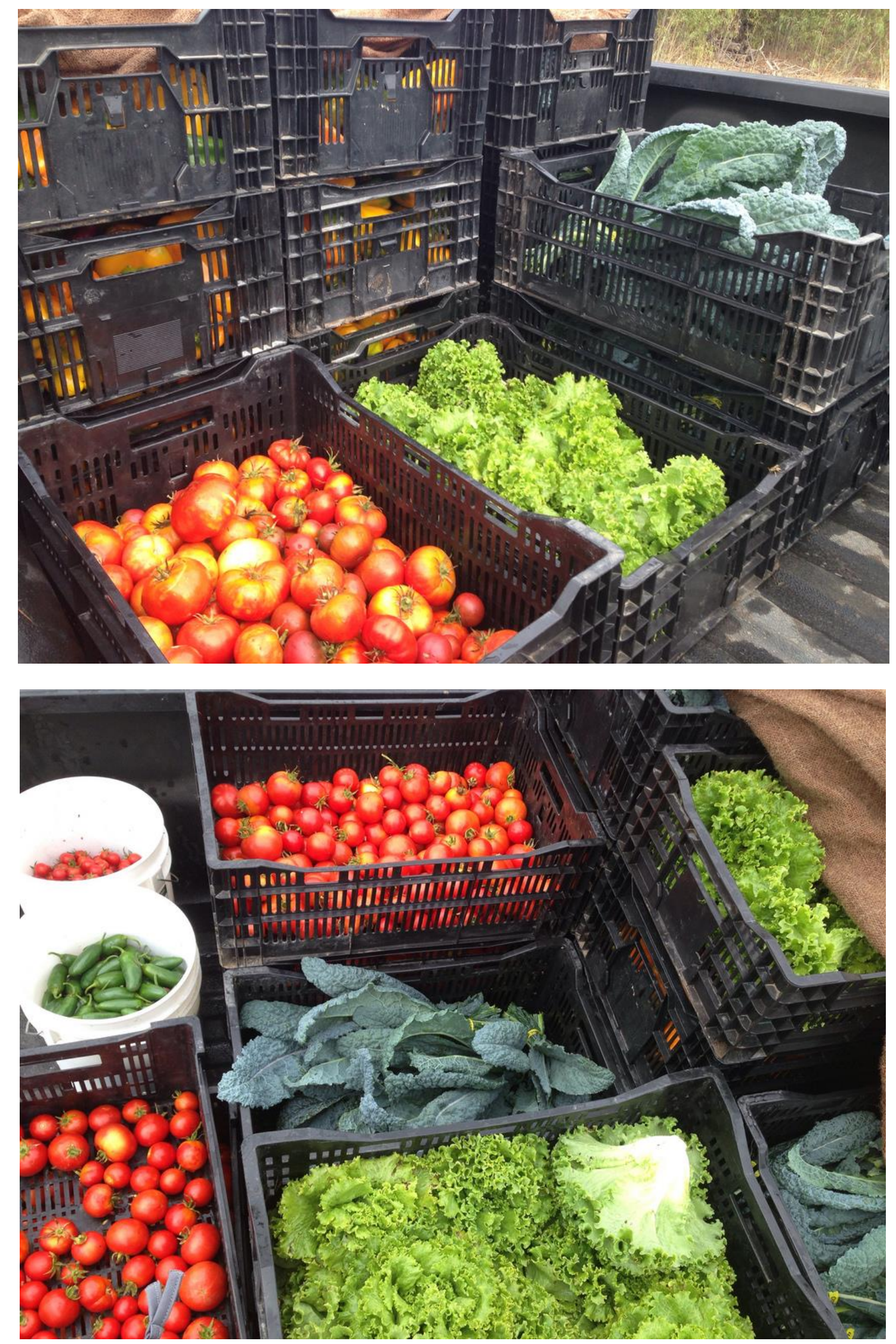


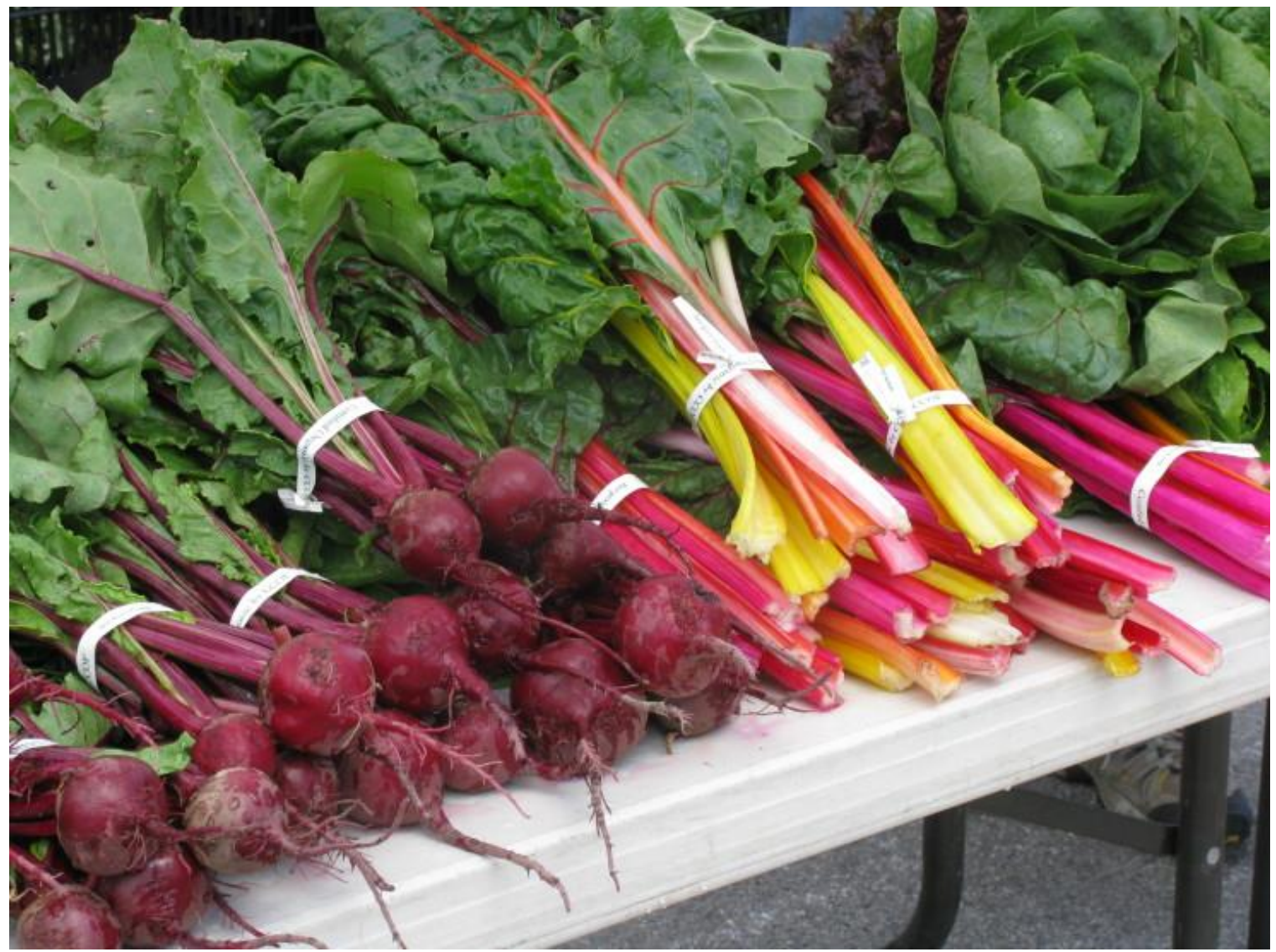

\section{Motivating Volunteers}

Despite having a volunteer list of more than 100 individuals and a leadership team of 20 individuals (with redundancy at key positions on the team), ensuring that essential tasks and work were accomplished was arduous. Throughout the first weeks and months of the first growing season, there was considerable inconsistency in the number of volunteers that arrived at the farm on designated work days. As mentioned before, our average number of needed harvesters on Saturday mornings was 15-20 people. Often, we only had about 10 and we had to hustle to get everything processed and delivered to God's Storehouse by 9:45am. There were also several occasions when one of the assigned Farm Managers had a last minute scheduling conflict and wasn't able to make it to the farm. The reduction and loss of volunteer or leadership help had to be absorbed somewhere else, and it usually meant increased work for others.

Keeping volunteers motivated to honor their commitments and remember the important work of the farm, was a delicate task. It is important to avoid using guilt as a motivating force, regardless of the worthiness of the cause. It can quickly deteriorate the morale and motivation of the volunteer corps. They can also begin to feel manipulated and used, and the resulting soured attitudes can infect the entire operation. At all costs, I strove to keep the motivation 
and communication positive. Attached are examples of e-mails sent by me and the Volunteer Coordinators to the volunteers to encourage participation in upcoming farm work days (arranged from older to newer).

\title{
Sample E-mails Sent to Volunteer Corps
}

\author{
Hi First Fruits Farmers! \\ Here's an update on our progress with the farm. \\ The farm managers met on Thursday to accomplish several key items: \\ 1. Develop a timeline for the growing season. \\ 2. Dedicate growing areas for specific crops. \\ 3. Decide on the crops/seed varieties we'll be growing this first year. \\ 4. Prioritize urgent resource needs.
}

We had a great meeting and I think we're in agreement on how and when to move forward. Our planning revealed that we will need to have a seed sowing day by mid March (in 2 weeks!), and probably another one by early April to get our greenhouse stocked with the seedlings that we will be transplanting into the field by the end of April or early May. This will be the beginning of our first growing season, and we should be getting our first harvests (of the faster growing crops) by the end of May. The resources we will need to accomplish the seed sowing are: seeds, potting soil, a few more seed trays, money, and manpower (probably only 4-5 people in addition to a couple of farm managers). Seed sowing into seed trays is a meticulous, but relaxing and enjoyable process. The farm managers will provide guidance on the proper technique to ensure maximum germination rates.

Speaking of money...on the Trinity side, we will hopefully have some answers soon on financial support. We need to follow up with Grace/God's Storehouse to inquire how they can contribute financially to this project. For resource donations, we don't currently have a letter to offer for 501c3 donations, but will hopefully in the near future. In the meantime, material or financial donations can be given to Trinity Presbyterian Church and a tax deduction can be claimed by the donor as though it were a cash donation. This would obviously work for donations through Grace Church as well.

The Special Projects team met on Friday to prioritize near-term projects and plan the layout of the structures. Then today, in the beautiful weather, they went out and built the frame for the greenhouse! They will have it completed within the next couple of days, and just in time for our freshly sown seeds to be kept warm and cozy as they grow. We will have work benches for the seed sowing day built soon as well.

We also now have a bed-shaper for the tractor! This will allow us to form raised beds for our seedling transplants (which provides a myriad of benefits to the plants as well as to those of us who will be bending over to transplant). This implement was a key missing piece to enable good production on the farm, and let me assure you, we are greatly blessed to have use of it!

Other items in the work: volunteer coordination using matrices and spreadsheets, an outhouse/port-a-potty installed at the farm, a native bee garden to improve plant pollination, a stainless steel sink for washing harvested crops, a shadehouse for hardening off seedlings and taking shelter under on hot days, a website for farm news and PR, a mission statement for the farm, and so much more. As you can see, we're moving! Thank you to those who have had opportunities to contribute so far. For those of you who don't feel like you've been able to contribute much yet, don't worry. There are plenty of opportunities coming.

Friends, let me end with a plea: pray for Wilbur Mellema and his family. They are mourning the loss of his mom, who passed away this morning at the age of 97 . He is down in Ontario with his family now.

Grace and Peace,

Darin 
Darin Laity <darin.laity@gmail.com>

to bcc: Anna, bcc: Anthony, bcc: Barb, bcc: Barbara, bcc: Ben, bcc: blenz715, bcc: Bonnie, bcc: Bret, bcc: clfletch91, b F

Friends of First Fruits Farm,

It's been a little while since l've sent out an update, so here we go...

The farm project is rolling along and we are just a few weeks away from planting our first crops! Here is a quick summary of the progress we've made:

- The greenhouse is assembled and it is well stocked with our first seedlings. We've had good germination rates from most of our seeds and the plants are progressing along nicely.

- Seedling benches are built and installed.

- Automatic sprinkler system is installed and faithfully watering our plants

- The shade house is very nearly complete.

- We have a stainless steel sink for vegetable washing ready to be installed.

- The field is mowed and the soil-building crop is ready to be turned into the soil.

By the end of April (or possibly the first part of May) we will begin transplanting the greenhouse seedlings. We will also begin direct seeding additional crops into the field. By mid to late May, we should have our first crops ready to be harvested and delivered to God's Storehouse. In the meantime, there are key resources that we need to acquire to be ready for the regular volunteer work to begin. Some of the items we urgently need are:

- Transplanting Trowels

- Harvesting Knives

- Organic Fertilizer and Compost

- Drip Irrigation Valves and Connectors

- Fabric Row Cover for the Transplants

- A Storage Shed

- Action Hoes

- D-Handle Forks

- Shovels

- Vegetable Crates

- Plumbing Parts for the Sink

- Port-a-Potty

- Wheelbarrow

- Picnic Table

- Lead-Free Hose (drinking water quality)

With this in mind, tomorrow we will set up a table at Trinity's church potluck that will provide a short description, picture, and approximate cost for many of these items. The idea is to offer an opportunity for church members to contribute toward specific material needs of the farm. That way, we can encourage participation and ownership of the farm project by our congregation. Instead of indiscriminately contributing money toward the farm and not knowing how it is spent, they/you are actually purchasing or contributing toward a specific item that the farm needs. We will ask that people make their donation for their chosen item(s) at the time that they sign up. Please consider participating in this opportunity to contribute materially to the farm project. Checks can be made out to Trinity Presbyterian Church with First Fruits Farm in the memo line.

For those of you who attend Grace Church, we are trying to work out a time soon when we can do the same thing at Grace. Any items remaining on the list will be presented to your congregation at a time and venue determined by church leadership.

Thank you to all who have been able to help so far. To everyone else, get ready! The weekly volunteer work is about to begin.

Looking forward to working with all of you, and may the Lord be honored in all that we do!

$\cdots$

- Darin

Hello, volunteers for First Fruit Farms

Please let me know if you can help out this Saturday, March 30th. We need a small crew of folks who are willing to seed. This is not strenuous work, and it's done in the greenhouse, so don't let the predictions of possible rain deter you.

The location is: at the Farm, 835 Serpa Ranch Rd

The time: from 10 a.m. to noon.

If you're inclined to bring a basic snack, feel free.

Kindly reply to this email Wednesday, even if your decision is tentative. We have a list and know of the experience, aptitudes and wishes you've described earlier. Now, we need to match up your available time with Farm needs.

So far, FFF has made great strides. The greenhouse is up, the seeds are ready, the "primer" crops--to feed the soil--are a couple feet high!

Praise the Lord for nature, grace, redemption and hope! 


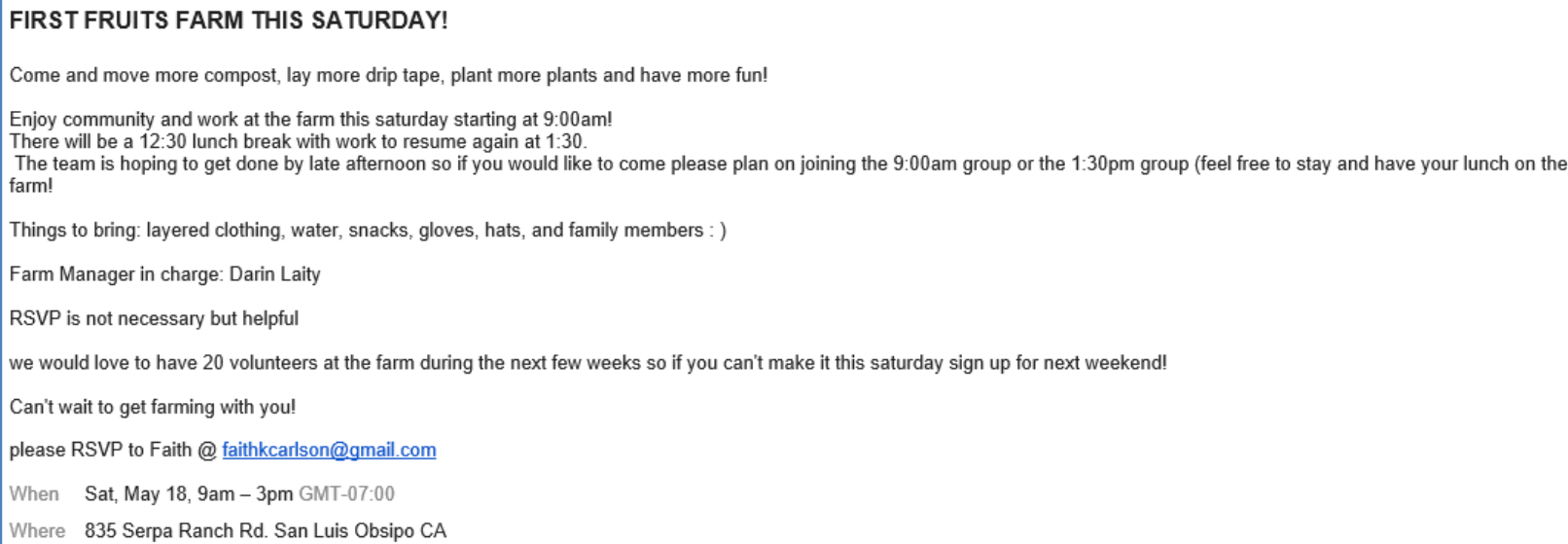

Friends,

I just wanted to share an encouraging, heartwarming note with you. Annie Schmidt, the chairperson for God's Storehouse leadership team made an announcement to the food recipients who were gathered for the food distribution this morning. She informed them about Firstfruits Farm and told them that they will soon be getting fresh, organically grown produce grown just for them. Friends, they cheered! They are so excited and thankful to hear about this project that they cheered at the news. I don't know about you, but that just stirs my heart.

You are all making this happen, each in your own capacities. And there are needy families in our community who are very thankful for you.

Blessings,

…

Darin 


\begin{tabular}{|c|c|c|c|c|}
\hline Help us break our harvest record & Inbox $\mathrm{x}$ & Farm $x$ & & $\overline{0}$ \\
\hline Darin Laity <darin.laity@gmail.com> & & Aug 30 t & $h$ & $\checkmark$ \\
\hline
\end{tabular}

to bcc: Anna, bcc: Anthony, bcc: Barb, bcc: Barbara, bcc: Ben, bcc: Bonnie, bcc: Bret, bcc: Carl, bcc: -

Friends of Firstfruits Farm,

I wanted to share a quick story with you. A couple of weeks ago, one of our volunteers was approached by a woman who receives food at God's Storehouse, and she wanted to express her gratitude for the weekly deliveries of fresh fruits and vegetables. This elderly lady has virtually zero income and recycles cans and bottles to generate a little money each month. She explained how much she appreciated that our food was produced organically, with no pesticides or chemical fertilizers, because she is extremely sensitive to various chemicals and toxins. She detailed how she prepares her veggies for meals, and made it very clear that she never lets a single thing go to waste. She then said she wanted to give a donation to help with the farm expenses, and she handed over a 20 dollar bill. Friends, this was her monthly revenue from collecting cans and bottles and it was an enormous sacrifice. Does this not remind you of the poor widow who Jesus watched put 2 small copper coins in the collection box? "...she, out of her poverty has put in everything she had, all she had to live on."

Your hard work this season has been a huge blessing to many people in our community, and they are truly grateful. We're very near to the day when we will be working alongside more of them out in the field, hearing their stories and building relationships with them. As we continue to get organized and work out our logistics, the blessings from this little farm will become more abundant. In the meantime, we still have loads of work to do to keep up with our harvests and farm work.

Last week we harvested and delivered over $680 \mathrm{lbs}$ of produce. We could nearly double that this weekend. But it won't be possible without YOUR help. On a good week, we have 9 or 10 harvesters. We need 20. This weekend we could use 25. Please don't think "they" will get the work done. There is no "they". There is only "we". You are part of the "we". Our harvesting season is quickly coming to an end, can you help us finish the year strong?

Harvest begins at $8 \mathrm{am}$ tomorrow, and we need to deliver by 9:30am. I'm looking forward to seeing you out there!

Blessings,

$\cdots$

Darin 
Darin Laity <darin.laity@gmail.com>

Sep 6

to bcc: Angela, bcc: Anna, bcc: Anne, bcc: Anthony, bcc: Barb, bcc: Barbara, bcc: Ben, bcc: Bonnie, b -

Friends,

Have you been watching the news? There doesn't seem to be any shortage of disheartening, sorrowful events happening around the world, does there? Even in our own community, the sad news seems inescapable. But you have pushed back against the bad news this year. You have refused to allow bad news to be the only kind of news. You have created good news! The sacrificial kindness in all of your hard work is most certainly newsworthy, but it is not the kind of news that most media outlets like to report. In fact, the wider community will quite possibly never know of the weekends you've given up, the hot weather you've endured, the clothes that you've dirtied, or the muscles and joints that you've pained. But there are hundreds of people in our community (who also get very little attention, by the way) that you have directly and significantly blessed. The veterans receiving help and counseling at the Veteran's Center, the women seeking protection at the Women's Shelter, the poor and homeless that show up at God's Storehouse and The Salvation Army, and the low-income senior citizens at Judson Terrace have expressed amazement and deep gratitude for the good news that you have made come true.

Friends, last weekend I asked for 25 volunteers to help harvest, and 26 showed up. We've never had so many people out there. The result? We were able to harvest and deliver over 1000 pounds of the freshest, tastiest, organically grown fruits and vegetables. It was truly an amazing day. This weekend we need 25 people again. This may be the last big harvest we have this year. It could top 1000 pounds again, and it would take our total yearly harvest to over 6000 pounds. But it won't happen unless YOU decide to come out and make more good news come true. Will you come join us?

Harvest begins at 8am with the first delivery at 9:30. Farm address: 835 Serpa Ranch Rd, SLO. Please park in the inner circle in front of the Peet's house. It will likely be cool in the morning and will quickly heat up.

We're looking forward to seeing you out there!

Darin

\section{Improving Communication}

In addition to regular e-mail updates, the need to employ social media, a website, and other means of communication are becoming more essential. Volunteers have a wide range of preferences for how they receive their information, and developing an organization that depends on these volunteers for success requires a great deal of flexibility to adapt to their needs. The bulk of our communication began with e-mail and announcements at the two churches. But we knew we needed to expand our methods, and early in the development process we began work on a website and a social media account.

Operating with a very small budget makes finding and using free or ultra-low-cost media a high priority. We chose to use a free Gmail account, Facebook, and a low-cost website for our primary communication tools during the first year. We quickly discovered that we would likely benefit from other options as it became apparent that a number of additional volunteers found us via the different tools. Attached are screen-captures of our first website and several Facebook postings. 


\section{Screen Captures of the Original Website}

\section{FIRSTFRUITS FARM, SLO}

Giving Our Best for Our Neighbors in Need
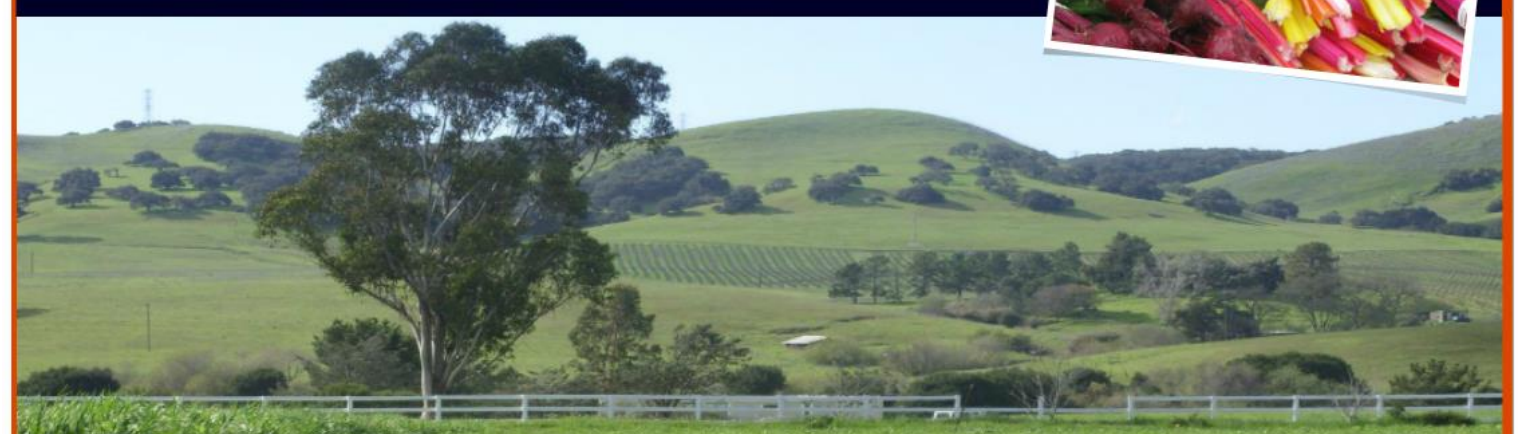

\section{ABOUT US}

Firstfruits Farm is a ministry of Trinity Presbyterian Church SLO and is dedicated to growing the freshest, organically grown fruits and vegetables for God's Storehouse, a satellite of the Food Bank. Our operation is accomplished entirely by our dedicated volunteers, and is completely non-profit. More than 180 families receive food from God's Storehouse each week. We wanted them to have the best, healthiest food we could possibly offer. We do this for them....and by extension for ourselves; this is our community.

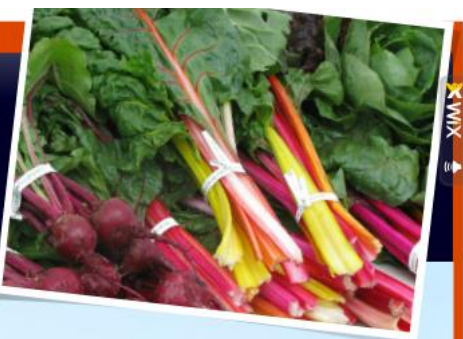

\section{FIRSTFRUITS FARM, SLO}

Giving Our Best for Our Neighbors in Need

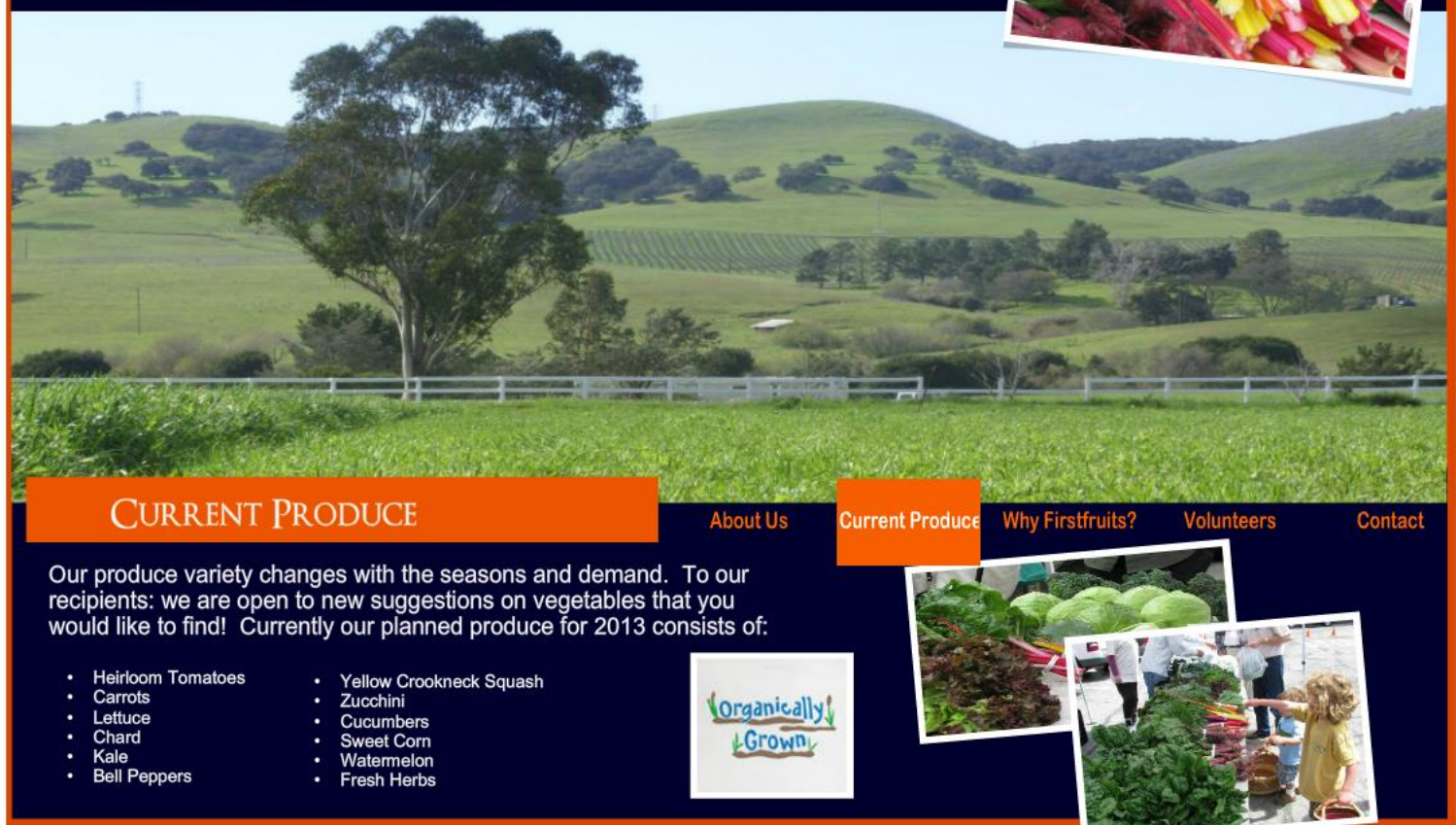




\section{FIRSTFRUITS FARM, SLO}

Giving Our Best for Our Neighbors in Need

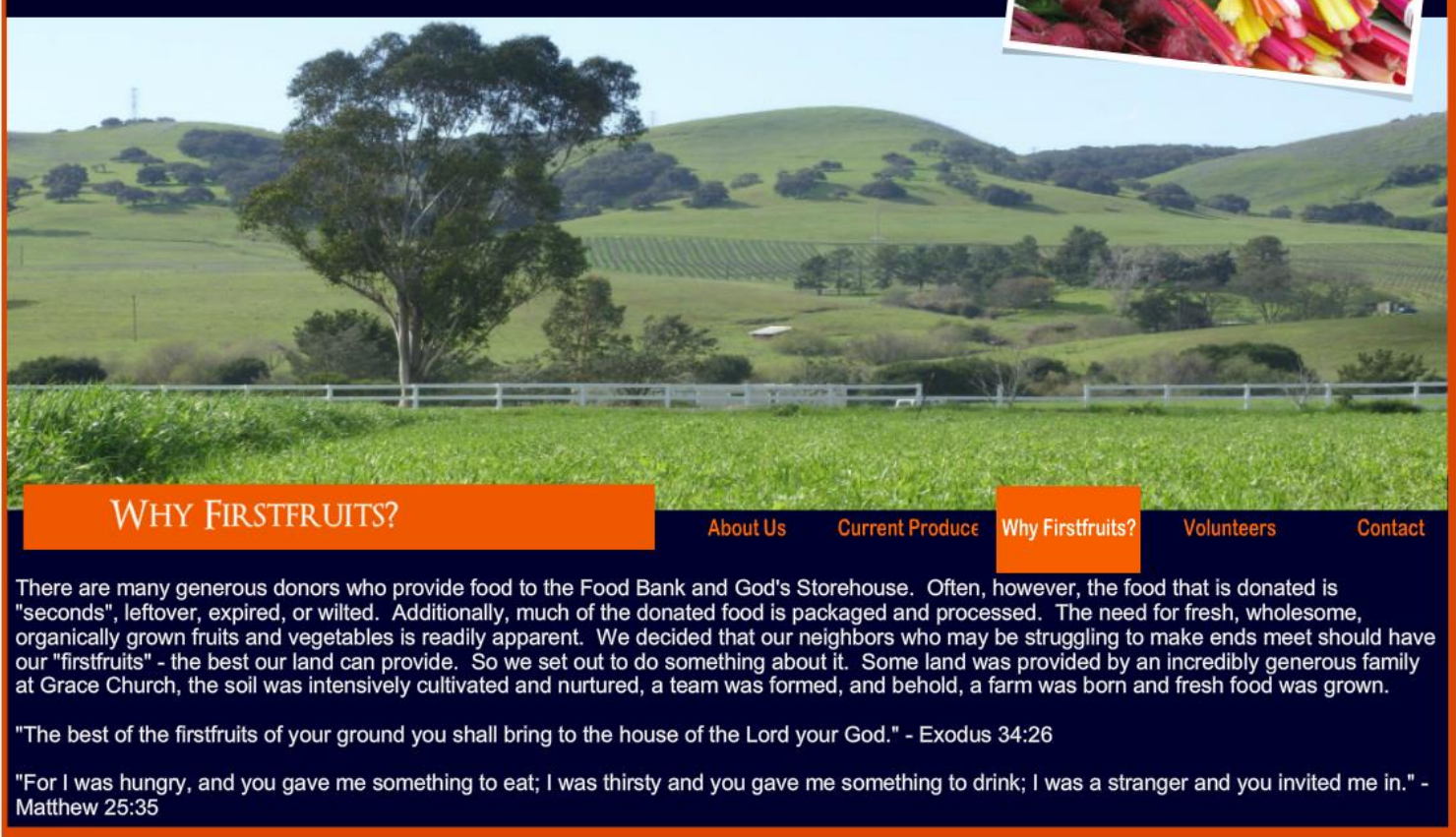

\section{FIRSTFRUITS FARM, SLO}

Giving Our Best for Our Neighbors in Need

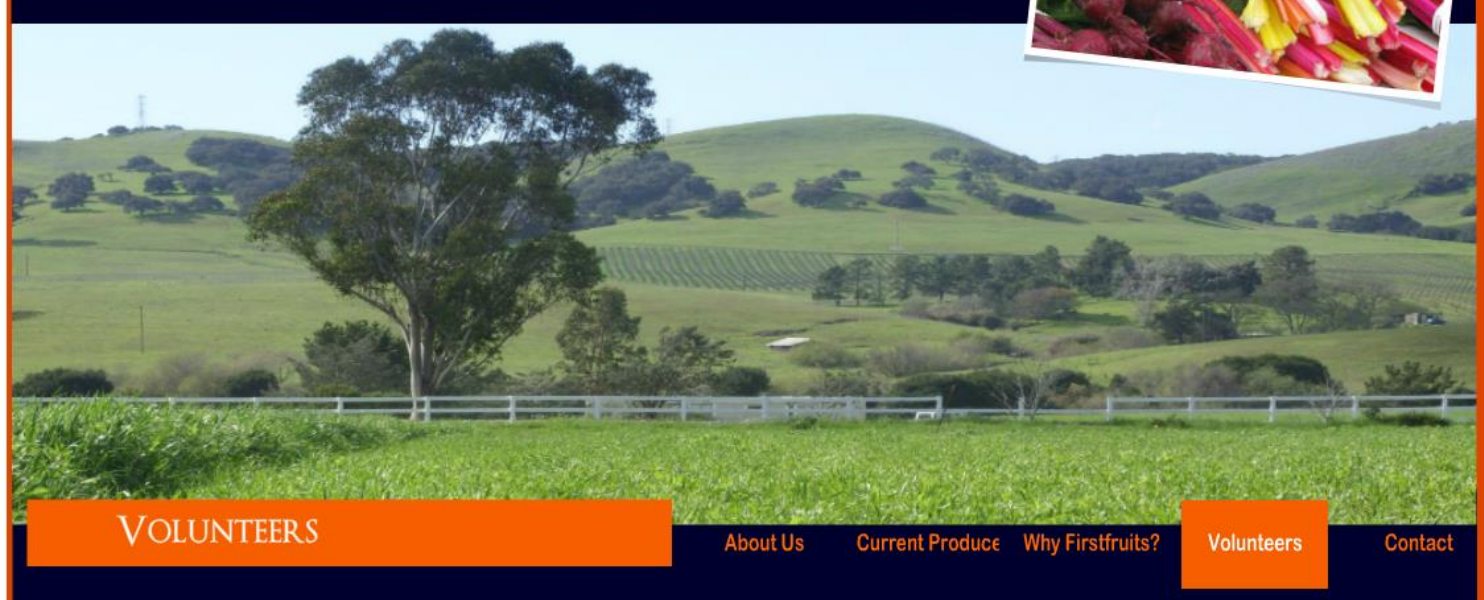

Our small operation is done entirely by hand by our dedicated volunteers. One of our primary goals is to work together with the recipients of our produce. We welcome you and anyone else in the community who believes in our mission, to come work with us! If you've ever been interested in learning or participating on a small scale organic farm, feel free to contact us. Volunteers often participate in transplanting, harvesting, seeding, weeding and more. You may find that breathing the fresh outdoor air, digging in the soil, and being closer to the natural world is just what is missing from your week. 


\section{Sample Facebook Postings}

Firstfruits Farm shared a link.

May 22

One of our biggest donors so far, has been Central Coast Landscape Products. They generously donated 40 cubic yards of their premium mushroom compost. This stuff is amazing! Our tomatoes immediately jumped out of the ground when we applied this around them. We've already used half of our supply on our crops, and they are all doing amazing. These guys are awesome! Thank you CCLP! http://www.cclandscapeproducts.com/

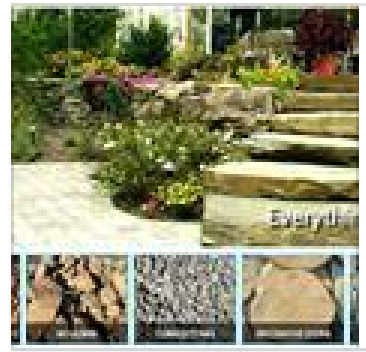

Central Coast Landscape Prodcuts for San Luis Obispo and the Central Coast

www.cclandscapeproducts.com

Central Coast Landscape Products stocks a wide variety of natural landscape mulch, rock and organic soil amendments for pick up or

Like · Comment * Promote * Share

的 32

\section{Firstfruits Farm}

May 26

A great day at the farm yesterday: composted and finished planting the row of kale, planted a row of rainbow chard, 2 rows of cucumbers, a row of squash, and a row of melons, seeded 5 trays of lettuce, seeded 13 six-packs of watermelon, repaired several rows of drip tape, planted 9 large pots of mixed herbs, worked on the native bee garden, pulled some weeds, comforted a sleepy baby, caught bugs with the kids, told stories, laughed, and treasured our time together!

Like - Comment - Promote * Share 
By any professional farmer's standard, our little farm is lowly and crude. Our rows aren't straight, our row covers are torn and tattered, our drip tapes are leaky and unmoored, our tools are worn, one of our wheelbarrows has a flat tire, our greenhouse is doubling as a storage shed, everything must be done by manual labor, and we have no hope of EVER making a single penny of income...but it's the most beautiful farm you'll ever see. You just have to know where to look. When the recipients at God's Storehouse receive our first delivery this weekend, not only are they going to receive an unmatched quality of produce that will physically nourish them, but they're going to receive a message: a message of love and goodwill from neighbors that care about them, and a message from God that He sees them and knows them. Come join us and share in this joyful endeavor.

\section{Firstfruits Farm}

June 29 near San Luis Obispo

I could be wrong, but I think our sun-baked volunteers were missing those overcast mornings today! Regardless, they were all amazing troopers despite the 102 degrees! 
Have you seen this field lately? This is what it looked like before we started planting. You'll have to come out to the farm to see what it looks like now. In the meantime, it's time for a mid-season summary! The delivery totals to God's Storehouse so far this growing season:

Red Butterhead, Romaine and Greenleaf Lettuce: 362 lbs (341 heads)

Dino Kale: 121 lbs (180 bunches)

Rainbow Chard: $110 \mathrm{lbs}$ (70 bunches)

Carrots: 119 lbs (60 bunches)

Yellow Crookneck and Scaloppini Squash: $73 \mathrm{lbs}$

Cucumbers: 22 lbs

Tomatoes: $13 \mathrm{lbs}$

That's a total of $820 \mathrm{lbs}$ of freshly harvested, organically grown produce delivered to date! Won't you come join us in this important work? Harvest begins at 8am this Saturday!

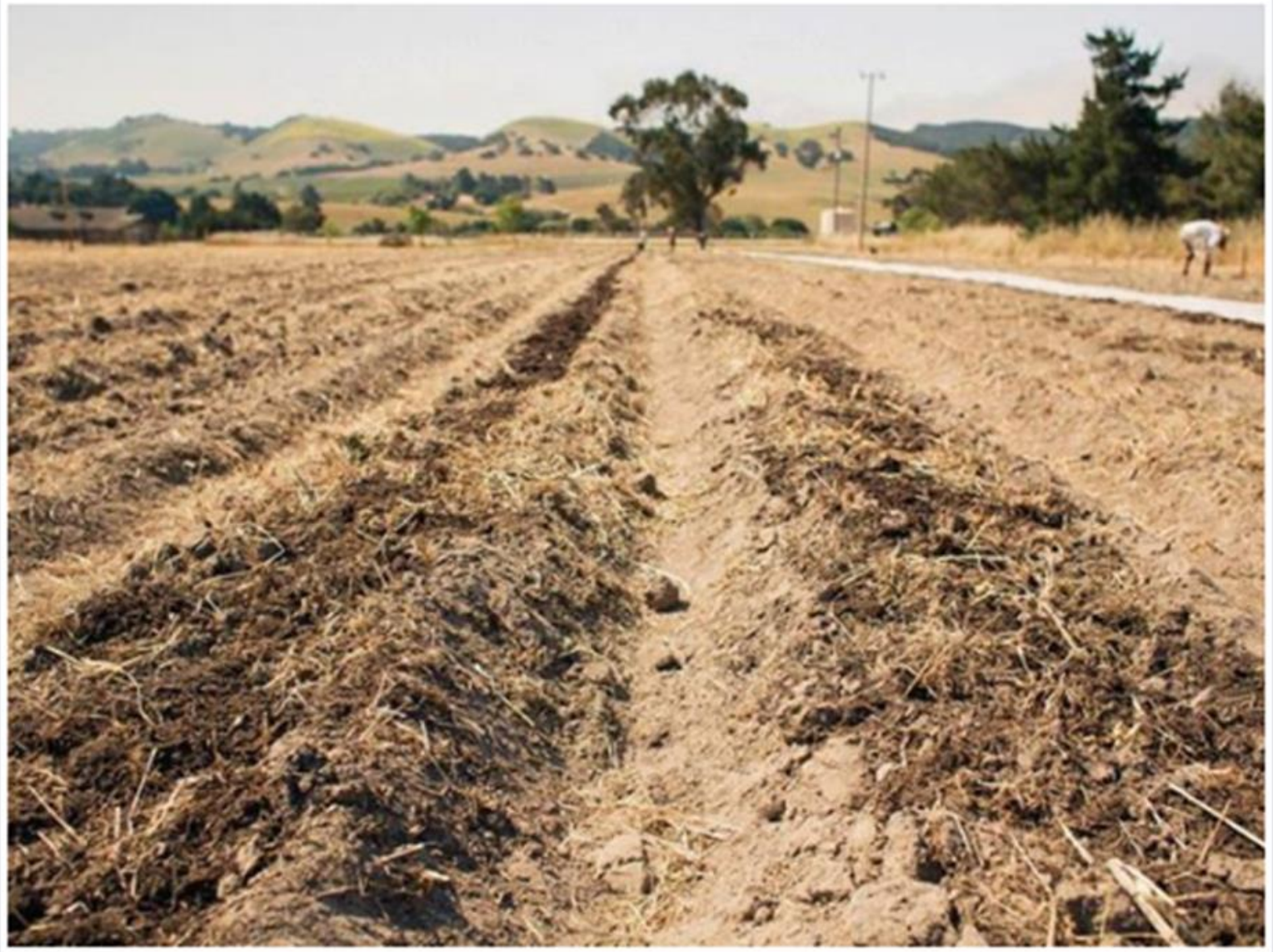

Like · Comment · Unfollow Post · Promote · Share

的10 听 圆2 


\section{Firstfruits Farm}

August 5 near San Luis Obispo

Great news! We have arranged 2 additional drop off locations for our fresh, organic produce: the Women's Shelter in SLO and the Veteran's Care Center in SLO. Both organizations are really excited to be able to provide freshly harvested, nutritious food to their clients. The Women's Shelter will use the produce in their meals they provide to their sheltered women, and the Veteran's Center will give it to the veterans who show up for PTSD counseling and other services. What a great privilege to be able to offer this to them!

So, what does that mean? We have an additional work day: Wednesday mornings starting at 9am, we will need at least 5 or 6 volunteers to come help harvest for the delivery later that morning. Obviously this is impossible for those who work a typical workday, so the number of available volunteers is going to be very low! If you are available, we absolutely need you! It will be a short workday, probably only $11 / 2$ 2 hours.

Meanwhile, our Saturday morning work routine will continue this weekend with deliveries to God's Storehouse and Judson Terrace in SLO. Please come out and help, our volunteer count has been quite low the last couple of weekends.

By the way, we delivered an additional $301 \mathrm{lbs}$ of fresh produce this weekend, which brings our total to over $1100 \mathrm{lbs}$ so far this growing season!

It's a privilege to be a part of this great project with you all! 
Last weekend I met Olivia. She was waiting in line at God's Storehouse to receive her food and was marveling at all the fresh produce being off-loaded. She was moved to tears that there were a number of people out in the field at that very moment working to bring that food to her. Annie Schmidt said it best: "So many of these people hear the message from society that they are unimportant. This farm effort sends them a very different message." Will you join us in refuting the lie that there is ANYONE in our community that doesn't matter? 


\section{Firstfruits Farm}

August 31 near San Luis Obispo

We set a new record today: over $1075 \mathrm{lbs}$ of fresh fruits and veggies harvested and delivered!! It took 2 truck loads to deliver it all. The recipients rejoiced when they saw all the goods arrive. And it couldn't have been done if we hadn't broken another record: 26 wonderful, hard working people came out in the hot, muggy weather and made it happen! Truly an amazing day!

Like - Comment - Promote * Share

的18品6 园1

\section{Firstfruits Farm}

Andotinfern August 30

A couple of weeks ago, one of our volunteers was approached by a woman who receives food at God's Storehouse, and she wanted to express her gratitude for the weekly deliveries of fresh fruits and vegetables. This elderly lady has virtually zero income and recycles cans and bottles to generate a little money each month. She explained how much she appreciated that our food was produced organically... See More

Like · Comment * Promote * Share

的9 目2

\section{Firstfruits Farm}

Andofibien. August 27

Can you help harvest tomorrow morning? There are several regular volunteers out of town this week. We sure could use your help to get the harvest done in time to deliver to the VA center and the Women's Shelter. As an extra incentive, you can break off an ear of sweet corn and eat it while you're out there! It's amazing! Harvest begins at 9am. Hope to see you there! 


\section{Firstfruits Farm}

September 10 near San Luis Obispo

We're coming down to the end! Our poor plants are exhausted, and so are we. We'll soon be giving the farm a rest over the winter months. But we have a few more harvests to go, starting with tomorrow morning at 9am. Last week's little crew was only 5 people, but they worked so hard and pulled off a great harvest. If you have even one hour to spare between 9 and 11, we need you! Please come share the morning with us!

Like · Comment · Promote · Share

As indicated in the transcript from the Facebook post above, the end of the first growing season was eagerly welcomed. The first year of production yielded many lessons learned, and there was considerable strategizing to be done in the off-season to figure out how to better distribute the workload, and ensure a steady supply of volunteer help would get the work done. The details of this strategizing are discussed in the Future Goals section. 
"Nothing is more pleasing or heartening than a plate of nourishing, tasty, beautiful food artfully and lovingly prepared." -- Wendell Berry

\section{Part 5: Results (First Year)}

The process of restoring marginal agricultural land to productivity, formulating a vision for a volunteer-run farm, organizing volunteers from two different churches and the wider community, gathering the necessary resources for a farm operation, working out the logistics for weekly volunteer farm work, maintaining farm operations, ensuring effective communication, coordinating deliveries of produce, keeping volunteers motivated and committed to the project, and enduring the long growing season, was simply tiring. There were periods along the way when the work became plodding and seemingly relentless. But the results of our first year of agricultural production, despite an imperfect organization and operation, were nothing short of remarkable.

By the end of our production year, we had harvested and delivered nearly 9,000 pounds of fresh, organically grown fruits and vegetables to five different locations. Nearly 500 families and individuals in the community received our goods. According to reports from God's Storehouse, the Salvation Army, the Women's Shelter, the Veteran's Center, and Judson Terrace, the addition of high quality produce at no cost, provided a significant financial and health benefit to many of these families. See Figure 8 for a summary of harvest totals.

Produce quality was exceptional throughout the season and we received many expressions of sincere gratitude from the recipients of our donated food. Scanned copies of "thank you" cards, appreciation letters, and testimonials are including in the forthcoming pages. 


\section{First Year Harvest Totals}

\begin{tabular}{|c|c|c|c|c|c|c|c|c|c|c|c|}
\hline \multicolumn{12}{|c|}{2013 Harvest Totals (lbs) } \\
\hline Date & Lettuce & Kale & Chard & Carrots & Squash & Cucumbers & Tomatoes & Peppers & Corn & Melons & Weekly Total \\
\hline $6 / 8 / 13$ & 60.0 & 20.0 & & & & & & & & & 80.0 \\
\hline $6 / 15 / 13$ & 60.0 & 20.0 & & & & & & & & & 80.0 \\
\hline $6 / 22 / 13$ & 80.0 & 15.0 & & & & & & & & & 95.0 \\
\hline $6 / 29 / 13$ & 50.0 & 15.0 & & & & & & & & & 65.0 \\
\hline $7 / 6 / 13$ & 40.0 & 12.0 & 28.0 & & & & & & & & 80.0 \\
\hline $7 / 13 / 13$ & 40.0 & 12.0 & 28.0 & & & & & & & & 80.0 \\
\hline $7 / 20 / 13$ & 32.0 & 11.0 & 28.0 & 29.0 & 17.0 & 4.0 & 4.0 & & & & 125.0 \\
\hline $7 / 27 / 13$ & 0.0 & 15.6 & 26.4 & 90.0 & 56.0 & 17.8 & 9.0 & & & & 214.8 \\
\hline $8 / 3 / 13$ & 0.0 & 11.0 & 7.0 & 71.2 & 87.8 & 99.0 & 25.5 & & & & 301.5 \\
\hline $8 / 7 / 13$ & 20.0 & 6.0 & 5.0 & 48.0 & 43.0 & 49.0 & 48.0 & 8.0 & 0.0 & 0.0 & 227.0 \\
\hline $8 / 10 / 13$ & 40.0 & 8.0 & 8.0 & 62.0 & 86.0 & 99.0 & 102.0 & 8.0 & 0.0 & 0.0 & 413.0 \\
\hline $8 / 14 / 13$ & 20.0 & 6.0 & 5.0 & 48.0 & 43.0 & 49.0 & 48.0 & 8.0 & 32.0 & 0.0 & 259.0 \\
\hline $8 / 17 / 13$ & 0.0 & 8.0 & 8.0 & 62.0 & 86.0 & 98.0 & 99.0 & 9.0 & 48.0 & 0.0 & 418.0 \\
\hline $8 / 21 / 13$ & 20.0 & 6.0 & 5.0 & 48.0 & 43.0 & 49.0 & 48.0 & 6.0 & 32.0 & 0.0 & 257.0 \\
\hline $8 / 24 / 13$ & 49.5 & 0.0 & 5.0 & 88.0 & 111.0 & 119.0 & 233.3 & 25.5 & 50.0 & 0.0 & 681.3 \\
\hline $8 / 28 / 13$ & 18.0 & 10.0 & 0.0 & 48.0 & 50.0 & 70.0 & 84.0 & 30.0 & 25.0 & 0.0 & 335.0 \\
\hline $8 / 31 / 13$ & 110.0 & 28.0 & 0.0 & 88.5 & 110.0 & 120.0 & 230.0 & 92.0 & 240.0 & 58.0 & 1076.5 \\
\hline $9 / 4 / 13$ & 36.0 & 10.0 & 0.0 & 52.0 & 68.0 & 85.0 & 86.0 & 38.0 & 60.0 & 32.0 & 467.0 \\
\hline $9 / 7 / 13$ & 68.0 & 22.0 & 5.0 & 72.0 & 80.0 & 88.0 & 210.0 & 76.0 & 210.0 & 44.0 & 875.0 \\
\hline $9 / 11 / 13$ & 42.0 & 14.0 & 6.0 & 50.0 & 58.0 & 73.0 & 120.0 & 39.0 & 0.0 & 36.0 & 438.0 \\
\hline $9 / 14 / 13$ & 78.0 & 18.0 & 3.0 & 96.0 & 18.0 & 8.0 & 210.0 & 66.0 & 0.0 & 115.0 & 612.0 \\
\hline $9 / 18 / 13$ & 44.0 & 16.0 & 0.0 & 0.0 & 47.0 & 31.0 & 120.0 & 32.0 & 0.0 & 0.0 & 290.0 \\
\hline $9 / 21 / 13$ & 22.0 & 28.0 & 0.0 & 0.0 & 31.0 & 12.0 & 220.0 & 72.0 & 0.0 & 32.0 & 417.0 \\
\hline $9 / 28 / 13$ & 0.0 & 62.0 & 11.0 & 0.0 & 132.0 & 15.0 & 380.0 & 81.0 & 0.0 & 99.0 & 780.0 \\
\hline $10 / 5 / 13$ & & & & & & & & & & & 0.0 \\
\hline $10 / 12 / 13$ & & & & & & & & & & & 0.0 \\
\hline $10 / 19 / 13$ & & & & & & & & & & & 0.0 \\
\hline $10 / 26 / 13$ & & & & & & & & & & & 0.0 \\
\hline $11 / 2 / 13$ & 32.0 & & & & & & & & & & 32.0 \\
\hline $11 / 9 / 13$ & 18.0 & 14.0 & & & & & & 80.0 & & & 112.0 \\
\hline $11 / 16 / 13$ & & & & & & & & & & & 0.0 \\
\hline $11 / 23 / 13$ & & & & & & & & & & & 0.0 \\
\hline $11 / 30 / 13$ & & & & & & & & & & & 0.0 \\
\hline Totals & 979.5 & 387.6 & 178.4 & 952.7 & 1166.8 & 1085.8 & 2276.8 & 670.5 & 697.0 & 416.0 & 8811.1 \\
\hline
\end{tabular}

Figure 8 


\section{Samples of Appreciation Letters and Testimonials}

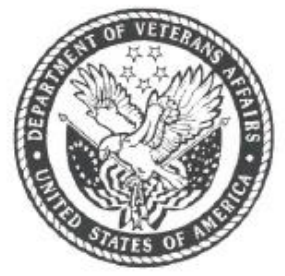

September 11, 2013

\author{
Department of Veterans Affairs \\ Readjustment Counseling Service \\ San Luis Obispo Vet Center \\ 1070 Southwood Drive \\ San Luis Obispo, CA 93401 \\ (805) 782-9101
}

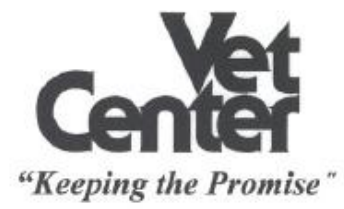

Dear Toni,

We wanted to thank you and First Fruits Farm once again for your generous donation of vegetables to the Vet Center. Receiving the crates of freshly harvested locally grown vegetables each Wednesday is the highlight of our week here at the Vet Center. Having fresh produce for our Veterans and their families is in keeping with our tradition of helping our Veterans recover from the injuries of war from a holistic approach. Our Veterans not only thoroughly enjoy and appreciate your wonderful vegetables but many have been inspired to improve their nutrition and make health and wellness more of a priority after being exposed to the benefits of your fresh vegetables.

It's clear that First Fruits Farm and its volunteers understands the sacrifice our Veterans and their Families have made and that it takes community involvement to effectively support our Vets when they come home. Your contribution is greatly appreciated and will not soon be forgotten.

On behalf of the San Luis Obispo Vet Center, our staff and clients, we want to thank you for your commitment to our local Veterans and their Families. We look forward to a long and mutually beneficial relationship with the First Fruits Farm and will always consider you part of our Vet Center family.

With Respect and Gratitude,

Mike Young

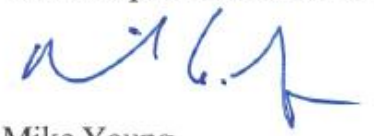

Team Leader 


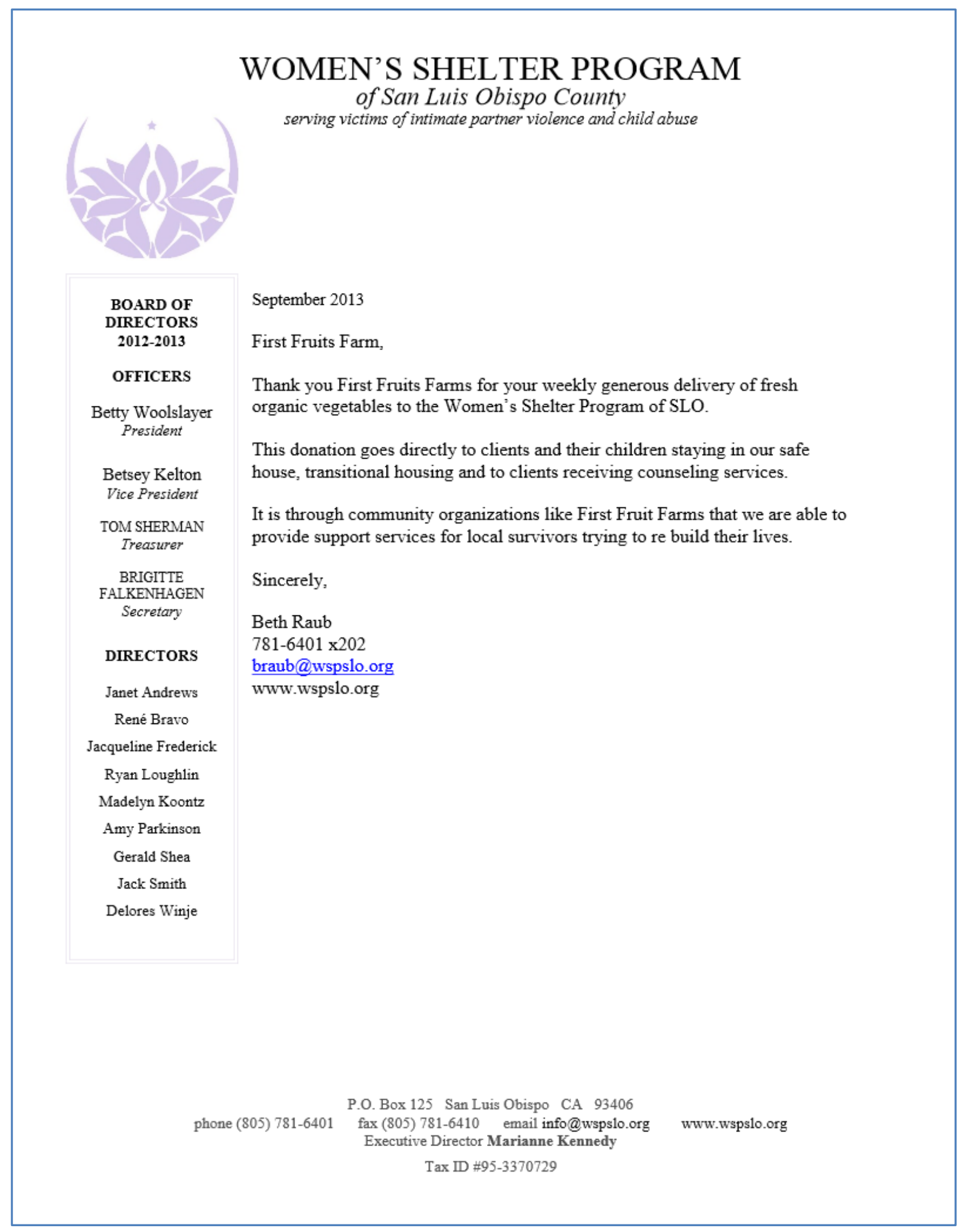


"I live at Judson Terrace which is a nonsectarian senior adult retirement home co-sponsored by the First Baptist Church of San Luis Obispo and the American Baptist Homes of the West (ABHOW). It was built through the Section 202 Program of the Department of Housing and Urban Development (HUD) of our federal government. It is specifically designed for persons 62 years of age or older with modest incomes. In addition to low monthly rents, Section 8 rent assistance is available to a limited number of residents.

Firstfruits Farm has been delivering fresh and nutritious organic harvests which are of a great benefit in promoting better health, especially for the elderly. Many of the residents have expressed how much better they feel after eating the delicious produce. We are greatly appreciative of Firstfruits Farm's generous donations and some folk are not able to shop for their own food so it has been a huge blessing which we are privileged to enjoy!"

-Barbara J. Smith

(Judson Terrace Resident)

"Firstfruits Farm provides much-needed fresh, organic produce for our needy clients. But more than that, Firstfruits Farm offers our clients an extra sense of self-worth because they know that the food they are receiving isn't the left overs that others didn't want; it is grown specifically for them. Many of our clients are homeless, elderly or disabled and our culture can make them feel marginalized, but efforts of the volunteers at Firstfruits Farm shows them that they are valued as people and worthy of the best that our community can offer them. We are thrilled to partner with Firstfirst Farm to serve the needy in San Luis Obispo."

-Annie Schmidt

(Director of God's Storehouse - an affiliate of the Food Bank) 


\section{Poster Board Created by Senior Citizens at Judson Terrace}

(Samples of notes enlarged on following pages.)

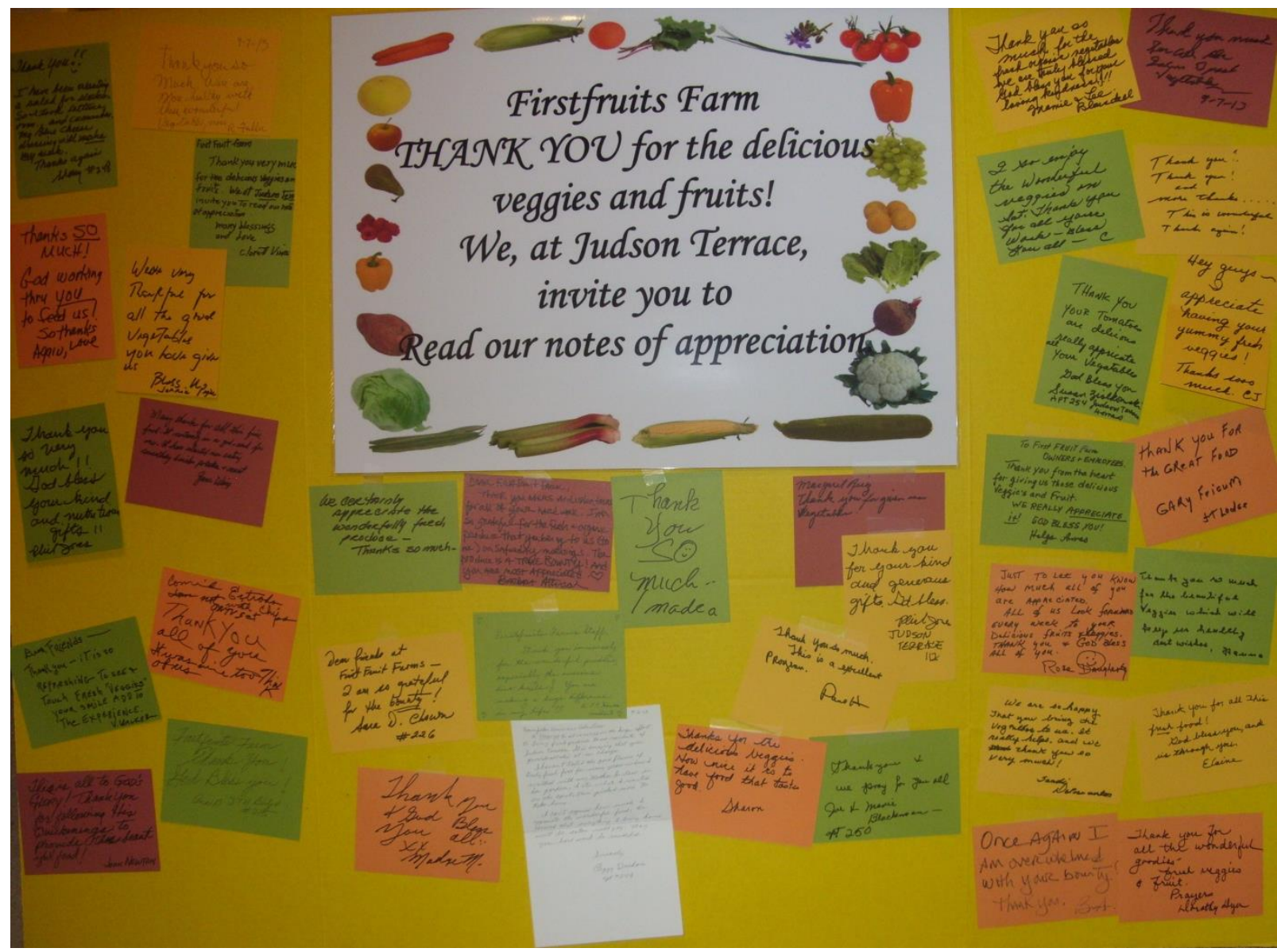


Samples of "Thank You" Notes by Senior Citizens at Judson Terrace

Friday $9-6-13$

Farnfoles, Peron and Volunteers:

a THANK You to all involved in the huge effort to bring fresh produce to us residents of Judson Terrace. Lt is amazing that you providoalt this at no charge.

theven't tested the good flavors of truly fresh fool for many years when d walked with my mother In -Law in her garden. S ate what of wanted on the spot, then picked more to take home.

d can't express how much $\&$ appreciate the wonderful food. Be assured that everything \& bring home will be eater with joy. May you hard work be rewarded.

Sincerely,

Peggy Durham

106 
dear firestromit farm,

Thank you wo res anduslunteres for all of your hared work. In so grateful for the fresh w organic produce that youbreing to us to me) on Safuedaty morevings. The produce is A T Pere Bonny! And y au are most Appreciated . O Barbara Athanor

107 
Aloor Friends

Thankyou - $i T$ is so REFPEShing To seet Touch ERESh "VEgGies" Your SMMILE ADDT The EXPERIEACE. V. WALKER

108 
JuST To Let you KNow How much all of you are APPRECIATED.

ALL of us Look forward Every week to your Delicious fruits ellaggies. TAHN you \& GoD Bless All of you.

Rose

Dingherty

109 
THANK You Your Tomatos are delecious really appricate Your Vegatable Dod Blecs you Susan ziolosuck:

Many thanke for all stis fine ford ot revtring in a getrend for me. ot how stastal meentis. something heribs pratate + anest gome tuling

110 
Thanks 50 MuCH!

God wonting thry you to feed us So thant's Agariv, Loue 


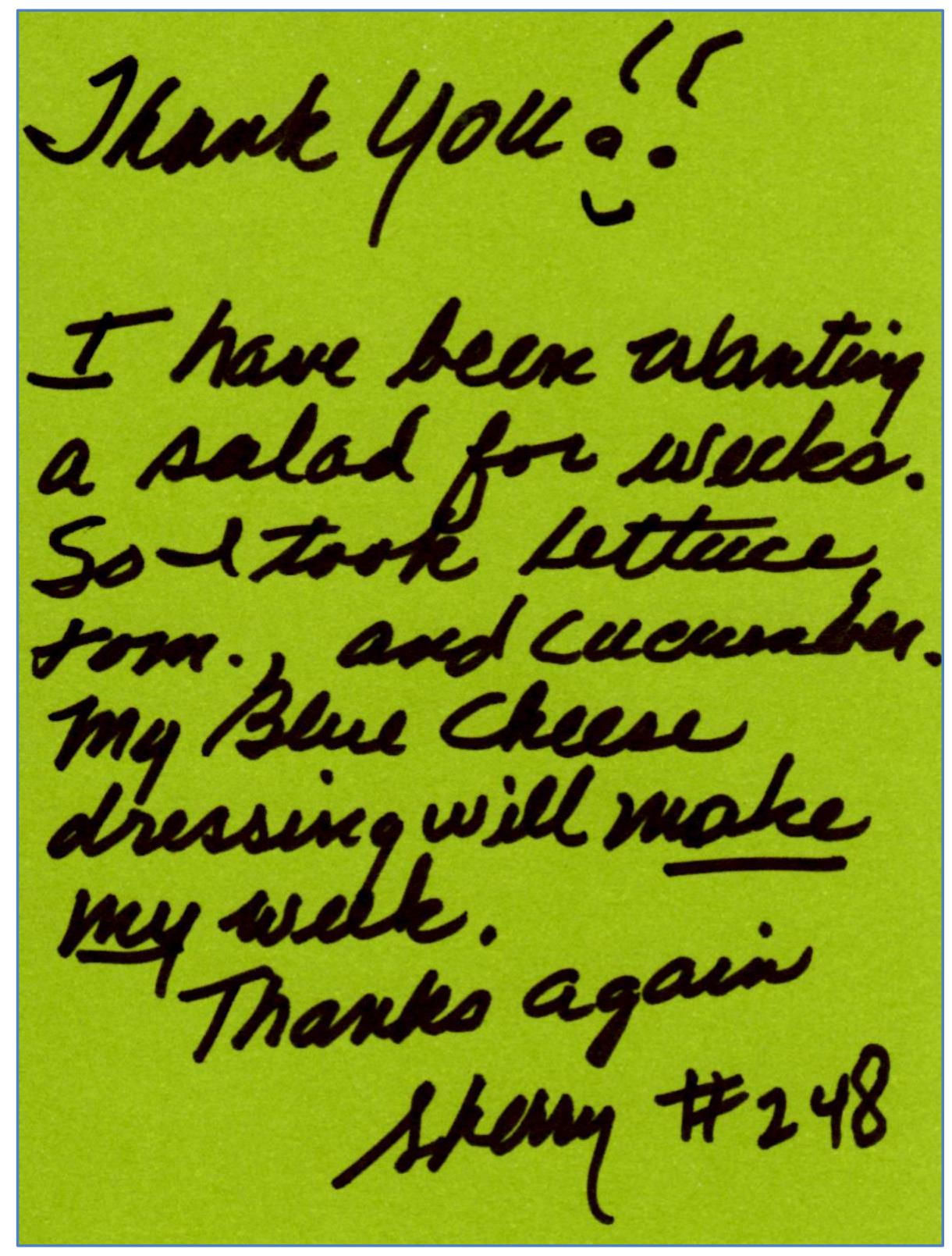

112 
$9-7-13$

Thank you so

Much. Were are Pore halley we th - these wonderful Veg tables, now R Fuller

This is all to Goo's Glory! Thank you for following His Evichenings to provide this beastiful food!

JOAN NEWTON

113 
"To forget how to dig the earth and tend the soil is to forget ourselves." -- Mahatma Gandhi

\section{Part 6: Future Goals}

There are several key goals that we hope to achieve in the coming months and years. These range from reducing the workload on several key leadership positions, to expanding production, to mobilizing more community support. Already, we have developed some strategies to address these needs and results are expected in the near future.

The farm director position has carried an enormous responsibility throughout the development of this project. Nearly all of the planning, organizing, communicating, managing, and decision making have fallen on the shoulders of this position. This is in addition to oversight of day-today farm management and volunteer work days. The number of hours spent per week on this project averaged between 20 and 25 for this unpaid position. This position could easily be a full-time job, but with the farm project being a diaconal ministry of a small church like Trinity, there is no budget that would allow this to be a paid position. With this in mind, the leadership at Trinity recognizes that many of the responsibilities of the director will need to be assumed by the deacons. We are currently working on a revised organizational chart that would give ownership of certain aspects of this ministry to different deacons on the deacon's board.

The position of the Public Relations/Media Coordinator was never fully realized during the first year. To mobilize additional community support and raise awareness about the farm, this position is going to be more fully developed. There has been very little "marketing" produced for the farm to-date, and this has been a weak link in volunteer recruitment and material support. Finding the right person for this job is a top priority for the leadership team at this time.

\section{GleanSLO}

One of the most exciting developments that we experienced toward the end of the season, was securing a partnership with GleanSLO. As an arm of the Food Bank Coalition of San Luis Obispo, GleanSLO is a well-funded organization that mobilizes members of the community to glean the fields of many farms and orchards in this county. Their work contributes a large supply of produce to the Food Bank and school lunch programs. The gleaned produce is made up of leftovers that farmers rejected or left in their fields due to blemishes or other problems with marketability. GleanSLO has more than a thousand people on their volunteer list, and they have developed a very efficient method of coordinating this manpower to "rescue" more than 50,000 pounds of produce each year.

GleanSLO will be able to provide Firstfruits Farm with a reliable source of harvesting help each week beginning next season. This will reduce the demand on our relatively small volunteer 
corps (currently about 100 individuals) and allow us to focus on farm maintenance, increased production, and relationship building with the food recipients.

Come glean with us this Saturday at FirstFruits Farm! They grow vegetables for the sole purpose of feeding the hungry in our local community. To register for the glean, click here:

http://www.gleanslo.org/signup.php?

access $=$ select\&harvesttemp $=779$

https://www.facebook.com/firstfruits.farm?fref=ts
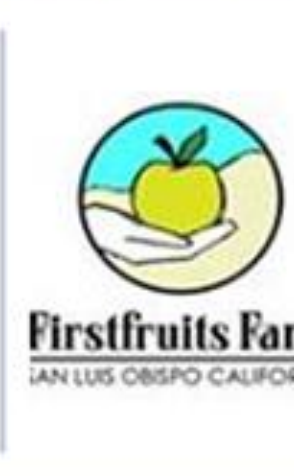

Firstfruits Farm

\section{Firstfruits Farm}

AN LUS Cesipo CNUFOENA

Like - Comment - Share 


\section{GleanSLO and Firstfruits Farm Volunteers}

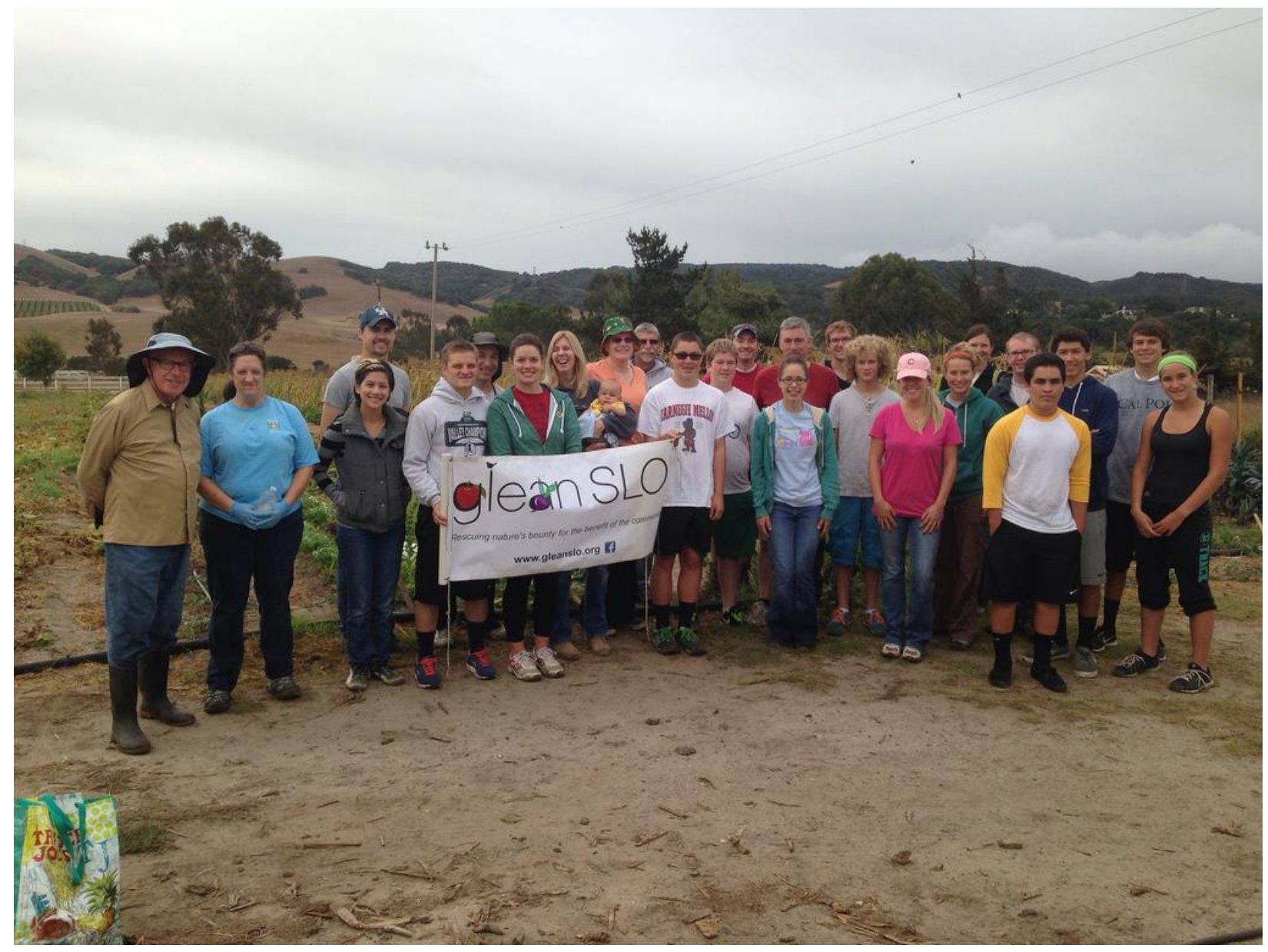

\section{Crop Specialists}

One of the primary lessons learned by the farm managers was the difficulty in directing a large group of inexperienced volunteers to accomplish specific tasks in a limited amount of time. With a Saturday morning show time of 8am (any earlier was unrealistic to ask of our volunteers), there was less than two hours available to accomplish all of the harvesting, washing, packing, and delivery in time for the distribution at God's Storehouse. Similar constraints were experienced on our Wednesday morning harvests. With more than a dozen different crops to harvest and specific instructions necessary for each one, it was difficult for one or two farm managers to be responsive to questions or problems. This was also true for the farm maintenance work (transplanting, weeding, bed preparation, etc.) that occurred after the harvest crews were finished. By the end of a farm work day, the farm managers were exhausted, feeling like they had been pulled in a hundred different directions and were never able to fully complete a task. 
To reduce the strain on the farm managers, we are exploring the idea of developing teams of "crop specialists" who will be responsible for one (or more) crops. Each member of these teams will receive complete training on all they will need to know to become experts on the transplanting, care, and harvesting of their assigned crop. Each team will contribute one of its members to an assigned farm work day each week, and they will oversee all aspects of work related to their specific crop. This will effectively supply the volunteer corps with several "farm managers" who will be able to answer their questions and provide guidance during the work day. The primary farm manager would then be able to focus on overall management of the work day, while his/her "crop specialists" would deflect many of the distractions related to specific crops. With the addition of GleanSLO volunteers, we will be able to afford to pull a number of people from our volunteer corps to build these crop specialist teams.

\section{Including Food Recipients in the Operation}

One of our primary goals at the outset of this project was to invite the food recipients to join us in this work. We were able to include a small number of them during the first year, but our goal is to greatly increase the number of recipients who contribute to the farm work. The logistics for providing them transportation, and communicating with them will be a responsibility of the deacons. The reasons for including them in the operation are numerous and include:

- Building inter-community relationships across socio-economics

- Providing an educational opportunity

- Giving them the dignity to contribute to their own needs

- Reducing the tendency and/or perception of our volunteers to be in an "elevated position" above the recipients

- Expanding the volunteer corps

\section{Increasing Production}

The need for fresh, high quality produce does not end in the fall and winter. In fact, it probably increases as the supply drops off with the cold weather. To be able to provide fresh produce to economically disadvantaged families in our community year-round, will be a goal we strive to achieve in the years ahead. It was important for us to take a break at the end of our first growing season so we could regroup and work out some of our inefficiencies. In the future, it will be a high priority to continue production through the colder months. It will require an even greater commitment from our volunteers as well as additional resources, but it seems like a realistic goal at this point.

In addition to expanding production to a year-round operation, we have immediate plans to expand our annual productive capacity. Estimating the demand during the first year was an evolving process, but by the end of the first year we knew that there were several crops that were in high demand. Not only will we be adding additional crops next year (including fruit 
trees, nut trees, herbs, garlic, onions, broccoli, cabbage, beets, berries, and more), we will also be increasing the amounts of the crops that we grew last year (specifically sweet corn, watermelon, and fresh herbs). There was plenty of field space available for this expansion, and now that we have teamed up with GleanSLO, we should have the necessary manpower to be able to expand. The only uncertainty is whether our well will have the capacity to irrigate even more acreage.

Another expansion we are exploring is the addition of egg production. By building and employing mobile chicken coops (or "tractors"), we will achieve several benefits:

- Natural fertilization of our soil

- Efficient decomposition of crop residue and weeds

- Light tillage of our field

- Provide fresh, high quality protein source to our food recipients

The addition of egg-laying hens will add an increased cost to our operation. Supplemental feed will likely be necessary at certain times of the year, replacement pullets will be an ongoing need, and materials for the mobile chicken coops will be a significant capital cost. It may be possible to get many of these resources donated by local businesses. Regardless, the addition of egg production could significantly enhance what we provide to the community.

\section{Native Bee Garden}

It would be improper not to mention the work being done to establish a native bee garden on the western boarder of the primary growing area. One of our dedicated volunteers spent hundreds of hours designing and creating this bee garden to attract beneficial pollinators to the farm. With the addition of fruit and nut trees in the future, these vigorous pollinators will be $n$ important addition. Notably different than commercially-tended honey bees, native bees can have a dramatic effect on the pollination of agricultural crops. Many of these species of bees live in the soil and are attracted by specific types of flowering plants. Creating an inviting habitat requires a great deal of specialized knowledge and effort. Once established, the bee garden will require limited but careful maintenance. A great deal of work was invested in invigorating the soil in this area to improve the success of the bee-attracted plants. There is more work to be done over the next year. But once completed, this specially designed habitat will likely significantly enhance the productivity of the farm. 


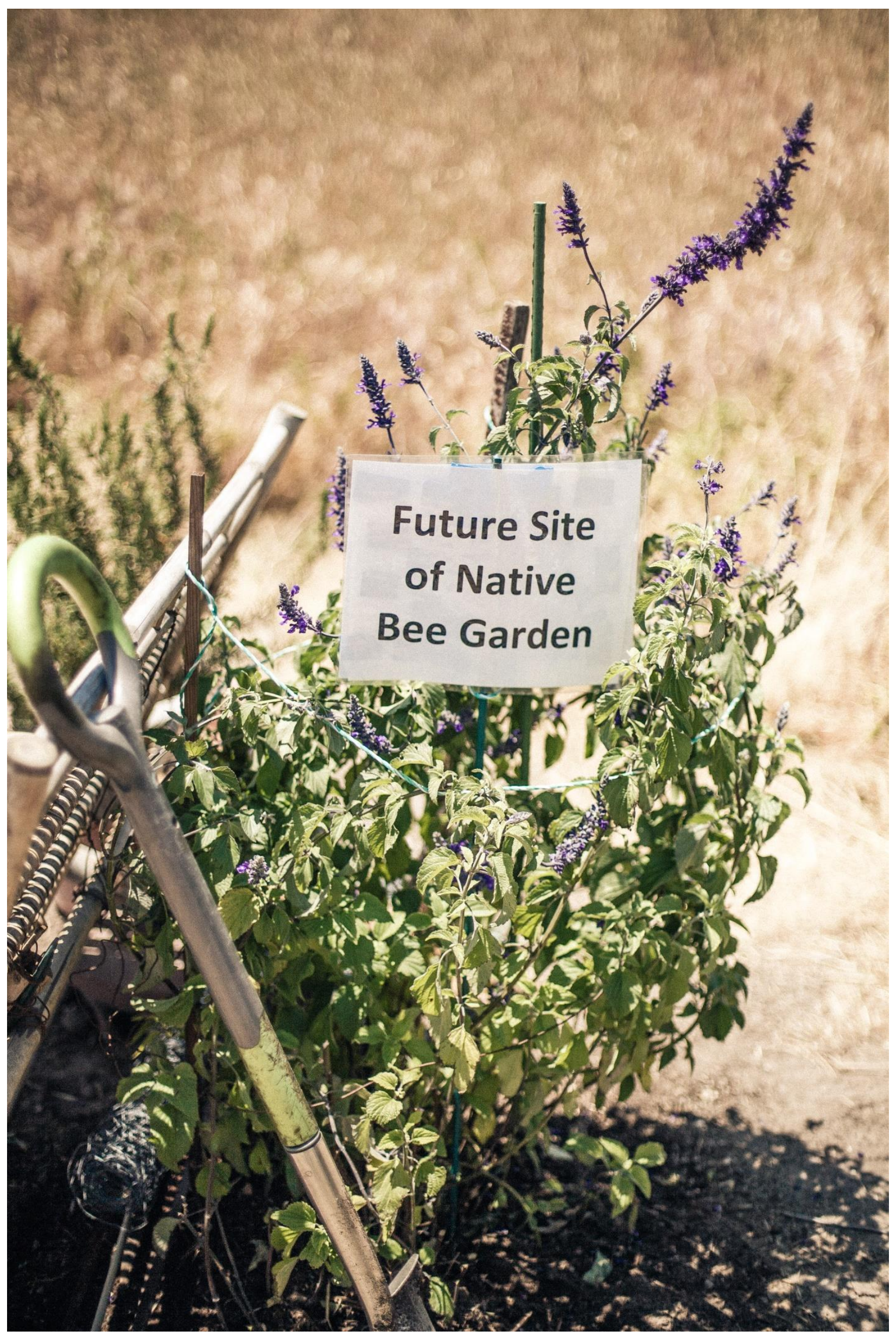


"The ultimate goal of farming is not the growing of crops, but the cultivation and perfection of human beings."--Masanobu Fukuoka

\section{Part 7: Conclusions}

There is no question that fresh food can be delivered to those in need in a more efficient manner than we have done at Firstfruits Farm. Moreover, there is an adequate (and sometimes abundant) supply of food that is donated to the Food Bank and is subsequently made available to those in need. Additionally, with the advent of GleanSLO, there is now an ample supply of fresh fruits and vegetables stocked in the Food Bank's storehouses. So it begs the question: Why spend so much time and energy creating and maintaining such a labor dependent farm operation?

In many ways, the farm is "low-tech", labor-intensive, and crude. But in so many other ways, this little farm has brought a little more life to this community; probably much more so than if we employed the latest mechanization, automation or other technological advancement. We get to work alongside one another, sharing stories and participating in work that is fundamentally good and worthwhile, yet simple and manageable. The outpouring of stories and comments from volunteers attesting to the sense of fulfillment they find after working at the farm is remarkable. Working at the farm seems to create a level of togetherness and gratification that continues to exceed our expectations. In such a highly independent society, this valuable interaction has a healing and restorative effect in our community.

The educational value of this farm project cannot be overlooked. Connecting more people to the natural world and the world of agriculture increases awareness and interest in environmental stewardship and the issues associated with agricultural production. Our volunteers have first-hand experience with environmental restoration and are familiar with the challenges associated with seasonal production, pest management, resource limitations, laborintensive work, and so much more. Including food recipients and community volunteers in the farm work also provides hands-on skills that can be beneficial to them and passed on to others.

The food recipients that line up to collect their food each week constantly receive an unspoken message from society: they are unimportant. When the announcement was first made to the $150+$ people gathered at God's Storehouse that a farm was established to provide them with fresh produce and would be delivering the goods soon, they cheered. Some were moved to tears. The very fact that this farm is labor intensive sends a different kind of message. The laborious planting, growing, harvesting, washing, packing and delivering - by hand - of high quality, fresh food, sends this message to its recipients: they are valuable, cared about, important, and deserve the best that is available.

While we may be able to measure the monetary value of the goods that we offered to people in our community, it is impossible to quantify the amount of the other "goods" that this farm 
produced: relational "goods", community "goods", environmental "goods", and spiritual "goods". By the end of the first year of production, many of our volunteers were asking how soon we could get started again. Let there be no doubt; this little farm will continue to produce countless goods, and our wish is that these goods will always be our "first fruits".

\section{Agricultural Education Application}

There should not be any question that a school farm designed solely to donate its products to needy people in the community could be valid and beneficial option for an Agricultural Education Program at any secondary school. Community support would likely be quite high for a project like this. Resources would conceivably be donated by local businesses at least to the degree that they are for a school farm that sells its goods to the public. Furthermore, student work at the farm could likely be augmented by enthusiastic community members who believe in the cause.

The lessons learned by students involved in a project like this would likely be multitudinous. In addition to the agricultural experience, students would be awakened to the scale and various needs in their community. They could learn compassion for those in need, become educated about the inequities in their own neighborhoods, and be stimulated to be mindful of ways they can make a difference in their world. 